\title{
Adaptation Opportunities, Constraints, and Limits
}

Coordinating Lead Authors:

Richard J.T. Klein (Sweden), Guy F. Midgley (South Africa), Benjamin L. Preston (USA)

\section{Lead Authors:}

Mozaharul Alam (Bangladesh), Frans G.H. Berkhout (Netherlands), Kirstin Dow (USA), M. Rebecca Shaw (USA)

\section{Contributing Authors:}

Wouter Botzen (Netherlands), Halvard Buhaug (Norway), Karl W. Butzer (USA), E. Carina H. Keskitalo (Sweden), Yu'e Li (China), Elena Mateescu (Romania), Robert Muir-Wood (UK), Johanna Mustelin (Finland/Australia), Hannah Reid (UK), Lauren Rickards (Australia), Sarshen Scorgie (South Africa), Timothy F. Smith (Australia), Adelle Thomas (Bahamas), Paul Watkiss (UK), Johanna Wolf (Germany/Canada)

\section{Review Editors:}

Habiba Gitay (Australia), James Thurlow (South Africa)

Volunteer Chapter Scientists:

Seraina Buob (Switzerland), Adelle Thomas (Bahamas) 


\section{Table of Contents}

Executive Summary

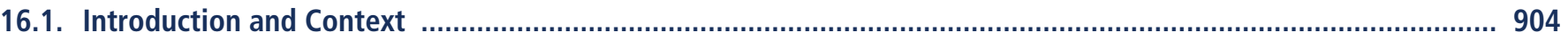

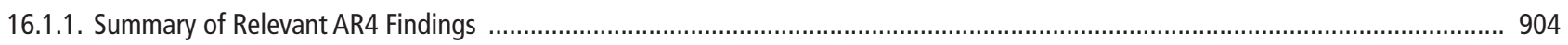

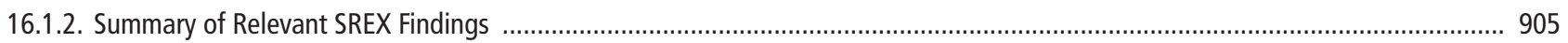

16.2. A Risk-Based Framework for Assessing Adaptation Opportunities, Constraints, and Limits ............................ 905

Box 16-1. Definitions of Adaptation Opportunities, Constraints, and Limits ...................................................................... 907

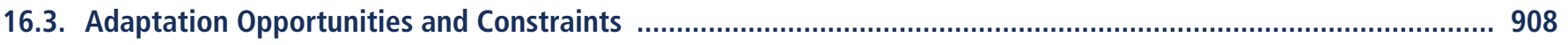

16.3.1. Adaptation Opportunities ......................................................................................................................... 908

16.3.1.1. Enabling Conditions for Adaptation .......................................................................................................... 908

Box 16-2. A Case Study of Opportunities for Adaptation and Disaster Risk Reduction ............................................ 910

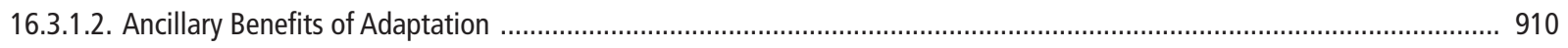

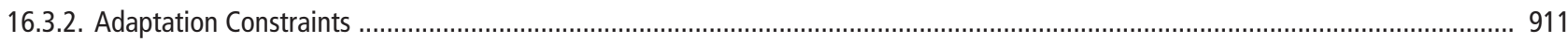

16.3.2.1. Knowledge, Awareness, and Technology Constraints .................................................................................. 911

Box 16-3. Rates of Change as a Cross-Cutting Constraint ..................................................................................... 912

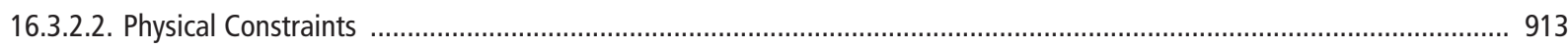

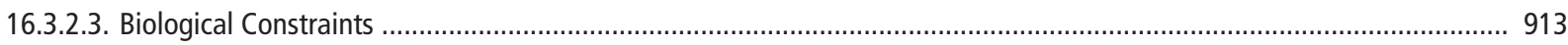

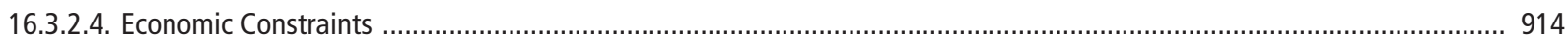

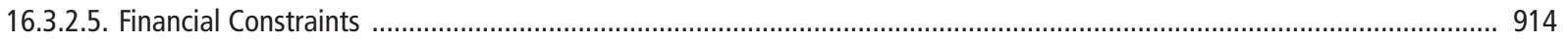

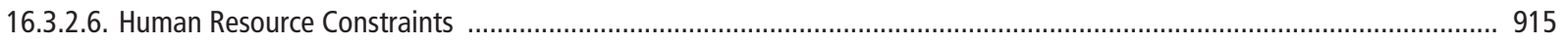

16.3.2.7. Social and Cultural Constraints ................................................................................................................ 915

16.3.2.8. Governance and Institutional Constraints ....................................................................................................... 916

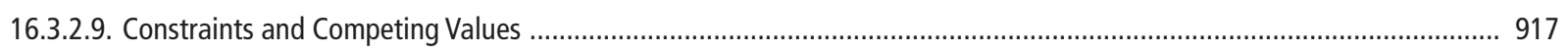

16.3.2.10. Consideration of Cross-Scale Dynamics .............................................................................................................. 918

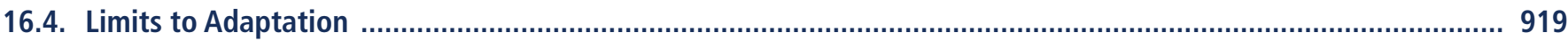

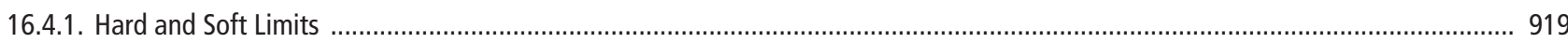

Box 16-4. Historical Perspectives on Limits to Adaptation ................................................................................ 920

16.4.2. Limits and Transformational Adaptation ........................................................................................................................ 921

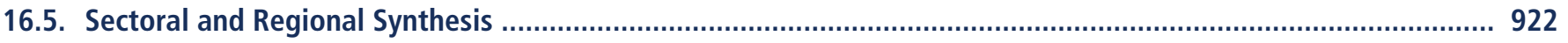

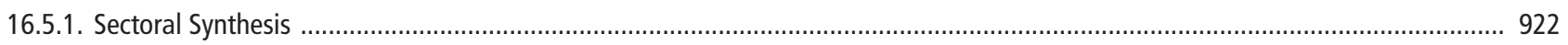

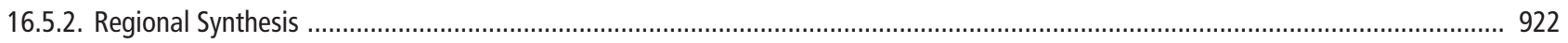


16.6. Effects of Mitigation on Adaptation Opportunities, Constraints, and Limits

16.7. Ethical Dimensions of Adaptation Opportunities, Constraints, and Limits

16.8. Seizing Opportunities, Overcoming Constraints, and Avoiding Limits

References

927

Frequently Asked Questions

16.1: What is the difference between an adaptation barrier, constraint, obstacle, and limit? ......................................................... 906

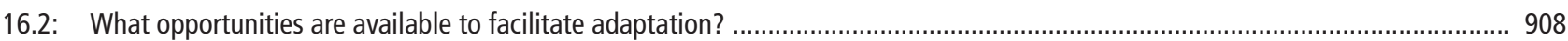

16.3: How does greenhouse gas mitigation influence the risk of exceeding adaptation limits? ..................................................... 924 


\section{Executive Summary}

Risk-based approaches to decision making provide a useful foundation for assessing the potential opportunities, constraints, and limits associated with adaptation of human and natural systems (medium evidence, high agreement). Risk management frames the consequences of climate change and potential adaptation responses in the context of actors' values, objectives, and planning horizons as they make decisions under uncertainty. Adaptation planning and implementation are therefore contingent on actors' perceptions of risk. Some risks may be routine and/or the consequences so minor that they are accepted. Other risks may be judged intolerable because they pose fundamental threats to actors' objectives or the sustainability of natural systems. A key objective of adaptation is to avoid such intolerable risks. Yet, the capacity of societal actors and natural systems to adapt is finite, and thus there are limits to adaptation. \{16.2, 16.3.2, 16.4, Box 16-1\}

Understanding of how the adaptive capacity of societal actors and natural systems influences the potential for adaptation to effectively manage climate risk has improved since the Fourth Assessment Report (AR4; very high confidence). Adaptive capacity is influenced by actors' abilities to capitalize on available opportunities that ease the planning and implementation of adaptation as well as constraints that make adaptation processes more difficult for both human and natural systems. Opportunities and constraints are unevenly distributed among global regions, communities, sectors, ecological systems, and species as well as across different time periods. Recent studies have provided greater recognition of the role of private businesses in facilitating adaptation. However, much of the current knowledge about adaptation opportunities and constraints is dominated by insights from public institutions and community-based case studies. $\{16.2-5$, Box 16-1\}

Opportunities exist to enable adaptation planning and implementation for actors across all sectors and geographic regions (very high confidence). Adaptation guidance, information, and tools are increasingly available to practitioners operating in different sectoral, regional, and organizational contexts. Enhancing the awareness of individuals, organizations, and institutions about climate change vulnerability, impacts, and adaptation can help build individual and institutional capacity for adaptation planning and implementation. However, addressing knowledge deficits alone is not sufficient to achieve successful adaptation. The development and provision of tools for risk and vulnerability assessment as well as decision-support tools and early warning systems can help actors prioritize adaptation needs and identify options that reduce vulnerability. Opportunities can also arise as actors learn from experience with climate variability and incorporate consideration for long-term climate change into disaster risk reduction efforts. Formal policies regarding infrastructure design standards or spatial planning can trigger adaptation action. However, many adaptation opportunities arise as ancillary benefits of actions implemented for reasons other than climate change. $\{16.2,16.3 .1,16.5$; Tables 16-1, 16-3; Boxes 16-1, 16-2, CC-EA $\}$

A range of biophysical, institutional, financial, social, and cultural factors constrain the planning and implementation of adaptation options and potentially reduce their effectiveness (very high confidence). Adaptation of both human and natural systems is influenced by the rate of climate change as well as rates of economic development, demographic change, ecosystem alteration, and technological innovation. Adaptation planning and implementation may require significant inputs of knowledge as well as human, social, and financial capital. Real or perceived deficiencies in access to such resources can and do constrain adaptation efforts in both developing and developed nations. Public and private institutions influence the distribution of such resources as well as the development of policies, legal instruments, and other measures that facilitate adaptation. Therefore, institutional weaknesses, lack of coordinated governance, and conflicting objectives among different actors can constrain adaptation. Cultural characteristics including age, gender, and sense of place influence risk perception, entitlements to resources, and choices about adaptation. Societal actors and natural systems may experience multiple constraints that interact. \{16.2, 16.3.2, 16.5; Tables 16-2, 16-3; Boxes 16-1, 16-3\}

Limits to adaptation can emerge as a result of the interactions among climate change and biophysical and socioeconomic constraints (medium evidence, high agreement). An adaptation limit occurs owing to the inability to avoid an intolerable risk to an actor's objectives and/or to the sustainability of a natural system. Understanding of limits is informed by historical and recent experience where limits to adaptation have been observed, as well as by limits that are anticipated to arise as a consequence of future global change. Recent studies have provided valuable insights regarding global "tipping points," "key vulnerabilities," or "planetary boundaries" as well as evidence of climate thresholds for agricultural crops, species of fish, forest and coral reef communities, and humans. However, for most regions and sectors, there is a lack of empirical evidence to quantify magnitudes of climate change that would constitute a future adaptation limit. Furthermore, economic 
development, technology, and cultural norms and values can change over time to enhance or reduce the capacity of systems to avoid limits. As a consequence, some limits may be considered "soft" in that they may be alleviated over time. Nevertheless, some limits may be "hard" in that there are no reasonable prospects for avoiding intolerable risks. Recent literature suggests that incremental adaptation may not be sufficient to avoid intolerable risks, and therefore transformational adaptation may be required to sustain some human and natural systems. \{16.2-7; Table 16-3; Boxes 16-1, 16-4\}

Greenhouse gas (GHG) mitigation can reduce the rate and magnitude of future climate change and therefore the likelihood that limits to adaptation will be exceeded (medium evidence, high agreement). Adaptation and GHG mitigation are complementary risk management strategies. However, residual loss and damage will occur from climate change despite adaptation and mitigation action. Knowledge about limits to adaptation can inform the level and timing of mitigation needed to avoid dangerous anthropogenic interference with the climate system. For example, the level of effort needed to adapt to a $4^{\circ} \mathrm{C}$ increase in global mean temperature would be significantly greater than that needed to adapt to lower magnitudes of temperature increase. Mitigation can reduce the likelihood of $4^{\circ} \mathrm{C}$ of warming and therefore the likelihood of exceeding limits to adaptation of natural and human systems. However, the empirical evidence needed to identify limits to adaptation of specific sectors, regions, ecosystems, or species that can be avoided with different GHG mitigation pathways is lacking. $\{16.3 .2 .2,16.6$; Box 16-3\}

The selection and implementation of specific adaptation options has ethical implications (very high confidence). Adaptation decision making involves the reconciliation of legitimate differences about how adaptation resources are distributed and the values that adaptation seeks to protect. For example, the costs and benefits of different adaptation options, such as insurance schemes or large-scale infrastructure projects, may be inequitably distributed among different actors and stakeholders. Such inequities may generate ethical questions regarding who is advantaged or disadvantaged by adaptation actions. In addition, awareness that climate change may exceed the capacity of actors to adapt may have ethical implications for decisions regarding mitigation and climate targets as well as investments in GHG mitigation policies and measures. National and international law as well as decision making at regional and local scales among both public and private actors will influence distributive and procedural justice in adaptation planning and implementation. \{16.3.3.8, 16.6-7; Table 16-4; Box 16-4\}

Successful adaptation requires not only identifying adaptation options and assessing their costs and benefits, but also exploiting available mechanisms for expanding the adaptive capacity of human and natural systems (medium evidence, high agreement). Since the AR4, a growing body of literature provides guidance on how enabling conditions for adaptation can be developed and how constraints can be reduced. Continued development of this knowledge through research and practice could accelerate more widespread and successful adaptation outcomes. However, seizing opportunities, overcoming constraints, and avoiding limits can involve complex governance challenges and may necessitate new institutions and institutional arrangements to effectively address multi-actor, multiscale risks. \{16.2-3, 16.5, 16.8; Table 16-1; Box CC-EA\} 


\subsection{Introduction and Context}

Since the IPCC's Fourth Assessment Report (AR4), demand for knowledge regarding the planning and implementation of adaptation as a strategy for climate risk management has increased significantly (Preston et al., 2011a; Park et al., 2012). This chapter assesses recent literature on the opportunities that create enabling conditions for adaptation as well as the ancillary benefits that may arise from adaptive responses. It also assesses the literature on biophysical and socioeconomic constraints on adaptation and the potential for such constraints to pose limits to adaptation. Given the available evidence of observed and anticipated limits to adaptation, the chapter also discusses the ethical implications of adaptation limits and the literature on system transformational adaptation as a response to adaptation limits.

To facilitate this assessment, this chapter provides an explicit framework for conceptualizing opportunities, constraints, and limits (Section 16.2). In this framework, the core concepts including definitions of adaptation, vulnerability, and adaptive capacity are consistent with those used previously in the AR4 (Adger et al., 2007). However, the material in this chapter should be considered in conjunction with that of complementary WGII AR5 chapters. These include Chapter 14 (Adaptation Needs and Options), Chapter 15 (Adaptation Planning and Implementation), and Chapter 17 (Economics of Adaptation). Material from other WGII AR5 chapters is also relevant to informing adaptation opportunities, constraints, and limits, particularly Chapter 2 (Foundations for Decision Making) and Chapter 19 (Emergent Risks and Key Vulnerabilities). This chapter also synthesizes relevant material from each of the sectoral and regional chapters (Section 16.5).

To enhance its policy relevance, this chapter takes as its entry point the perspective of actors as they consider adaptation response strategies over near, medium, and longer terms (Eisenack and Stecker, 2012; Dow et al., 2013a,b). Actors may be individuals, communities, organizations, corporations, non-governmental organizations (NGOs), governmental agencies, or other entities responding to real or perceived climaterelated stresses or opportunities as they pursue their objectives (Patt and Schröter, 2008; Blennow and Persson, 2009; Frank et al., 2011). These actors may seek to navigate near-term constraints to implement adaptation while simultaneously working to alleviate those constraints to enable greater flexibility and adaptive capacity in the future. Therefore, it is necessary to consider diverse time frames for possible social, institutional, technological, and environmental changes. These time frames also differ in the types of uncertainties that are relevant, ranging from those of climate scenarios and models, possible system thresholds, nonlinear responses or irreversible changes in social or environmental systems, and the anticipated magnitude of impacts associated with higher or lower levels of climate change (Meze-Hausken, 2008; Hallegatte, 2009; Briske et al., 2010).

To provide further background and context, this chapter proceeds by revisiting relevant findings on adaptation opportunities, constraints, and limits within the AR4 and the more recent IPCC Special Report on Managing the Risks of Extreme Events and Disasters to Advance Climate Change Adaptation (SREX) (IPCC, 2012). The chapter then presents a framework for adaptation, opportunities, and limits with an emphasis on explicit definitions of these concepts to facilitate assessment. Key components of this framework are assessed in subsequent chapters, including the synthesis of how these components are treated among the different sectoral and regional chapters of the WGII AR5 report. The chapter subsequently assesses relationships between mitigation and adaptation opportunities, constraints, and limits as well as their ethical implications. The chapter concludes with discussion of key pathways forward for research and practice to seize opportunities, overcome constraints, and avoid limits.

\subsubsection{Summary of Relevant AR4 Findings}

The AR4 Summary for Policymakers of Working Group II concluded that there are "formidable environmental, economic, informational, social, attitudinal and behavioural barriers to the implementation of adaptation" and that "availability of resources and building adaptive capacity are particularly important" (IPCC, 2007a, p. 19). These findings were based primarily on Chapter 17, Assessment of Adaptation Practices, Options, Constraints and Capacity (Adger et al., 2007). The key conclusion from Adger et al. (2007, p. 719), as relevant to this chapter, was as follows: "There are substantial limits and barriers to adaptation (very high confidence)." The authors go on to discuss biophysical and technological limits to adaptation as well as barriers arising from technological, financial, cognitive and behavioral, and social and cultural factors. The authors also noted both significant knowledge gaps and impediments to the sharing of relevant information to alleviate those gaps.

These findings were further evidenced by the sectoral, and particularly regional, chapters of the WGII AR4 report. For example, the chapters assessing impacts and adaptation in Africa, Asia, and Latin America collectively emphasized the significant constraints on adaptation in developing nations. Meanwhile, the chapter on Small Islands by Mimura et al. (2007) identified several constraints to adaptation including limited natural resources and relative isolation. Finally, in the chapter on Polar Regions, Anisimov et al. (2007) noted that indigenous groups have developed resilience through sharing resources in kinship networks that link hunters with office workers, and even in the cash sector of the economy. However, they concluded that such responses may be constrained by social, cultural, economic, and political factors. For all of these regions, adaptation constraints are linked to governance systems and the quality of national institutions as well as limited scientific capacity and ongoing development challenges (e.g., poverty, literacy, and civil and political rights).

The AR4 also provided evidence that constraints on adaptation are not limited to the developing world. For example, Hennessy et al. (2007) reported that while adaptive capacity in Australia and New Zealand has strengthened over time, a number of constraints remain including access to tools and methods for impact assessment as well as appraisal and evaluation of adaptation options. They also note weak linkages among the various strata of government regarding adaptation policy and skepticism among some populations toward climate change science. For North America, Field et al. (2007) identify a range of social and cultural barriers, informational and technological barriers, and financial and market barriers. The chapter on Europe mentions the limits faced by species and ecosystems due to lack of migration space, low soil fertility, and human alterations of the landscape (Alcamo et al., 2007). 
Several other AR4 chapters assessed literature relevant to this chapter. Chapter 18, Inter-Relationships between Adaptation and Mitigation (Klein et al., 2007), discussed the possible effect of mitigation on adaptation (an issue also considered by WGIII AR4, in particular by Fisher et al. (2007) and Sathaye et al. (2007)). Finally, Chapter 19, Assessing Key Vulnerabilities and the Risk from Climate Change (Schneider et al., 2007), outlined how the presence of adaptation constraints and limits is a contributing factor to vulnerability. Chapters that address similar themes also appear in the AR5, and cross-references are provided in this chapter to this more recent material.

\subsubsection{Summary of Relevant SREX Findings}

The IPCC Special Report on Managing the Risks of Extreme Events and Disasters to Advance Climate Change Adaptation (SREX) assesses a broad array of literature on climate change, extreme events, adaptation, and disaster risk reduction. A central framing concept for the SREX was the assertion that (Lavell et al., 2012, p. 37), " . . while there is a longstanding awareness of the role of development policy and practice in shaping disaster risk, advances in the reduction of the underlying causes - the social, political, economic, and environmental drivers of disaster risk - remain insufficient to reduce hazard, exposure, and vulnerability in many regions (UNISDR, 2009, 2011) (high confidence)."

This summary of relevant SREX material focuses on how the key findings of the SREX provide insights relevant to the treatment of opportunities, constraints, and limits in this chapter.

With respect to opportunities, the linkages between development and disaster risk reduction provide a number of avenues for enhancing societal resilience to natural disasters and climate change. For example, the SREX highlights the benefits of considering disaster risk in national development planning if strategies to adapt to climate change are adopted (Lal et al., 2012). The observed dependence of disasters on underlying patterns of development is indicative of the opportunities for increasing societal resilience through sustainable development. In addition, incorporating adaptation into multi-hazard risk management may be an effective strategy for the efficient integrated management of natural hazards and future climate risk (O'Brien et al., 2012).

The SREX report also discussed the constraints associated with enhancing disaster risk reduction and climate adaptation. In particular, ongoing development deficits as well as inequality in coping and adaptive capacities pose fundamental constraints (Cardona et al., 2012). The SREX noted that national systems and institutions are critical for generating the capacity needed to manage the risks associated with climate variability and change (Lal et al., 2012). Yet capacity at one level of governance does not necessarily convey capacity to other levels (Burton et al., 2012). Even in the presence of robust institutions, rates of socioeconomic and climate change can interact to constrain adaptation. For example, O'Brien et al. (2012) note that rapid socioeconomic development in vulnerable urban areas can increase societal exposure to natural hazards while simultaneously constraining the capacity of actors to implement policies and measures to reduce vulnerability. Overcoming these constraints to achieve development objectives is constrained by a paucity of disaster data at the local level as well as persistent uncertainties regarding the manifestation of extreme events in future decades (Cutter et al., 2012; Seneviratne et al., 2012).

The SREX report cautioned that natural hazards, climate change, and societal vulnerability can pose fundamental limits to sustainable development. Such limits can arise from the exceedance of natural and/or societal thresholds or tipping points (Lal et al., 2012; O'Brien et al., 2012; Seneviratne et al., 2012). Accordingly, the SREX concludes that adaptation options should include not only incremental adjustments to climate variability and climate change, but also transformational changes that alter the fundamental attributes of systems. Though challenging to implement, such transformation may be aided by actors questioning prevailing assumptions, paradigms, and management objectives toward the development of new ways of managing risk and identifying opportunities (O'Brien et al., 2012).

\subsection{A Risk-Based Framework for Assessing Adaptation Opportunities, Constraints, and Limits}

Risk is an intrinsic element of any understanding of "dangerous anthropogenic interference with the climate system" (UNFCCC, 1992) and associated assumptions about the capacity of human and natural systems to adapt to climatic change. The United Nations Framework Convention on Climate Change (UNFCCC) refers specifically to adaptation of ecosystems, threats to food production, and sustainable economic development. While there is evidence of opportunities in natural and human systems to adapt to climate changes, there is also evidence that the potential to adapt is constrained, or more difficult, in some situations, and faces limits in others (very high confidence; e.g., Adger et al., 2009; Dow et al., 2013a,b; see also Sections 16.3-5).

This chapter applies a risk-based framework and a set of linked definitions to the assessment of adaptation opportunities, constraints, and limits. This approach is consistent with other risk management approaches to guiding adaptation responses to climate change (IPCC, 2012; see also Sections 1.3.4, 2.1.2, 14.4, 15.3). The adaptation literature ascribes a number of different meanings to the terms opportunities, constraints, and limits, which may have added confusion to an important scientific and policy debate. The AR4, for example, provided a specific definition of adaptation limits, but used the terms barriers and constraints interchangeably to describe general impediments to adaptation (Adger et al., 2007). Similar ambiguities are apparent within the rapidly expanding literature focused on adaptation constraints (Biesbroek et al., 2013a).

The framework and definitions employed here draw on a number of literatures (Dow et al., 2013a,b), in particular vulnerability assessment (Füssel, 2006; Füssel and Klein, 2006) and risk assessment (Jones, 2001; Klinke and Renn, 2002; Renn, 2008; National Research Council, 2010) as well as climate adaptation (Hulme et al., 2007; Adger et al., 2009; Hall et al., 2012). Moving from such general definitions to applications requires specifying who or what is adapting, what they are adapting to, and the process of adaptation (Smit et al., 1999). Hence, this chapter explores adaptation opportunities, constraints, and limits from the context of social actors, which includes individuals, businesses, government agencies, or informal social groups. 


\title{
Frequently Asked Questions \\ FAQ 16.1 | What is the difference between an adaptation barrier, constraint, obstacle, and limit?
}

\begin{abstract}
An adaptation constraint represents a factor or process that makes adaptation planning and implementation more difficult. This could include reductions in the range of adaptation options that can be implemented, increases in the costs of implementation, or reduced efficacy of selected options with respect to achieving adaptation objectives. In this context, a constraint is synonymous with the terms adaptation barrier or obstacle that also appear in the adaptation literature. However, the existence of a constraint alone does not mean that adaptation is not possible or that one's objectives cannot be achieved. In contrast, an adaptation limit is more restrictive in that it means there are no adaptation options that can be implemented over a given time horizon to achieve one or more management objectives, maintain values, or sustain natural systems. This implies that certain objectives, practices, or livelihoods as well as natural systems may not be sustainable in a changing climate, resulting in deliberate or involuntary system transformations.
\end{abstract}

An explicit focus on risk is particularly useful to understanding climate adaptation (Jones and Preston, 2011; Dow et al., 2012b). Adaptation is intended to reduce the risk to assets or systems of value (Adger et al., 2012b). The concept of risk integrates the dimensions of probability and uncertainty with the material and normative dimensions that shape societal responses to threats (Renn, 2008). Figure 16-1 relates judgments about risk and the ability to maintain risks at a tolerable level to the concept of adaptation and adaptation opportunities, constraints, and limits (Box 16-1). Drawing on the work of Klinke and Renn (2002), actors evaluate risks based on one of three categories: acceptable, tolerable, and intolerable. Acceptable risks are those deemed so low that additional efforts at risk reduction, in this case climate adaptation efforts, are not justified. Tolerable risks relate to situations where adaptive risk management efforts are required and effective for risks to be kept within reasonable levels. The scope of risks that fall within the tolerable area is influenced by adaptation opportunities and constraints. Therefore, the categorization of risks varies across spatial, jurisdictional, and temporal. As discussed later in this chapter, opportunities and constraints may be physical, technological, economic, institutional, legal, cultural, or environmental in nature (Sections 16.3, 16.5-7). Constraints may limit the range of available adaptation options creating the potential for residual damages for actors, species, or ecosystems associated with specific regions or sectors. Under some circumstances, the risk of residual damage may be viewed as an acceptable or tolerable trade-off (Stern et al., 2006; de Bruin et al., 2009a).

Intolerable risks may be related to threats to core social objectives associated with health, welfare, security, or sustainability (Klinke and Renn, 2002; Renn, 2008; Dow et al., 2013a,b). Risks become intolerable when practicable or affordable adaptation options to avoid escalating risks to such valued objectives or biophysical needs become unavailable. Therefore, a limit is a point when an intolerable risk must be accepted; the objective itself must be relinquished; or some adaptive transformation must take place to avoid intolerable risk. Such a discontinuity may take several forms such as individual's decision to relocate, an insurance company's decision to withdraw coverage, or a species' extinction. The alternative to such discontinuities is an escalating and unmediated risk of losses (Moser and Ekstrom, 2010; see also Section 16.4.2). While individuals have their own perspectives about what are acceptable, tolerable, or intolerable risks, collective judgments about risk are also codified through mechanisms such as engineering design standards, air and water quality standards, and legislation that establishes goals for regulatory action. There are also international agreements that establish norms and rights relevant to climate change risks (Knox, 2009; OHCHR, 2009; Crowley, 2011), such as the Universal Declaration of Human Rights, the International Covenant on Civil and Political Rights, and the International Covenant on Economic, Social and Cultural Rights. Further, these high level responses often shape the constraints and opportunities to adaptation and responses to risk at lower levels through the distribution

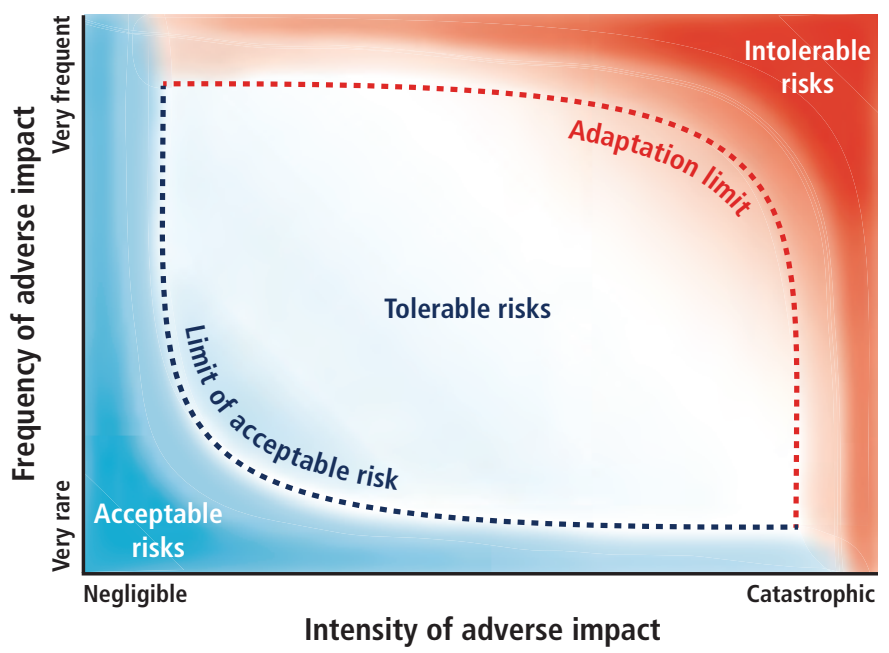

Figure 16-1 | Conceptual model of the determinants of acceptable, tolerable, and intolerable risks and their implications for limits to adaptation (Dow et al., 2013b, based on Klinke and Renn, 2002; see also Renn and Klinke, 2013). In this conceptual diagram, adaptation efforts are seen as keeping risks to objectives within the tolerable risk space. Opportunities and constraints influence the capacity of actors to maintain risks within a tolerable range. The dotted lines indicate that individual or collective views on risk tolerance with respect to the frequency and intensity of climate-related risks are not fixed, but may vary and change over time. In addition, the shape or angle of the lines and the relative area in each section of the diagram are illustrative and may themselves change as capacities and attitudes change. The shaded areas represent the potential differences in perspective among actors. 


\section{Box 16-1 | Definitions of Adaptation Opportunities, Constraints, and Limits}

Adaptation Opportunities: Factors that make it easier to plan and implement adaptation actions, that expand adaptation options, or that provide ancillary co-benefits. These factors enhance the ability of an actor(s) to secure their existing objectives, or for a natural system to retain productivity or functioning. For instance, increased public awareness and support for adaptation, availability of additional resources from actors at other levels of governance to overcome constraints and soft limits, and interest in acquiring cobenefits arising from adaptation strategies can all facilitate adaptation planning and implementation. Private sector efforts in research and development that can improve affordability, flexibility, or ease of implementation could also create opportunities (Section 14.2.4). Such adaptation opportunities, sometimes also referred to as adaptation enablers, are distinct from opportunities arising from climate change (e.g., longer growing seasons), which are commonly referred to as potential benefits of climate change or adaptation options.

Adaptation Constraints: Factors that make it harder to plan and implement adaptation actions. Adaptation constraints restrict the variety and effectiveness of options for actors to secure their existing objectives, or for a natural system to change in ways that maintain productivity or functioning. These constraints commonly include lack of resources (e.g., funding, technology, or knowledge) (Section 16.3.2), institutional characteristics that impede action (Section 16.3.2.8), or lack of connectivity and environmental quality for ecosystems (Section 4.4). The terms "barriers" and "obstacles" are frequently used as synonyms. Constraints—alone or in combination—can drive an actor or natural system to an adaptation limit.

Adaptation Limit: The point at which an actor's objectives or system's needs cannot be secured from intolerable risks through adaptive actions (Adger et al., 2009; Moser and Ekstrom, 2010; Dow et al., 2013a,b; Islam et al., 2014).

Hard Adaptation Limit: No adaptive actions are possible to avoid intolerable risks.

Soft Adaptation Limit: Options are currently not available to avoid intolerable risks through adaptive action.

A limit to adaptation means that, for a particular actor, system, and planning horizon of interest, no adaptation options exist, or an unacceptable measure of adaptive effort is required, to maintain societal objectives or the sustainability of a natural system. Objectives include, for example, maintaining safety standards such as those codified in laws, regulations, or engineering design standards (e.g., 1-in-500 year levees); security of air or water quality; as well as equity, cultural cohesion, and preservation of livelihoods. Requirements for sustaining natural systems might include temperature ranges or moisture availability. In the case of hard limits, no adaptation options are foreseeable, even when looking beyond the current planning horizon. For soft limits, however, adaptation options could become available in the future owing to changing attitudes or values or as a result of innovation or other resources becoming available to an actor. For example, 31 Native Alaskan villages are facing "imminent threats" due to coastal erosion and at least 12 of the 31 have begun to explore relocation or have decided to partially or totally relocate (US GAO, 2009). In the case of these communities with minimum local revenue, the ability to relocate depends on the political and financial support of the U.S. federal government (Huntingon et al., 2012). Therefore, limits are strongly influenced by relationships among public and private actors and institutions across different spatial, temporal, and jurisdictional scales (Cash et al., 2006; see also Section 16.4.1).

of resources, institutional design, and support of capacity development (Sections 16.2-3, 16.4.1). If these risks and discontinuities have globalscale consequences, they can be linked to "key vulnerabilities" to climate change (Section 19.6). Consistent with our framing of adaptation limits, such key vulnerabilities would need to be assessed in terms of the limits they imply for specific social actors, species, and ecosystems.

It is essential to evaluate opportunities, constraints, and limits with respect to both the rate and magnitude of climate change and the relevant time horizon for an actor, a species, or an ecosystem. Opportunities, constraints, and limits to adaptation develop along a dynamic continuum (i.e., the dotted lines in Figure 16-1 can shift), together conditioning the capacity of natural and human systems to adapt to climate change. New opportunities for adaptation may emerge through time; constraints may be loosened; and some, although not all, limits that arise in the present may eventually be shifted or removed altogether. For a given social actor, the time horizon for adaptation decisions usefully bounds an analysis of opportunities, constraints, and limits. For natural systems, 
the rate of species responses relative to changes in environmental conditions is a limit to the capacity to adapt (Sections 4.3.2.5, 4.4, 16.3.2.3, 16.4.1). The observed rate of evolutionary and other species responses ranges from rapid to inadequate to allow persistence (Hoffmann and Sgro, 2011).

Because adaptation limits relate to adaptation resources and attitudes to risk that may change over time, some limits may be viewed as "soft" or time sensitive (Section 16.4.1). While a given adaptation option may not be available today or require impracticable levels of effort, it may become available through innovation or changes in attitudes in time. Soft limits may be shifted by investments in research and development, changes in regulatory rules or funding arrangements, or by changing social or political attitudes (Park et al., 2012; Adger et al., 2013). Other limits are "hard" or time insensitive in that there is no known process to change them (Section 16.4.1). Examples of hard limits include water supply in fossil aquifers, limits to retreat on islands, and loss of genetic diversity.

\subsection{Adaptation Opportunities and Constraints}

Different actors, sectors, and geographic regions have differential capacities to adapt to climate variability and change (very high confidence; Adger et al., 2007; IPCC, 2012), although those capacities can be difficult to measure (Tol et al., 2008; Hinkel, 2011). Since the AR4 (Adger et al., 2007), the literature on the factors that contribute to adaptive capacity has deepened (Adger et al., 2009; Moser and Ekstrom, 2010). This literature has evolved along two different pathways. One focuses on the range of opportunities that exist to facilitate adaptation planning and implementation. The other, which is also more extensive, focuses on describing the constraints that inhibit adaptation. Although they are sometimes treated in the literature as distinct, opportunities and constraints are complementary in that adaptive capacity is influenced jointly by the extent to which actors take advantage of available opportunities to pursue adaptation responses and the extent to which those actors or natural, unmanaged systems experience constraints. In addition, factors that are identified as constraints may also reveal valuable opportunities for adaptation interventions to build adaptive capacity.

While some level of generalization regarding opportunities and constraints that are common to different regions, sectors, communities, and actors is possible, the manner in which they manifest is context dependent (very high confidence; Adger et al., 2007; Orlove, 2009; Kasperson and Berberian, 2011; Weichselgartner and Breviere, 2011; IPCC, 2012). For example, actors that frame adaptation as a process of capacity building or sustainable development may pursue different adaptation options with different opportunities and constraints compared with those that frame adaptation as largely addressing climate change impacts (McGray et al., 2007; Fünfgeld and McEvoy, 2011). Adaptation researchers apply their own frameworks and heuristics that influence understanding of adaptation processes (Biesbroek et al., 2013b; Preston et al., 2013b). Therefore, one must be cautious in applying generic assumptions regarding adaptation opportunities and constraints in assessments of vulnerability and adaptive capacity or in the identification of appropriate adaptation responses (Adger and Barnett, 2009; Barnett and Campbell, 2009; Mortreux and Barnett, 2009). The recent adaptation literature suggests significant work remains in understanding such context-specific determinants of vulnerability and adaptive capacity and in effectively using the knowledge gained from available case studies to facilitate adaptation more broadly (Tol and Yohe, 2007; Klein, 2009; Smith et al., 2010; Hinkel, 2011; Preston et al., 2011 b; Biesbroek et al., 2013a). Therefore, the discussion of opportunities and constraints here should be considered in the context of the sectoral and regional synthesis (Section 16.5) as well as the sector- and region-specific material on constraints and opportunities in other WGII AR5 chapters.

\subsubsection{Adaptation Opportunities}

\subsubsection{Enabling Conditions for Adaptation}

Adaptation opportunities represent enabling factors that enhance the potential for actors to plan and implement actions to achieve their

Frequently Asked Questions

\section{FAQ 16.2 | What opportunities are available to facilitate adaptation?}

Although an extensive literature now exists regarding factors that can constrain adaptation, there is very high confidence that a broad range of opportunities exist for actors in different regions and sectors that can ease adaptation planning and implementation. Generally, sustainable economic development is an overarching process that can facilitate adaptation, and therefore represents a key opportunity to reduce adaptation constraints and limits. More specifically, those actions or processes that enhance the awareness of adaptation actors and relevant stakeholders and/or enhance their entitlements to resources can expand the range of adaptation options that can be implemented and help overcome constraints. The development and application of tools to support assessment, planning, and implementation can aid actors in weighing different options and their costs and benefits. Policies, whether formal policies of government institutions, initiatives of informal actors, or corporate policies and standards, can direct resources to adaptation and/or reduce vulnerability to current and future climate. Finally, the ability for humans to learn from experience and to develop new practices and technologies through innovation can significantly expand adaptive capacity in the future. 
Table 16-1 | Identification of key adaptation opportunities. Each type of opportunity is represented by multiple illustrative examples as well as supporting references.

\begin{tabular}{|c|c|c|}
\hline Opportunity & Examples & References \\
\hline \multirow{3}{*}{$\begin{array}{l}\text { Awareness } \\
\text { raising }\end{array}$} & Positive stakeholder engagement & O'Neill and Chicholson-Cole (2009); Kahan (2010) \\
\hline & Communication of risk and uncertainty & Berry et al. (2011); Pidgeon and Flschhoff (2011); Pidgeon (2012); Lieske et al. (2013) \\
\hline & Participatory research & Pearce et al. (2009); McNamara and McNamara (2011); Sheppard et al. (2011); Duru et al. (2012); Faysse et al. (2012) \\
\hline \multirow{5}{*}{$\begin{array}{l}\text { Capacity } \\
\text { building }\end{array}$} & Research, data, education, and training & PCAST (2011); WMO (2011); Bangay and Blum (2012); Lemos et al. (2013) \\
\hline & Extensions services for agriculture & Deressa et al. (2009); Fosu-Mensah et al. (2012) \\
\hline & Resource provision & Ayers (2009); Ayers and Huq (2009); Grasso (2010); Klein (2010); Rübbelke (2011) \\
\hline & Development of human capital & Bowen et al. (2012); Lemos et al. (2013) \\
\hline & Development of social capital & Deressa et al. (2009); Adger et al. (2010); Engle and Lemos (2010); Huang et al. (2011) \\
\hline \multirow[t]{6}{*}{ Tools } & Risk analysis & van Aalst et al. (2008); Pidgeon and Butler (2009); Chin et al. (2010); Zhou et al. (2012); Wade et al. (2013) \\
\hline & Vulnerability assessment & Allison et al. (2009); Moreno and Becken (2009); Nelson et al. (2010b); Romieu et al. (2010); Koh (2011); Preston et al. (2011b) \\
\hline & Multi-criteria analysis & de Bruin et al. (2009b); Garfi et al. (2011); Yang et al. (2012); Kyung-Soo et al. (2013) \\
\hline & Cost/benefit analysis & Tol et al. (2008); Hallegatte (2009); Weitzman (2009); Mechler and Islam (2013) \\
\hline & Decision support systems & Norman et al. (2010); Wenkel et al. (2013) \\
\hline & Early warning systems & Lowe et al. (2011); Lenton (2013); Marvin et al. (2013) \\
\hline \multirow[t]{3}{*}{ Policy } & $\begin{array}{l}\text { Integrated resource and infrastructure } \\
\text { planning }\end{array}$ & Rosenberg et al. (2010); Becker et al. (2012); Heeres et al. (2012) \\
\hline & Spatial planning & Brown (2011); Wheeler (2012); Pinto et al. (2013) \\
\hline & Design/planning standards & Hamin and Gurran (2009); Mailhot and Duchesn (2009); Kwok and Rajkovich (2010); Ren et al. (2011); Nassopoulos et al. (2012) \\
\hline \multirow[t]{3}{*}{ Learning } & $\begin{array}{l}\text { Experience with climate vulnerability and } \\
\text { disaster risk }\end{array}$ & Fiksel (2006); Crespo Cuaresma et al. (2008); Cutter et al. (2012) \\
\hline & Learning-by-doing & Berkhout et al. (2006); Bulkeley and Castán Broto (2012); Roberts et al. (2012) \\
\hline & Monitoring and evaluation & GIZ (2011a,b); Preston et al. (2011a); Adaptation Sub-Committee (2012) \\
\hline \multirow[t]{3}{*}{ Innovation } & Technological change & Hanjra and Qureshi (2010); Chhetri et al. (2012); Lybbert and Sumner (2012); Rodima-Taylor et al. (2012); Vermeulen et al. (2012) \\
\hline & Infrastructure efficiencies & Beard et al. (2009); Newton (2013) \\
\hline & Digital/mobile telecommunications & Ospina and Heeks (2010a,b); Meera et al. (2012) \\
\hline
\end{tabular}

adaptation objective(s) or facilitate adaptive responses by natural systems to climate risk (Box 16-1). Therefore, an opportunity is distinct from an adaptation option, which is a specific means of achieving an adaptation objective (such as an early warning system as a means of reducing vulnerability to tropical cyclones) or a strategy for the conservation of an ecological system (Section 14.3; Table 14-1). Adaptation opportunities described here also do not consider the potential beneficial consequences of climate change (Box 16-1), an issue addressed to varying degrees among the various sectoral and regional chapters.

Opportunities for adaptation range from increasing awareness of climate change, its consequences, and the potential costs and benefits of adaptation options to the implementation of specific policies that create conditions that are conducive to adaptation implementation. For example, rice is a key food crop, particularly in Asia, in which $90 \%$ of rice is produced and subsequently consumed (Timmer, 2010). Multiple studies have identified rice as being particularly vulnerable to the effects of climate change, including both temperature and water availability impacts (Papademetriou et al., 2000). Therefore, planning and implementation of adaptive responses will be an important component of managing the risk of climate change to rice production (Howden et al., 2007; Lobell et al., 2008; Tilman et al., 2011; Anwar et al., 2013). A range of opportunities are available to support adaptation (Tables 16-1, 16-3) (very high confidence). Hypothetically, these could include the use of analysis tools to better understand vulnerabilities and thresholds in rice and develop scenarios of future consequences. That information could then be communicated to farmers, national governments, and international agencies to increase awareness of potential risks. Policies can be used to incentivize adaptation including investments in biotechnology research to breed more resistant strains as well as field studies to identify potential new regions that might be appropriate for rice cultivation in the future.

Such opportunities exist for other agricultural commodities as well as other sectors and regions at risk from climate change (Box 16-2). For example, there is growing recognition of the potential for using disaster response and recovery processes as a means of increasing resilience to future extreme events (Lavell et al., 2012). Meanwhile, case studies of Australian local governments as well as Inuit communities in the Arctic have identified a range of opportunities for building adaptive capacity and overcoming constraints (Smith et al., 2008; Ford, 2009; Ford et al., 2010). These include risk assessment, partnerships, establishment of monitoring and evaluation frameworks, developing finance mechanisms, and formal adaptation policy development.

Sustainable economic development is a critical foundation for the creation of adaptation opportunities (Sections 20.2, 20.6), because it has the potential to build the capacity of individuals and organizations to adapt (very high confidence). Sustainable development is associated with increasing opportunities for research, training, and education as 


\section{Box 16-2 | A Case Study of Opportunities for Adaptation and Disaster Risk Reduction}

Bangladesh has been identified as a region of South Asia that is particularly vulnerable to tropical cyclones (Ali, 1999; Mallick and Rahman, 2013), and this vulnerability is projected to increase due to climate change (Karim and Mimura, 2008; Dasgupta et al., 2010). The nation's response to this vulnerability illustrates the manner in which multiple opportunities can converge to facilitate adaptation and disaster risk reduction. The Cyclone Preparedness Program (CPP) was launched in the 1960s to establish a warning system in coastal regions (Habib et al., 2012). The CPP has been continually improved in subsequent years with assistance from the International Federation of Red Cross and Red Crescent Societies and the International Foundation (Mallick and Rahman, 2013). A coastal reforestation program was also established in the 1960s to enhance natural buffers to storm surge (Mallick and Rahman, 2013; Box CC-EA). The Bangladesh Government initiated construction of cyclone shelters in the late 1980s, yet a cyclone in 1991 revealed that too few shelters were available (Bern et al., 1991; Chowdhury et al., 1993). This prompted collaboration between the government of Bangladesh, the United Nations Development Programme, and the World Bank to launch the Multipurpose Cyclone Shelter Program. That program characterized shelter needs along the coast and provided resources for their construction. In addition, shelter construction, which was concentrated around primary and secondary schools, coincided with national legislation requiring compulsory attendance in primary school, which required the construction of new schools. This created the opportunity for multipurpose construction of buildings, reflecting the potential ancillary benefits that can arise from integrated planning (Section 16.3.1.2).

More recently, Bangladesh has begun to focus on increasing the resilience of the built environment. This effort has focused on the development of disaster-resilient habitat (Mallick and Rahman, 2007), where communities participate in the design and construction of resilient housing with support from international donors (Mallick et al., 2008; Mallick and Rahman, 2013). This may be a more cost-effective strategy for both reducing mortality and property damage (Mallick et al., 2008). The observed progress in reducing vulnerability to tropical cyclones is a function of various opportunities (awareness, assessment, policies, innovation, and capacity building) that have emerged over the past several decades that created conditions that enabled the implementation of specific policies, projects, and programs. Nevertheless, the additional risk posed by future climate change may necessitate further future investments (Dasgupta et al., 2010).

well as for enhancing access to expertise and tools for assessment activities and decision support. It also increases access to technologies that can enhance efficiencies. For example, water use in the USA has remained relatively constant since the mid-1980s, despite population growth, increases in agricultural yields, and expansion of electricity generation (Kenny et al., 2009). Improvements in technology and management practice stimulated by innovation, education, and learning have increased water use efficiency. This phenomenon may increase the resilience of U.S. water resources to climate change. Yet, these advances are a function of broader national and regional economic development trends. Therefore, future development pathways may have a significant influence on the opportunities for adaptation and therefore the adaptive capacity of adaptation actors (Sections 16.3.2.10, 20.6; Box 16-3).

\subsubsection{Ancillary Benefits of Adaptation}

Some adaptation options may offer ancillary benefits (or co-benefits) independent of their direct benefits with respect to reducing vulnerability to climate change (very high confidence; Section 17.2.3). The potential for ancillary benefits has two important implications for adaptation planning and implementation. First, their consideration may result in a more favorable assessment of the cost-effectiveness of a specific adaptation option (Hallegatte, 2009). Second, consideration of the ancillary benefits of adaptation may help in efficiently integrating adaptation into existing management and decision-making processes (Ahmed and Fajber, 2009; Dovers, 2010).

Such ancillary benefits may arise from adaptation responses in three ways:

- Stimulating adaptation to current climate variability: Although it is generally assumed that physical, ecological, and social systems are well adapted to current climatic conditions, this is frequently not the case (Dugmore et al., 2009; Heyd and Brooks, 2009). Increased awareness of the potential impacts of future climate change may, in some instances, lead to the implementation of adaptation options to reduce vulnerability or capitalize on opportunities (medium evidence, high agreement; Section 16.3.2.1). These options may have near-term ancillary benefits with respect to reducing vulnerability to current climate variability and extreme weather events (Füssel, 2008; Hallegatte, 2009; Ford et al., 2010). On the other hand, future reductions in vulnerability to climate change can be perceived as 
ancillary benefits of near-term responses to current climate variability and natural disasters (Ziervogel et al., 2010a,b). Hence, there may be some ambiguity with respect to what actors perceive as the primary versus ancillary benefit of a particular policy or measure.

- Generation of climate adaptation goods and services: Adaptation planning and implementation often may require additional knowledge and investment of resources. Adaptation therefore represents a potential economic opportunity for producers of goods and services used to satisfy adaptation needs (limited evidence, medium agreement; EBI, 2013). Such services range from vulnerability assessment and risk analysis to the implementation of technology and engineering solutions. The Stern Review indicated that the market opportunities for new infrastructure and buildings resilient to climate change in Organisation for Economic Co-operation and Development (OECD) countries could be quite significant (Stern et al., 2006). For example, the market for snow machines will be influenced by growing concerns about snow cover in more marginal ski resorts (Scott et al., 2006). Higher elevation regions may see new opportunities as a result of snow resort shifts (Bark et al., 2010). Likewise, increased risks associated with track buckling caused by higher summer temperatures may trigger innovation and investment in new railway track and drainage systems (Bark et al., 2010). Rising damage caused by climate change could provide new markets for innovative insurance products and other risk-based financial services (limited evidence, medium agreement; Botzen et al., 2009, 2010). However, these ancillary benefits must be weighed against the adverse impacts that create the market for such services.

- Advancing sustainable development: As part of a larger portfolio of policies and measures, adaptation can assist in addressing existing development deficits while also meeting long-term sustainable development objectives (very high confidence; Sections 20.2, 20.6). For example, policy options related to management of water and natural resources under a changing climate; the development of water, transportation, and communication infrastructure; and the promotion of credit and insurance services can promote economic development, increase adaptive capacity, and reduce the impacts of climate change on the poor (Hertel and Rosch, 2010). Therefore, effective adaptation and climate risk management may be important enablers of sustainable economic development.

\subsubsection{Adaptation Constraints}

As discussed in the AR4 (Adger et al., 2007), a number of factors constrain planning and implementation of adaptation options (very high confidence). More recent studies have documented an expanded range of constraints in a diverse array of contexts, but Biesbroek et al. (2013a) note that there is no consensus definition of constraints or a consistent framework for their assessment. Although constraints are often discussed in the literature as discrete determinants of adaptive capacity, they rarely act in isolation (Dryden-Cripton et al., 2007; Smith et al., 2008; Moser and Ekstrom, 2010; Shen et al., 2011). Rather actors are challenged to navigate multiple, interacting constraints in order to achieve a given adaptation objective (very high confidence; Adger et al., 2007, 2009; Dryden-Cripton et al., 2007; Shen et al., 2008, 2011; Smith et al., 2008; Jantarasami et al., 2010; Moser and Ekstrom, 2010; see also Section 16.3.2.10). Multiple constraints can significantly reduce the range of adaptation options and opportunities available to actors and therefore may pose fundamental limits to adaptation (very high confidence; Section 16.4) and/or drive actors toward responses that may be maladaptive (limited evidence, medium agreement; Barnett and O'Neill, 2010; Eriksen et al., 2011).

\subsubsection{Knowledge, Awareness, and Technology Constraints}

The AR4 concluded that there are significant knowledge gaps and impediments to flows of information that can constrain adaptation, but knowledge in itself is not sufficient to drive adaptive responses (Adger et al., 2007). These conclusions are echoed by more recent literature. Adaptation practitioners and stakeholders in both developed (Tribbia and Moser, 2008; Gardner et al., 2010; Jantarasami et al., 2010; Ford et al., 2011; Milfont, 2012) and developing nations (Bryan et al., 2009; Deressa et al., 2009; Begum and Pereira, 2013; Pasquini et al., 2013) continue to identify knowledge deficits as an adaptation constraint (very high confidence). Often this demand for more information is linked to concerns regarding decision making under uncertainty about the future (medium evidence, medium agreement; Tribbia and Moser, 2008; Moser, 2010a; Whitmarsh, 2011; Stoutenborough and Vedlitz, 2013). A broad range of guidance on adaptation planning and implementation continues to emerge as a means of empowering actors to pursue adaptation efforts (Clar et al., 2013; EC, 2013; FAO, 2013; USCTI, 2013; Webb and Beh, 2013), and the World Meteorological Organization has emphasized the importance of climate services for vulnerability and disaster risk reduction (WMO, 2011).

A number of recent studies have investigated the extent to which education and knowledge about climate change influences perceptions of risk (Hamilton, 2011; McCright and Dunlap, 2011; Milfont, 2012). For example, studies suggest overconfidence in the ability of actors to manage risk (Wolf et al., 2010; Kuruppu and Liverman, 2011) or differences in the perception of climate risk between actors and governing institutions (Patt and Schröter, 2008a) can constrain adaptation (medium evidence, medium agreement). Therefore, capacity building through education, training, and information access represents a valuable opportunity for adaptation (Section 16.3.1.1).

Nevertheless, numerous recent studies caution that addressing knowledge deficits may not necessarily lead to adaptive responses (very high confidence; Kellstedt et al., 2008; Tribbia and Moser, 2008; Adger et al., 2009; Malka and Krosnick, 2009; Moser, 2010b; Preston et al., 2011b; Kahan et al., 2012; Lemos et al., 2012). Research from the USA indicates that those most informed about science and climate change are not necessarily the most concerned about its potential consequences (Kellstedt et al., 2008; Kahan et al., 2012), although these findings run counter to research from New Zealand, where increased knowledge translated into increased public concern and efficacy (Milfont, 2012). Recent research also indicates that multiple factors influence how knowledge is perceived including political affiliation (Hamilton, 2011; McCright and Dunlap, 2011), educational attainment (McCright and Dunlap, 2011), and the confidence placed on different information sources (Sundblad et al., 2009). Various studies have questioned a common assumption in the climate change literature that improvements in climate information are needed to facilitate adaptation 


\section{Box 16-3 | Rates of Change as a Cross-Cutting Constraint}

Future rates of global change will have a significant influence on the demand for, and costs of, adaptation (very high confidence). Since the AR4, new research has confirmed the commitment of the Earth system to future warming (Lowe et al., 2009; Armour and Roe, 2011; WGI AR5 Section 12.5) and elucidated a broad range of tipping points or "key vulnerabilities" that would result in significant adverse consequences should they be exceeded (Lenton et al., 2008; Rockstrom et al., 2009; see also Chapter 19). While the specific rate of climate change to which different ecological communities or individual species can adapt remains uncertain (Sections 16.3.2.3, 16.4.1), more rapid rates of change can constrain adaptation of natural systems (Hoegh-Guldberg, 2008; Gilman et al., 2008; Maynard et al., 2008; CCSP, 2009; Hallegatte, 2009; Malhi et al., 2009a,b; Thackeray et al., 2010; Lemieux et al., 2011; Fankhauser and Soare, 2013; see also Sections 4.3.2.5, 5.5.6), particularly in the presence of other environmental pressures (very high confidence; Brook et al., 2008). Literature suggests that the near-term economic costs of societal adaptation may be substantial, and those costs increase incrementally over time as the climate changes (Section 17.4.4). Therefore, higher rates or magnitudes of climate change may reduce the effectiveness of some adaptation options, and higher costs for adaptation may be incurred (New et al., 2011; Stafford Smith et al., 2011; Peters et al., 2013; see also Section 16.6). However, more rapid rates of change may also create greater incentives for adaptation, resulting in a faster pace of implementation (Travis and Huisenga, 2013).

Although rapid socioeconomic change, including economic development and technological innovation and diffusion, can enhance adaptive capacity (Section 16.3.1), it can also pose constraints (very high confidence; Section 20.3.2). Globally, economic losses from climate extremes are doubling approximately every 1 to 2 decades owing to increasing economic exposure (Pielke Jr. et al., 2008; Baldassarre et al., 2010; Bouwer, 2011; Gall et al., 2011; Munich Re, 2011; IPCC, 2012; Preston, 2013). Such losses are associated with high interannual variability (Preston, 2013), but current trends are projected to continue in future decades (Pielke Jr., 2007; Montgomery, 2008; O'Neill et al., 2010; UN DESA Population Division, 2011; Preston, 2013; see also Section 10.7.3), although losses may decline relative to growth in gross domestic product (GDP; IPCC, 2012). In addition, population growth and economic development can lead to greater resource consumption and ecological degradation (Alberti, 2010; Chen et al., 2010; Raudsepp-Hearne et al., 2010; Liu et al., 2012), which can constrain adaptation in regions where livelihoods are closely linked to ecosystem goods and services (very high confidence; Badjeck et al., 2010; Marshall, 2010; Warner et al., 2010; see also Section 16.3.2.3 and Box (C-EA). The adaptation literature also suggests that successful adaptation will be dependent in part on the rate at which institutions can learn to adjust to the challenges and risks posed by climate change and implement effective responses (very high confidence; Adger et al., 2009; Moser and Ekstrom, 2010; Stafford Smith et al., 2011).

(Dessai et al., 2009; Hulme et al., 2009; Wilby and Dessai, 2010; VerdonKidd et al., 2012; see also Section 2.4). Similarly, multiple authors have questioned the utility and robustness of vulnerability metrics and indices for informing adaptation decision making (Barnett et al., 2009; Klein, 2009; Hinkel, 2011; Preston et al., 2011b).

Similar tensions arise with respect to the role of traditional knowledge in adaptation. For example, cultural preferences regarding the value of traditional versus more formal scientific forms of knowledge influence what types of knowledge, and therefore adaptation options, are considered legitimate (Jones and Boyd, 2011). In the Arctic, Inuit traditional knowledge (Inuit Qaujimajatuqangit, IQ) encompasses all aspects of traditional Inuit culture including values, world-view, language, life skills, perceptions, and expectations (Nunavut Social Development Council, 1999; Wenzel, 2004). IQ includes, for example, weather forecasting, sea ice safety, navigation, and hunting and animal preparation skills that may have value for managing climate risk. Yet, as noted in the AR4 and more recent studies, these skills are declining among youth (medium evidence, medium agreement; Adger et al., 2007; Pearce et al., 2011). Increasing reliance on non-traditional forecasting (national weather office forecasts) and other technologies (GPS) in Arctic communities is in part responsible for increased risk taking when traveling on the land and sea ice (medium evidence, medium agreement; Aporta and Higgs, 2005; Ford et al., 2006; Pearce et al., 2011). Collectively, the recent literature suggests the extent to which knowledge acts to constrain or enable adaptation is dependent on how that knowledge is generated, shared, and used to achieve desired adaptation objectives (very high confidence; Patt et al., 2007; Nelson et al., 2008; Tribbia and Moser, 2008; Moser, 2010a,b).

Individual, institutional, and societal knowledge influences the capacity to develop and use technologies to achieve adaptation objectives (very high confidence; UNFCCC, 2006; Adger et al., 2007). The AR4 noted the role of technology in contributing to spatial and temporal heterogeneity in adaptive capacity and the potential for technology to constrain 
adaptation or create opportunities (Adger et al., 2007). Key considerations with respect to technology as an adaptation constraint include (1) availability; (2) access (including the capacity to finance, operate, and maintain); (3) acceptability to users and affected stakeholders; and (4) effectiveness in managing climate risk (Adger et al., 2007; Dryden-Cripton et al., 2007; van Aalst et al., 2008; see also Sections 9.4.4, 11.7, 14.2.4, 15.4.3). Although technology has implications for regional adaptive capacity (e.g., Sections 22.4.5.7, 27.3.6.2, 29.6.2), in-depth exploration of technology in the adaptation literature is often associated with specific sectors (Howden et al., 2007; Bates et al., 2008; van Koningsveld et al., 2008; EPA, 2009; Parry et al., 2009; Zhu et al., 2010). For example, Howden et al. (2007) note the importance of technology options for facilitating adaptation including applications of existing management strategies as well as introduction of innovative solutions such as bio- and nanotechnology (see also Hillie and Hlophe, 2007; Bates et al., 2008; Fleischer et al., 2011). Several studies from Africa have explored how different factors drive awareness, uptake, and use of adaptation technologies for agriculture (Nhemachena and Hassan, 2007; Hassan and Nhemachena, 2008; Deressa et al., 2009, 2011). While such literature identifies specific adaptation technology options, and in some cases the costs associated with their implementation, quantitative understanding of the extent to which improving technology will enhance adaptive capacity or reduce climate change impacts remains limited (Piao et al., 2010).

\subsubsection{Physical Constraints}

The capacity of human and natural systems to adapt to a changing climate is linked to characteristics of the physical environment including the climate itself. Recent studies have suggested that the effort required to adapt to an increase in global mean temperature of $4^{\circ} \mathrm{C}$ by 2100 may be significantly greater than adapting to lower magnitudes of change (very high confidence; Fung et al., 2011; Gemenne, 2011; New et al., 2011; Nicholls et al., 2011; Stafford Smith et al., 2011; Thornton et al., 2011; Zelazowski et al., 2011; see also Section 19.5.1). This challenge arises from the magnitude of climate change, as well as the rate (Box 16-3).

A variety of non-climatic physical factors also can constrain adaptation efforts of natural systems (very high confidence). For example, migration can be constrained by geographical features such as lack of sufficient altitude to migrate vertically or barriers posed by coastlines or rivers (Clark et al., 2011). Alternatively, Lafleur et al. (2010) identify soil conditions as a factor that may influence the migration of North American forests in response to climate change. Such physical barriers to migration can also arise from human activities. Feeley and Silman (2010) note that anthropogenic land use change can constrain the migration of Andean plant species to higher altitudes. Meanwhile, Titus et al. (2009) analyze state and local land use plans along the U.S. Atlantic coast and conclude that approximately $60 \%$ of coastal land below 1 meter in elevation is anticipated to be developed in the future, posing a physical barrier to inland migration of wetlands (see also Bulleri and Chapman, 2010; Jackson and Mcllvenny, 2011). Collectively, such physical constraints can reduce available migration corridors and the distances over which migration is a feasible adaptive response.

Physical constraints have important implications for human adaptation as well (medium evidence, high agreement). For example, the distribution and abundance of water is a feature of the physical environment that is influenced by climate. Human consumption of freshwater increasingly is approaching the sustainable yield of surface and groundwater systems in a number of global regions (Shah, 2009; Pfister et al., 2009, 2011a,b; see also Sections 3.3.2, 3.5). Water-dependent enterprises in such regions may therefore have reduced flexibility to cope with transient or longterm reductions in water supply. This in turn influences the portfolio of adaptation actions that can be implemented effectively to manage risk to water security and, subsequently, agriculture and food security (Hanjra and Qureshi, 2010) as well as energy security (Voinov and Cardwell, 2009; Dale et al., 2011). Similarly, water quality and soil quality can constrain agricultural activities and therefore the capacity of agricultural systems to adapt to a changing climate (Delgado et al., 2011; Kato et al., 2011; Lobell et al., 2011; Olesen et al., 2011).

It is important to note, however, that these physical characteristics of the environment are often amenable to management (very high confidence). The AR4 presented case studies where adaptive capacity was linked to the ability of human populations or communities to access physical capital (Adger et al., 2007), such as machinery or infrastructure, to manage the environment and associated risks. Similar findings have appeared in more recent studies (Paavola, 2008; Thornton et al., 2008; Iwasaki et al., 2009; Badjeck et al., 2010; Nelson et al., 2010a,b). Human modification of the physical environment is particularly apparent in urban areas, where the location and design of buildings and infrastructure influence vulnerability to climate variability and change (Section 8.2.2.2). However, past decisions regarding the built environment and its need for continual maintenance can constrain future adaptation options and/or their costs of implementation (Section 16.3.2.10).

\subsubsection{Biological Constraints}

Since the AR4, the literature on biological (including behavioral, physiological, and genetic) tolerances of individuals, populations, and communities to climate change and extremes has continued to expand (Sections 4.4, 5.5.6, 6.2). This has resulted in a significant increase in the number of studies describing mechanisms by which biological factors can constrain the adaptation options for humans, nonhuman species, and ecological systems more broadly. In particular, biological characteristics influence the capacity of organisms to cope with increasing climate stress in situ through acclimation, adaptation, or behavior (Jensen et al., 2008; Somero, 2010; Tomanek, 2010; Aitken et al., 2011; Donelson et al., 2011; Gale et al., 2011; Sorte et al., 2011) as well as the rate at which organisms can migrate to occupy suitable bioclimatic regions (very high confidence; Morin and Thuiller, 2009; Hill et al., 2011; Feeley et al., 2012). Studies of humans also find age and geographic variation among populations with respect to perceptions of thermal comfort in indoor and outdoor space, which in turn influences the use of technologies (e.g., air conditioning, vegetation) and behavior to adjust to the thermal environment (Indraganti, 2010; Chen and Chang, 2012; Yang et al., 2012; Fuller and Bulkeley, 2013; Müller et al., 2013).

The biological capacity for migration among nonhuman species is linked to characteristics such as fecundity, phenotypic and genotypic variation, dispersal rates, and interspecific interactions (Aitken et al., 2008; Engler et al., 2009; Hellmann et al., 2012). For example, Aitken et al. (2008) 
argue that migration rates of tree species necessary to track a changing climate are higher than what has been observed since the last glaciation. However, Kremer et al. (2012) note that long-distance gene flow of tree species can span distances in one generation that are greater than habitat shifts predicted under climate change. Additional research is needed to clarify the capacity of species and communities to migrate in response to a changing climate.

The degradation of environmental quality is another source of constraints (very high confidence; Côté and Darling, 2010), with multiple studies including natural capital as a foundation for sustainable livelihoods (Paavola, 2008; Thornton et al., 2008; Iwasaki et al., 2009; Badjeck et al., 2010; Nelson et al., 2010a,b). Non-climatic stresses to ecological systems can reduce their resilience to climate change as evidenced by studies on coral reefs and marine ecosystems, tropical forests, and coastal wetlands (very high confidence; Diaz and Rosenberg, 2008; Kapos and Miles, 2008; Malhi et al., 2009a,b; Afreen et al., 2011; see also Section 4.2.4 and Box CC-CR). For example, several studies have noted interactions between anthropogenic land use change and species migration rates on the risk of extirpation (Feeley et al., 2010; Yates et al., 2010; Cabral et al., 2013; Svenning and Sandel, 2013).

Ecological degradation also reduces the availability of ecosystem goods and services for human populations (very high confidence; Nkem et al., 2010; Tobey et al., 2010; see also Sections 4.4.3, 6.4.1). For example, degradation of coastal wetlands and coral reef systems may reduce their capacity to buffer coastal systems from the effects of tropical cyclones (Das and Vincent, 2009; Tobey et al., 2010; Gedan et al., 2011; Keryn et al., 2011; Box CC-EA). Similarly, soil degradation and desertification can reduce crop yields and the resilience of agricultural and pastoral livelihoods to climate stress (Iglesias et al., 2011; Lal, 2011).

Ecosystem constraints can also arise from non-native species, including pests and disease, that compete with endemic species (Hellman et al., 2008; Dukes et al., 2009; Moser et al., 2011; Ziska et al., 2011; Pautasso et al., 2012; Svobodová et al., 2013; see also Section 4.2.4.6). Climate change could reduce the effectiveness of current control mechanisms for invasive species (very low confidence; Hellmann et al., 2008). However, studies also indicate that uncertainty associated with predictions of future pests, disease, and invasive species remains high (Dukes et al., 2009).

\subsubsection{Economic Constraints}

The AR4 concluded that adaptive capacity is influenced by the entitlements of actors to economic resources and by larger macro-level driving forces such as economic development and trends in globalization (Adger et al., 2007). More recent literature continues to identify economic constraints associated with adaptation. However, such constraints often involve the financing of discrete adaptation options (e.g., Matasci et al., 2013; Islam et al., 2014). This chapter draws a distinction between such financial constraints (Section 16.3.2.5) and economic constraints, which are associated with broader macroeconomic considerations.

Long-term trends in economic development as well as short-term dynamics in economic systems can have a significant influence on the capacity of actors to adapt to climate change (very high confidence;
Section 16.3.1.1). Multiple authors, for example, discuss the concept of "double exposure" where actors are subjected to stresses associated with climate change as well as those associated with economic disruptions such as the recent global financial crisis or other stresses (Leichenko et al., 2010; Silva et al., 2010; Leichenko, 2012; Jeffers, 2013; McKune and Silva, 2013). Similarly, Kiem and Austin (2013) argue that prevailing economic conditions have an important influence on the capacity of Australian farmers to cope with drought.

The implications of economic constraints vary among different sectors that have differential vulnerability to climate change. Economies that are disproportionately composed of climate-sensitive sectors such as agriculture, forestry, and fisheries may be particularly vulnerable to the effects of climate change and may encounter greater constraints on their capacity to adapt (very high confidence). Such economies occur disproportionately in the developing world (Thornton et al., 2008; Allison et al., 2009; Feng et al., 2010; Füssel, 2010), although multiple studies have explored climate-sensitive regional economies in developed nations as well (Edwards et al., 2009; Leichenko et al., 2010; Aaheim et al., 2012; Kiem and Austin, 2013). Poverty and development deficits that are linked to economic conditions also exist in urban areas (Sections 8.1.3, 8.3.2.1).

While economic development and diversification are generally seen as factors that can ameliorate resource deficits (Sections 20.2.1.2, 20.3.2), certain economic enterprises can constrain adaptation. For example, the AR4 noted that activities such as shrimp farming and conversion of coastal mangroves, though profitable in an economic sense, can exacerbate vulnerability to sea level rise (Agrawala et al., 2005; Adger et al., 2007). More recent studies have demonstrated that economic development and urbanization of hazardous landscapes may increase human exposure to extreme weather events and climate change, resulting in greater economic losses and risks to public health and safety (Baldassare et al., 2010; IPCC, 2012; Preston, 2013). Economic development also can put pressure on natural resources and ecosystems that can constrain their capacity to adapt (Titus et al., 2009; Sydneysmith et al., 2010; see also Sections 16.3.2.3, 20.3.2). The extent to which economic development creates opportunities or constrains adaptation is dependent on the development pathway (Section 20.6). Low resource-intensive economic growth can enhance adaptive capacity while minimizing externalities of development that can increase vulnerability of human and natural systems (Section 20.6).

\subsubsection{Financial Constraints}

In addition to broader macroeconomic constraints on adaptation (Section 16.3.2.4), the implementation of specific adaptation strategies and options can be constrained by access to financial capital (very high confidence). Financial capital can manifest in a variety of forms including credit, insurance, and tax revenues, as well as earnings of individual households or private entities. The AR4 concluded that the global costs of adaptation could be quite substantial over the next several decades (Adger et al., 2007). More recent studies suggest costs on the order of US\$75 to US $\$ 100$ billion per year by 2050 (Section 17.4; Table 17-2). In the context of the UNFCCC, mechanisms have been established to help meet these costs. The Least Developed Country Fund was established to assist 
developing nations in generating National Adaptation Plans of Action (Sections 14.4.4, 15.2.3). The Adaptation Fund was established within the context of the UNFCCC to finance adaptation in developing nations through the sale of certified emissions reductions (CERs) credits under the Clean Development Mechanism (Sections 14.3.2, 15.2.2.1). Nevertheless, declines in CER credit prices since early 2011 have reduced the flow of revenue to the Adaptation Fund (Adaptation Fund Board, 2013), and the demand for adaptation finance in general is larger than the current availability of resources represented through these funds (Bouwer and Aerts, 2006; Flåm and Skjærseth, 2009; Hof et al., 2009). Furthermore, developing a framework for the equitable and effective allocation of adaptation funds to developing nations is a non-trivial challenge (Smith et al., 2009a; Barr et al., 2010).

Overseas development assistance (ODA) represents another mechanism for channeling financial capital into adaptation programs and projects. However, multiple authors have identified potential constraints associated with the use of ODA for financing adaptation, including concerns among donors for the effectiveness of ODA (Kalirajan et al., 2011), lack of incentives among donors to allocate ODA to adaptation (Buob and Stephan, 2013), and potential for allocation of ODA to adaptation to reduce the availability of funds for achieving development goals (Ayers and Huq, 2009).

The potential for finance to constrain adaptation also emerges from a broad range of recent case studies exploring adaptive capacity in different sector and regional contexts, although finance is often identified as just one of a broad range of resource constraints (Paavola, 2008; Jantarasami et al., 2010; Moser and Ekstrom, 2010; Osbahr et al., 2010; Biesbroek et al., 2013a). Investigations of farming communities in Africa have identified finance as a key determinant of vulnerability and adaptive capacity of farmers to climate variability and change (Nhemachena and Hassan, 2007; Hassan and Nhemachena, 2008; Deressa et al., 2009, 2011). Islam et al. (2014) cite access to credit as a key constraint on adaptation among fishing communities in Bangladesh, and financial constraints have also been documented in municipal governments in South Africa (Pasquini et al., 2013). Huntington et al. (2012) question whether relocating the 184 Alaskan Native villages threatened by coastal erosion and inundation is politically feasible given the high costs, estimated at up to US\$1 million per person or US\$100 million per village on average.

Institutions in developed nations face constraints in funding adaptation options despite their comparatively high adaptive capacity. For example, Jantarasami et al. (2010) report that staff from U.S. federal land management agencies identified resource constraints as a key barrier to adaptation. Similarly, surveys and interviews with state and local government representatives in Australia indicate that the costs of investigating and responding to climate change are perceived to be significant constraints on adaptation at these levels of governance (Smith et al., 2008b; Gardner et al., 2010; Measham et al., 2011). However, Burch (2010) argues that financial constraints on adaptation reported by local governments in Canada are secondary to other institutional practices and cultures (Section 16.3.2.8).

Insurance represents a cross-cutting financial instrument that is relevant to a range of public and private institutions in both developing and developed nations. While insurance can represent an opportunity to influence decision making regarding climate risk management (Næss et al., 2005; Herweijer et al., 2009; see also Section 10.7), reduced accessibility and/or increased costs of insurance can constrain the utility of insurance as an adaptation option (Herwijer et al., 2009; Islam et al., 2014; see also Section 10.7).

\subsubsection{Human Resource Constraints}

The effectiveness of societal efforts to adapt to climate change is dependent on humans who are the primary agents of change (very high confidence). Human resources provide the foundation for intelligence gathering, the uptake and use of technology, as well as leadership regarding the prioritization of adaptation policies and measures and their implementation. Although the AR4 and subsequent adaptation literature identify human resources as one of the factors influencing adaptive capacity (Adger et al., 2007), there has been little attention given specifically to human resources as a constraint on adaptation by adaptation researchers. Rather the literature mentions human resources in two principal contexts. First, it highlights the linkages between the development of human resources and adaptive capacity more broadly. For example, Ebi and Semenza (2008) treat human resources as part of the portfolio of resources that can be harnessed to facilitate adaptation in the public health arena. Similarly, Nelson et al. $(2010 a, b)$ use human capital as one indicator of the capacity of rural communities to cope with climate impacts. In addition, a number of recent studies call attention to the role of leadership in enabling or constraining organizational adaptation (Gupta et al., 2010; Tompkins et al., 2010; van der Berg et al., 2010; Termeer et al., 2012). Murphy et al. (2009) discuss the emergence of institutions to build human resources in the climate change arena, including expanded higher education opportunities to build climate expertise as well as professional societies. Second, the literature highlights the finite nature of human resources as a need to prioritize adaptation efforts including the extent of engagement in participatory processes (van Aalst et al., 2008) as well as the selection of adaptation actions for implementation (Millar et al., 2007).

\subsubsection{Social and Cultural Constraints}

Adaptation can be constrained by social and cultural factors that are linked to societal values, world views, and cultural norms and behaviors (very high confidence; O'Brien, 2009; Moser and Ekstrom, 2010; O'Brien and Wolf, 2010; Hartzell-Nichols, 2011). These social and cultural factors can influence perceptions of risk, what adaptation options are considered useful and by whom, as well as the distribution of vulnerability and adaptive capacity among different elements of society (Grothmann and Patt, 2005; Weber, 2006; Patt and Schröter, 2008; Adger et al., 2009; Kuruppu, 2009; O'Brien, 2009; Nielsen and Reenberg, 2010; Wolf and Moser, 2011; Wolf et al., 2013). Although the AR4 noted that social and cultural constraints on adaptation have not been well researched, more recent literature has significantly expanded their understanding. As a case in point, the erosion of traditional knowledge among the Arctic Inuit is the consequence of a long-term process of changing livelihoods, technology, and sources of knowledge (Pearce et al., 2011; see also Section 16.3.2.1). Studies from the USA indicate that increasing demand 
for amenity lifestyles is resulting in the settlement of individuals in locations where there is little experience or oral history regarding natural hazards - a phenomenon that subsequently influences risk perception and engagement in risk management (Heyd and Brooks, 2009; Gordon et al., 2013).

Different actors within and among societies experience different constraints, which result in differential adaptive capacities and preferences for adaptation options (Wolf et al., 2013). As discussed in the AR4, for example, gender can be a factor that constrains adaptation. Recent studies from Nepal and India report that adaptation decisions among women, in particular, can be constrained by cultural and institutional pressures that favor male land ownership (Jones and Boyd, 2011) and constrain access to hazard information (Ahmed and Fajber, 2009), respectively. Studies of evacuation during Hurricane Katrina suggest that females were more likely to evacuate New Orleans than males (Brunsma et al., 2010), as were individuals without sufficient resources and access to transportation (Cutter and Emrich, 2006). Studies from both the USA and UK find that the elderly do not necessarily perceive themselves as vulnerable to extreme heat events (Sheridan, 2007; Wolf et al., 2009), which may create disincentives to react to such events (Chapter 11).

Barriers to taking action have also been attributed to sense of place, which shapes individual identity (Adger et al., 2011, 2012; FresqueBaxter and Armitage, 2012). Foresight (2011) notes that processes that constrain migration could be maladaptive, resulting in the abandonment of livelihoods or geographic locations. For example, Park et al. (2012) find that sense of place attachment among some wine grape growers in Australia precludes consideration for migration to other growing areas in response to a changing climate.

Case studies from multiple developing countries report that some actors view natural phenomena as being controlled by God, supernatural forces, or ancestral spirits that are not amenable to human management (Sehring, 2007; Schipper, 2008; Byg and Salick, 2009; Mustelin et al., 2010; Kuruppu and Liverman, 2011; Artur and Hilhorst, 2012). Such perspectives are not confined to the developing world. Surveys conducted after Hurricane Katrina also indicated that religious beliefs were a factor influencing the decision to remain rather than evacuate (Brunsma et al., 2010). Yet, religion was also identified as a factor that enabled affected individuals to cope with the stress of the event.

\subsubsection{Governance and Institutional Constraints}

Research conducted since the AR4 has expanded understanding of adaptation constraints associated with governance, institutional arrangements, and legal and regulatory issues. Adaptation to climate change will necessitate the mobilization of resources, decision making, and the implementation of specific policies by societal institutions (Huang et al., 2011). Yet, these processes may be most effective when they are aligned to the given context and group of actors (Berkhout, 2012; Garschagen, 2013). The adaptation literature provides extensive evidence that institutional capacity is a key factor that can potentially constrain the adaptation process (very high confidence; Berkhout, 2012). Lesnikowski et al. (2013), for example, find that planned adaptation by the public health sector among different nations is significantly associated with national GDP. Similarly, it has been argued that U.S. institutions across different levels of governance lack the mandate, information, and/or professional capacity to select and implement adaptation options (National Research Council, 2009). Institutional capacity may be linked to the level of priority assigned to adaptation (Keskitalo et al., 2010; Westerhoff et al., 2010; Maibach et al., 2011; Measham et al., 2011; Sowers et al., 2011). For example, Ebi et al. (2009) argue that U.S. public health agencies allocate less than US\$3 million per year to address climate change, yet a budget greater than US $\$ 200$ million is needed to adequately address the problem. Keskitalo (2010) and Lesnikowski et al. (2013) find that adaptation efforts are associated with the extent to which institutions prioritize environmental management more broadly. Corruption within institutions may also undermine adaptation efforts, as evidenced by empirical studies among multiple nations (Lesnikowski et al., 2013), as well as case studies within nations (Schilling et al., 2012).

A key role that institutions play in facilitating adaptation is through legal and regulatory responsibilities and authorities (very high confidence). Multiple studies have documented the adaptation constraints affecting institutions in Australia engaged in the development of local and regional planning policy (Pini et al., 2007; Measham et al., 2011; Matthews, 2013). Similar capacity constraints have been observed within institutions governing Canada's Inuit population (Ford et al., 2010). Li and Huntsinger (2011) observe how increasing land privatization and the institutionalization of rigid land tenure in the Inner Mongolia region of China have reduced the resilience of pastoralists to cope with drought, although the lack of secure land tenure has been found to constrain adaptation in other contexts (Almansi, 2009; Ebi et al., 2011; Hisali et al., 2011; Larson, 2011; see also Sections 8.4.2.2, 9.3.5.1.3). In addition to such capacity issues, multiple studies from both developed and developing nations suggest that the current structure of institutions and regulatory policies may be poorly aligned to achieve adaptation objectives (Craig, 2010; Spies, 2010; Stillwell et al., 2010; Stuart-Hill and Schulze, 2011; Eisenack and Stecker; 2012; Huntjens et al., 2012; Herrfahrdt-Pähle, 2013). Changing legal principles to accommodate more forward-looking adaptation responses as opposed to basing them on historical precedent and practice may be a difficult process (Craig, 2010; McDonald, 2011).

Adaptation can also be constrained owing to the complexities of governance networks that are often composed of multiple actors and institutions such as government agencies, market actors, NGOs, as well as informal community organizations and social networks (very high confidence; Rosenau, 2005; Adger et al., 2009; Juhola and Westerhoff, 2011; Carlsson-Kanyama et al., 2013; Sosa-Rodriguez, 2013). Coordination among these different actors is important for facilitating adaptation decision making and implementation (Young, 2006; van Nieuwaal et al., 2009; Grothmann, 2011). Yet, different actors may have different objectives, jurisdictional authority, as well as levels of power or resources. Adaptation efforts may recognize these constraints, but do not necessarily articulate institutional arrangements that facilitate their coordination and reconciliation to achieve common adaptation objectives (Zinn, 2007; Preston, 2009; Birkmann et al., 2010; see also Section 15.5.1). This may arise, in part, from the dominant focus of the adaptation discourse on formal, public institutions of governance 
(Eisenack et al., 2012), although work examining the role of private institutions has emerged recently (Tompkins et al., 2010; CDP, 2012; Mees et al., 2012; Taylor et al., 2012; Tompkins and Eakin, 2012; EBI, 2013; see also Section 14.2.4).

Actors and institutions associated with different scales may have different perceptions of the need for adaptation as well as the factors that constrain or enable adaptation (very high confidence; Biesbroek et al., 2011). In this context, scale refers to analytical dimensions used to study adaptation (including spatial, temporal, institutional, or jurisdictional), and each scale can be comprised of multiple levels (e.g., local to global in the context of spatial scales or household to central government in the context of jurisdictions of governance) (Cash et al., 2006; Adger et al., 2009). A large number of studies have emerged since the AR4 that focus on how local adaptation efforts are constrained by higher levels of governance, such as state or federal governments or private companies (Urwin and Jordan, 2008; Huntjens et al., 2010; Abel et al., 2011; Measham et al., 2011; Pittock, 2011; Westerhoff et al., 2011; Amaru and Chhetri, 2013; Carlsson-Kanyama et al., 2013; Mukheibir et al., 2013; Sosa-Rodriguez, 2013). This has led some to question whether it is appropriate to consider adaptation as an exclusively local process (Burton et al., 2008; Preston et al., 2013b). For example, a study of adaptation policy initiatives in EU member countries concluded that central governments can play a significant role in supporting local adaptation policies. However, in cases where there is weak top-down leadership on adaptation, it may be useful to have less centralized mechanisms for supporting local adaptation efforts (Keskitalo, 2010). In addition, EU funding has enabled local adaptation even in the absence of funding from the relevant EU member state (Keskitalo, 2010), suggesting opportunities exist for transnational governance to overcome adaptation constraints.

Other authors have also noted that informal social institutions may help to extend the reach of formal government actors (Wolf et al., 2010; Juhola and Westerhoff, 2011) or drive adaptation processes when formal actors are unable to do so (Measham and Preston, 2012). Adaptation planning and implementation thus creates new governance challenges, and new institutions and bridging organizations may be needed to facilitate integration of complex planning processes across scales (medium evidence, high agreement; Preston, 2009; National Research Council, 2010; UKCIP, 2011).

\subsubsection{Constraints and Competing Values}

A number of the aforementioned types of adaptation constraints arise from a common cause-the differential values of societal actors and the trade-offs associated with prioritizing and implementing adaptation options (very high confidence; Haddad, 2005; UNEP, 2011; see also Section 2.3.3 and Table 16-2). At the international level, for example, agreements such as the Bali Action Plan (UNFCCC, 2007a) and Cancun Adaptation Framework (UNFCCC, 2011) indicate that deliberation over how the adaptation needs of least developed countries will be financed has become central to the UNFCCC policy agenda (see also UNFCCC, 2007b; Ayers and Huq, 2009; Dellink et al., 2009; Flåm and Skjærseth, 2009; Denton, 2010; Patt et al., 2010a). Yet the extent to which the developed world bears responsibility for compensating the developing world for climate impacts has been a contentious issue (Hartzell-Nichols, 2011). Rayner and Jordan (2010) and Brouwer et al. (2013) report concern among EU water policy makers that adaptation may undermine efforts to maintain water quality. For example, technological solutions to enhance water supply in a changing climate may occur at the expense of water quality. Alternatively, placing adaptation on the policy agenda may create the perception that climate change will eventually necessitate the acceptance of reduced water quality. At the local level, Measham et al. (2011) report that some local governments in Australia find it difficult to pursue adaptation efforts owing to perceived conflicts between potential adaptation options and the values and preferences of individuals and stakeholder groups within the community.

Such potential differences among stakeholders regarding adaptation options may result in some actions being simultaneously perceived as adaptive and maladaptive (limited evidence, medium agreement; Bardsley and Hugo, 2010). Maladaptation arises from the implementation of adaptation options that increase the vulnerability of individuals, institutions, sectors, or regions (Barnett and O'Neill, 2010). Individuals or institutions may have specific management objectives or values that they seek to achieve or maintain through adaptation (Section 16.2, Table 16-2). For every objective, however, there may be multiple adaptation options, each of which is associated with a particular set of costs, benefits, and externalities. For example, biotechnology may contribute to the development of drought- and pest-resistant cultivars that can maintain or enhance yields despite more challenging climate conditions. Yet, ecological and public health concerns over the use of biotechnology and genetically modified crops, in particular, can constrain the use of such technologies (Table 16-2). Agricultural producers may view biotechnology as an adaptive response, while some consumers may view it as a maladaptation that increases risks to ecosystems and food security. Similar types of trade-offs can be identified across different sectors (Table 16-2), and thus a challenge in adaptation planning and implementation is determining who decides what options are adaptive or maladaptive and successful or unsuccessful. The potential for maladaptation or for some adaptation options to undermine sustainability (Eriksen et al., 2011) suggests that actors may choose to regulate adaptation and deliberately constrain possible options to avoid adverse externalities (very low confidence).

Recognizing the potential for values conflicts to constrain adaptation, researchers and practitioners have advocated for so-called "no regrets" or "low regrets" adaptation strategies that create net benefits under the current climate as well as a range of future potential climates (Hallegatte, 2009; Heltberg et al., 2009). Such strategies can focus adaptation efforts on options where there are fewer perceived tradeoffs (Preston et al., 2013b). However, identifying options that are perceived as having no regrets across all potential stakeholders may be quite difficult (Merz et al., 2010; Preston et al., 2013b), and it has been suggested such strategies may reduce the perceived need for more substantive adaptations necessary to protect highly vulnerable systems or avoid irreversible consequences (Preston et al., 2013b). Reconciling such trade-offs may necessitate deliberation among decision makers and other stakeholders regarding adaptation objectives and the manner in which competing or conflicting values can be reconciled to achieve outcomes (de Bruin et al., 2009b; McNamara and Gibson, 2009; McNamara et al., 2011; UNEP, 2011). 
Table 16-2 | Examples of potential trade-offs associated with an illustrative set of adaptation options that could be implemented by actors to achieve specific management objectives.

\begin{tabular}{|c|c|c|c|c|}
\hline Sector & Actor's adaptation objective & Adaptation option & Real or perceived trade-off & References \\
\hline \multirow[t]{3}{*}{ Agriculture } & $\begin{array}{l}\text { Enhance drought and pest resistance; } \\
\text { enhance yields }\end{array}$ & $\begin{array}{l}\text { Biotechnology and genetically modified } \\
\text { crops }\end{array}$ & $\begin{array}{l}\text { Perceived risk to public health and } \\
\text { safety; ecological risks associated with } \\
\text { introduction of new genetic variants to } \\
\text { natural environments }\end{array}$ & $\begin{array}{l}\text { Howden et al. (2007); Nisbet and } \\
\text { Scheufele (2009); Fedoroff et al. (2010) }\end{array}$ \\
\hline & $\begin{array}{l}\text { Provide financial safety net for farmers } \\
\text { to ensure continuation of farming } \\
\text { enterprises }\end{array}$ & $\begin{array}{l}\text { Subsidized drought assistance; crop } \\
\text { insurance }\end{array}$ & $\begin{array}{l}\text { Creates moral hazard and distributional } \\
\text { inequalities if not appropriately } \\
\text { administered }\end{array}$ & $\begin{array}{l}\text { Productivity Commission (2009); Pray et } \\
\text { al. (2011); Trærup (2011); O'Hara (2012); } \\
\text { Vermeulen et al. (2012) }\end{array}$ \\
\hline & $\begin{array}{l}\text { Maintain or enhance crop yields; } \\
\text { suppress opportunistic agricultural pests } \\
\text { and invasive species }\end{array}$ & $\begin{array}{l}\text { Increased use of chemical fertilizer and } \\
\text { pesticides }\end{array}$ & $\begin{array}{l}\text { Increased discharge of nutrients and } \\
\text { chemical pollution to the environment; } \\
\text { adverse impacts of pesticide use on } \\
\text { non-target species; increased emissions } \\
\text { of greenhouse gases; increased human } \\
\text { exposure to pollutants }\end{array}$ & $\begin{array}{l}\text { Gregory et al. (2005); Howden et al. } \\
\text { (2007); Boxall et al. (2009) }\end{array}$ \\
\hline \multirow[t]{3}{*}{ Biodiversity } & $\begin{array}{l}\text { Enhance capacity for natural adaptation } \\
\text { and migration to changing climatic } \\
\text { conditions }\end{array}$ & $\begin{array}{l}\text { Migration corridors; expansion of } \\
\text { conservation areas }\end{array}$ & $\begin{array}{l}\text { Unknown efficacy; concerns over } \\
\text { property rights regarding land } \\
\text { acquisition; governance challenges }\end{array}$ & $\begin{array}{l}\text { Hodgson et al. (2009); West et al. (2009); } \\
\text { Krosby et al. (2010); Levin and Petersen } \\
(2011)\end{array}$ \\
\hline & $\begin{array}{l}\text { Enhance regulatory protections for } \\
\text { species potentially at risk due to climate } \\
\text { and non-climatic changes }\end{array}$ & $\begin{array}{l}\text { Protection of critical habitat for } \\
\text { vulnerable species }\end{array}$ & $\begin{array}{l}\text { Addresses secondary rather than primary } \\
\text { pressures on species; concerns over } \\
\text { property rights; regulatory barriers to } \\
\text { regional economic development }\end{array}$ & $\begin{array}{l}\text { Clark et al. (2008); Ragen et al. (2008); } \\
\text { Bernanzzani et al. (2012) }\end{array}$ \\
\hline & $\begin{array}{l}\text { Facilitate conservation of valued species } \\
\text { by shifting populations to alternative } \\
\text { areas as the climate changes }\end{array}$ & Assisted migration & $\begin{array}{l}\text { Difficult to predict ultimate success of } \\
\text { assisted migration; possible adverse } \\
\text { impacts on indigenous flora and fauna } \\
\text { from introduction of species into new } \\
\text { ecological regions }\end{array}$ & $\begin{array}{l}\text { Lovejoy (2005, 2006); McLachlan et al. } \\
\text { (2007); Dunlop and Brown (2008) }\end{array}$ \\
\hline \multirow[t]{3}{*}{ Coasts } & $\begin{array}{l}\text { Provide near-term protection to financial } \\
\text { assets from inundation and/or erosion }\end{array}$ & Sea walls & $\begin{array}{l}\text { High direct and opportunity costs; equity } \\
\text { concerns; ecological impacts to coastal } \\
\text { wetlands }\end{array}$ & $\begin{array}{l}\text { Nicholls (2007); Hayward (2008); } \\
\text { Hallegatte (2009); Zhu et al. (2010) }\end{array}$ \\
\hline & $\begin{array}{l}\text { Allow natural coastal and ecological } \\
\text { processes to proceed; reduce long-term } \\
\text { risk to property and assets }\end{array}$ & Managed retreat & $\begin{array}{l}\text { Undermines private property rights; } \\
\text { significant governance challenges } \\
\text { associated with implementation }\end{array}$ & $\begin{array}{l}\text { Rupp-Armstrong and Nicholls (2007); } \\
\text { Hayward (2008); Abel et al. (2011); Titus } \\
\text { (2011) }\end{array}$ \\
\hline & $\begin{array}{l}\text { Preserve public health and safety; } \\
\text { minimize property damage and risk of } \\
\text { stranded assets }\end{array}$ & Migration out of low-lying areas & $\begin{array}{l}\text { Loss of sense of place and cultural } \\
\text { identify; erosion of kinship and familial } \\
\text { ties; impacts to receiving communities }\end{array}$ & $\begin{array}{l}\text { Hess et al. (2008); Heltberg et al. (2009); } \\
\text { McNamara and Gibson (2009); Adger et } \\
\text { al. (2011) }\end{array}$ \\
\hline \multirow[t]{3}{*}{$\begin{array}{l}\text { Water } \\
\text { resources } \\
\text { management }\end{array}$} & $\begin{array}{l}\text { Increase water resource reliability and } \\
\text { drought resilience }\end{array}$ & Desalination & $\begin{array}{l}\text { Ecological risk of saline discharge; high } \\
\text { energy demand and associated carbon } \\
\text { emissions; creates disincentives for } \\
\text { conservation }\end{array}$ & $\begin{array}{l}\text { Adger and Barnett (2009); Barnett and } \\
\text { O'Neill (2010); Becker et al. }(2010,2012) ; \\
\text { Rygaard et al. (2011); Tal et al. }(2011)\end{array}$ \\
\hline & $\begin{array}{l}\text { Maximize efficiency of water } \\
\text { management and use; increase flexibility }\end{array}$ & Water trading & $\begin{array}{l}\text { Undermines public good/social aspects } \\
\text { of water }\end{array}$ & $\begin{array}{l}\text { Alston and Mason (2008); Bourgeon et } \\
\text { al. (2008); Donohew (2008); Mooney and } \\
\text { Tan (2012); Tan et al. (2012) }\end{array}$ \\
\hline & $\begin{array}{l}\text { Enhance efficiency of available water } \\
\text { resources }\end{array}$ & Water recycling/reuse & Perceived risk to public health and safety & Hartley (2006); Dolcinar et al. (2011) \\
\hline
\end{tabular}

\subsubsection{Consideration of Cross-Scale Dynamics}

The AR4 noted that adaptation processes can be constrained by interactions and dynamics within or among different scales (Adger et al., 2007). Recent literature since the AR4 has expanded understanding of vulnerability and adaptive capacity as a cross-scale and multilevel process. The vulnerabilities of different communities, regions, and sectors are linked through processes and feedbacks that span multiple scales and levels (medium evidence, high agreement). Adger et al. (2008) and Eakin et al. (2009) refer to this phenomenon as "nested and teleconnected vulnerability."

A number of recent studies focused on agriculture and global commodities provide evidence of this phenomenon. Adger et al. (2008) and Eakin et al. (2009) illustrate such teleconnected vulnerability with case studies of coffee production. Although coffee is a global commodity, the majority of production occurs in developing nations among small-scale farmers.
As such, household vulnerability and adaptive capacity among coffee farmers is linked to global markets and coffee prices as well as local environmental conditions and policies. Such interactions were also apparent in 2006-2008 and again in 2010-2011 when global food commodity prices increased sharply in part due to the impacts of extreme weather events on food-producing regions (FAO, 2011). The resulting increase in food prices benefited producers that were unaffected by the drought and were able to capitalize on higher prices, but higher prices adversely affected consumer welfare and food security (Abbott and de Battisti, 2009; Woden and Zaman, 2009; FAO, 2011).

Similar constraints on adaptation arise in the context of transboundary water resources where river management is influenced by processes occurring at different jurisdictional levels (i.e., local, regional, national, and international water policies and management practice) as well as different spatial levels (e.g., linkages between global climate change and climate trends at more regional or local levels) (Iglesias et al., 2007; 
Goulden et al., 2009; Huntjens et al., 2010; Krysanova et al., 2010; Timmerman et al., 2011; Wilby and Keenan, 2012; Milman et al., 2013).

Constraints on adaptation are also associated with temporal scaling. A key factor constraining future adaptation options and costs is path dependence (very high confidence), which Preston (2013, p. 719) defines as "the dependence of future societal decision processes and/or socioecological outcomes on those that have occurred in the past." Libecap (2010) suggests that water infrastructure developed in the U.S. West in the late-19th and early 20th centuries has constrained management choice regarding water allocation in the present. Chhetri et al. (2010) suggest similar constraints may exist for the U.S. agricultural industry in the future owing to constraints on farmers' capacity to alter management practices and technology in response to a changing climate. Major development of water management and allocation systems in watersheds of Australia and the U.S. Southeast over the latter half of the 20th century occurred during periods of favorable rainfall relative to long-term instrumental and paleo records (Jones and Pittock, 2002; Jones, 2010; Chiew et al., 2011; Pederson et al., 2012), and thus those systems were adapted to conditions that were not representative of the long-term risk of extensive drought (Jones and Pittock, 2002; Jones, 2010; Connell and Grafton, 2011; Pederson et al., 2012).

Adjusting large-scale, complex systems and institutional behavior established by past decision making can be costly. The Australian government, for example, has engaged in a water management reform process since the 1980s (Connell and Grafton, 2011), and in recent years has committed more than AUS\$12.9 billion for a number of initiatives to address historical resource over-allocation and support sustainable water management practices in the Murray-Darling Basin (Commonwealth of Australia, 2010).

To avoid adverse outcomes associated with path dependence, literature on flexible adaptation pathways emphasizes the implementation of reversible and flexible options that allow for ongoing adjustment (Stafford Smith et al., 2011; Haasnoot et al., 2013). In addition, the literature on "real options" suggests that, under certain circumstances, there may be value in such flexible adaptation strategies or in delaying investments in certain adaptation options until new information or management options are available (Hertzler, 2007; Dobes, 2008; Jeuland and Whittington, 2013).

\subsection{Limits to Adaptation}

The various constraints discussed previously (Section 16.3.2) can, if sufficiently severe, pose limits to the ability of actors to adapt to climate change (medium evidence, high agreement; Meze-Hausken, 2008; Adger et al., 2009; 0'Brien, 2009; Moser and Ekstrom, 2010; Dow et al., $2013 a, b)$. A limit is reached when adaptation efforts are unable to provide an acceptable level of security from risks to the existing objectives and values and prevent the loss of the key attributes, components, or services of ecosystems (Box 16-1). For example, one of the key messages from the WGII AR5 chapter on Africa (Chapter 22) is, "Progress is being achieved on managing risks to food production from current climate variability but these will likely not be sufficient to address long-term risks from climate change (high confidence)."
There are a variety of circumstances and terminology in the literature that imply adaptation limits including "thresholds" (Meze-Hausken, 2008; Briske et al., 2010; Washington-Allen et al., 2010); "regime shifts" (Washington-Allen et al., 2010); "tipping points" (Lenton et al., 2008; Kriegler et al., 2009); "dangerous climate change" (Mastrandrea and Schneider, 2004; Ford, 2009a); "reasons for concern" (Smith et al., 2009a); "planetary boundaries" (Rockström et al., 2009); or "key vulnerabilities" (Schneider et al., 2007; Hare et al., 2011; Johannessen and Miles, 2011; see also Section 19.6). In addition, terms such as barriers, constraints, and limits are sometimes used interchangeably. Owing to this diversity in language, this discussion builds on recent efforts to develop a common lexicon to facilitate research and practice (Hulme et al., 2007; Adger et al., 2009; Dow et al., 2013a,b; see also Section 16.2 and Box 16-1).

\subsubsection{Hard and Soft Limits}

Although limits to adaptation are at times described in the literature as fixed thresholds (Adger et al., 2009), recent studies have emphasized the need to consider the perspective of actors in defining adaptation limits (Adger et al., 2009; Dow et al., 2013 a,b; see also Sections 16.1-2) as well as the dynamic nature of both biophysical and socioeconomic processes that influence adaptation decision making and implementation (Park et al., 2012; Preston et al., 2013a; Islam et al., 2014). Informed by the distinctions drawn in the work of Meze-Hausken (2008), Adger et al. (2009), and Moser and Ekstrom (2010), one can distinguish between "hard" limits, those that will not change, and "soft" limits, which could change over time. For human actors, whether a limit is hard or soft is usefully evaluated at a given point in time by asking whether an adaptation response to manage an intolerable risk could emerge in the future. For example, projected climate change impacts in Europe indicate that increasing irrigation needs will be constrained by reduced runoff, demand from other sectors, and economic costs. As a consequence, by the 2050s, farmers will be limited by their inability to use irrigation to prevent damage from heat waves to crops (Sections 23.4.1, 23.4.3). For natural systems, whether a limit is hard or soft is defined by the rate and capacity of species and ecosystem responses relative to environmental changes (Shaw and Etterson, 2012).

Discussions of hard limits in the literature are often associated with thresholds in physical systems that, if exceeded, would lead to irreversible changes or the loss of critical structure or function (Lenton et al., 2008; Adger et al., 2009; IPCC, 2012). Such limits arise from the magnitude and/or rate of climate change (Box 16-3). For example, a number of physical thresholds in the Earth system have been proposed as posing potential limits to adaptation, particularly large-scale events such as irreversible melting of the Greenland or Antarctic ice sheets (Schneider and Lane, 2006a; Sheehan et al., 2008; Travis, 2010). Such physical thresholds, however, though relevant to understanding adaptation limits, are not necessarily limits in themselves as they neglect consideration for the adaptive capacity of natural and human systems (Adger et al., 2009; Leary et al., 2009; Dow et al., 2013a,b; Klein and Juhola, 2013; Preston et al., 2013a).

For species and ecosystems, hard limits to adaptation are often associated with exceedance of the physiological capacity of individual organisms 


\section{Box 16-4 | Historical Perspectives on Limits to Adaptation}

Does human history provide insights into societal resilience and vulnerability under conditions of environmental change? Archeological and environmental reconstruction provides useful perspectives on the role of environmental change in cases of significant societal change, sometimes termed "collapse" (Diamond, 2005). These may help to illuminate how adaptation limits were either exceeded, or where collapse was avoided to a greater or lesser degree. Great care is necessary to avoid oversimplifying cause and effect, or overemphasizing the role of environmental change, in triggering significant societal change, and the societal response itself. Coincidence does not demonstrate causality, such as in the instance of matching climatic events with social crises through the use of simple statistical tests (Zhang et al., 2011), or through derivative compilations of historical data (deMenocal, 2001; Thompson et al., 2002; Drysdale et al., 2006; Butzer, 2012). Application of social theories may not explain specific cases of human behavior and community decision making, especially because of the singular importance of the roles of leaders, elites, and ideology (Hunt, 2007; McAnany and Yoffee, 2010; Butzer, 2012; Butzer and Endfield, 2012).

There are now roughly a dozen case studies of historical societies under stress, from different time ranges and several parts of the world, that are sufficiently detailed (based on field, archival, or other primary sources) for relevant analysis (Butzer and Endfield, 2012). These include Medieval Greenland and Iceland (Dugmore et al., 2012; Streeter et al., 2012), Ancient Egypt (Butzer, 2012), Colonial Cyprus (Harris, 2012), the prehistoric Levant (Rosen and Rivera-Collazo, 2012), Islamic Mesopotamia and Ethiopia (Butzer, 2012), the Classic Maya (Dunning et al., 2012; Luzzadder-Beach et al., 2012), and Colonial Mexico (Endfield, 2012). Seven such civilizations underwent drastic transformation in the wake of multiple inputs, triggers, and feedbacks, with unpredictable outcomes. These can be seen to have exceeded adaptation limits. Five other examples showed successful adaptation through the interplay of environmental, political, and socio-cultural resilience, which responded to multiple stressors (e.g., insecurity, environmental or economic crises, epidemics, famine). In these cases, climatic perturbations are identified as only one of many "triggers" of potential crisis, with preconditions necessary for such triggers to stimulate transformational change. These preconditions include humaninduced environmental decline mainly through overexploitation.

Avoidance of limits to adaptation requires buffering feedbacks that encompass social and environmental resilience. Exceedance of limits occurred through cascading feedbacks that were characterized by social polarization and conflict that ultimately result in societal disruption. Political simplification undermined traditional structures of authority to favor militarism, while breakdown was accompanied or followed by demographic decline. Although climatic perturbations and environmental degradation did contribute to triggering many cases of breakdown, the most prominent driver at an early stage was institutional failure, which refers to the inability of societal institutions to address collective-action problems (Acheson, 2006). In these cases, collapse was neither abrupt nor inevitable, often playing out over centuries. Lessons from the implementation of adaptation responses over historical time periods in Mexico City suggest that some responses may create new and even more significant risks (Sosa-Rodriguez, 2010).

Recent work on resilience and adaptation synthesizes lessons from extreme event impacts and responses in Australia (Kiem et al., 2010). This further emphasizes an institutional basis for resilience, finding that government intervention through the provision of frameworks to enable adaptation is beneficial. Furthermore, it was found that a strong government role may be necessary to absorb a portion of the costs associated with natural disasters. On the other hand, community awareness and recognition of novel conditions were also found to be critical elements of effective responses. It would be useful to consider how lessons learned from historical experience may relate to the perceived multiple environmental changes characterized by the "Anthropocene" era (Crutzen, 2002).

or communities to adapt to changes in the climate (i.e., temperature, rainfall, and/or disturbance regimes; Peck et al., 2009), or to climateinduced changes in the abiotic environment (e.g., ocean circulation and stratification; Harley et al., 2006; Doney et al., 2012; see also Sections 16.3.2.2-3). Such systems tend to be those that persist at the upper limit of their climate tolerances (Sheehan et al., 2008; Benito et al., 2011; Dirnböck et al., 2011); those for which sustainability is closely tied to vulnerable physical systems (Johannessen and Miles, 2011); or those that are under significant pressure from non-climatic forces (Jenkins et al., 2011). For example, many species, including humans (Section 11.8.1) 
and key food crops (e.g., wheat, maize, and rice; Sections 7.3.2, 11.8.2), are known to have thermal limits to survival. Similarly, increased ocean acidity is expected to reduce the ability of some marine organisms such as corals to grow, posing threats of significant ecosystem damage (Boxes CC-OA and CC-CR). Nevertheless, defining those limits remains challenging owing to system complexity and lack of information regarding responses across different levels of biological organization (Steffen et al., 2009; Wookey et al., 2009; Lavergne et al., 2010; Preston et al., 2013a). Furthermore, species have mechanisms for coping with climate change including phenotypic plasticity (Charmantier et al., 2008; Matesanz et al., 2010), genetic (evolutionary) responses (Bradshaw and Holzapfel, 2006; Gienapp et al., 2008; Visser, 2008; Wang et al., 2013), and range shifts (Colwell et al., 2008; Thomas, 2010; Chen et al., 2011; see also Section 16.3.2.3). Such mechanisms influence adaptation limits by extending the range of climate conditions with which individual organisms can cope in situ and/or enabling species to migrate over time to more suitable climates. Yet, more comprehensive assessments of such adaptive mechanisms are needed to develop robust understanding of ecological limits.

While human systems may also experience hard limits, such systems are influenced by exogenous climate change as well as endogenous processes such as societal choices and preferences (Adger et al., 2009). This creates the potential for limits encountered by actors to be soft. Although they may limit adaptation for the current planning horizon, they may be ameliorated in the future by changing circumstances. Various authors have noted that adaptation limits are socially constructed by human agency in that economics, technology, infrastructure, laws and regulations, or broader social and cultural considerations can limit adaptation (medium evidence; high agreement; Adger et al., 2009; de Bruin et al., 2009b; Flåm and Skjærseth, 2009; O'Brien, 2009; Wilbanks and Kates, 2010; McNamara et al., 2011; Morrison and Pickering, 2012; see also Section 16.3). Cost-benefit analyses and associated discount rates, for example, reflect a social value on investment returns (Section 17.4.1). Yet, Morgan (2011) notes that adaptation planning based on cost-benefit analysis can pose limits to adaptation by discounting the future economic benefits of adaptation actions and excluding nonmarket benefits. Meanwhile, increasing loss and damage from societal exposure and climate change may pose financial limits to the insurability of disaster risks (Section 10.7.3), which ultimately influences what activities can occur in certain locations. All of these factors are dynamic and can change over time. The Shared Socioeconomic Pathways, which have been designed to facilitate comparison of findings across modeling teams, reflect different perspectives on future changes in the capacity of actors to adapt (Kriegler et al., 2012; Ebi et al., 2013; Schweizer and 0'Neill, 2013; van Ruijven et al., 2013). Given rising incomes and advances in knowledge and technology, a greater number of adaptation options may become available to a greater number of actors over time. In contrast, impediments to development, constraints on investments in adaptation, or rapid escalations in risk may increase the likelihood of experiencing a limit.

Societal assessments of risk and willingness to invest in risk management are subject to many influences (Renn, 2008; IPCC, 2012; see also Section 14.5), such as experience of a recent disaster, some of which can result in rapid changes (Ho et al., 2008; Breakwell, 2010; Renn, 2011). Adger et al. $(2009$, p. 338) argue that many limits to adaptation are dependent on the changing goals, values, risk tolerances, and social choices of society which make them "mutable, subjective, and socially constructed." Similarly, Meze-Hausken (2008) views adaptation as being triggered in part by subjective thresholds including perceptions of change; choices, needs, and values; and expectations about the future (see also O'Brien, 2009). For instance, the distribution of grape suitability will change in response to climate change, but the potential for relocation as an adaptation is limited by the concept of "terroir," which reflects biophysical traits and local knowledge and wine making traditions to a cultural landscape (Box 23-1). However, terroir could become a soft limit if the rigid, regionally defined regulatory frameworks and concepts of regional identity that prescribe what grapes can be grown where were to become more geographically flexible and tied to the culture and history of the winemakers rather than regional climate and grape suitability (Box 23-1).

Limits also have scale-dependent properties (see also Section 16.3.2.10) (limited evidence, high agreement). Adaptation finance and capacity building activities more broadly, for example, enable resources for adaptation to be transferred from a variety of governmental and nongovernmental entities to developing nations in order to overcome soft limits to adaptation (Section 16.3.2.5). For example, a local community may not have the necessary resources to adapt, but these constraints may be overcome by drawing in resources, such as technical expertise, from regional, national, or international authorities as well as from NGOs, other civil society organizations, or the private sector (Section 16.3.2.5). Scale dependence also manifests among different actors within sectoral supply chains. For example, climate change that poses limits to the sustainability of an individual farm enterprise may have less impact on a national or international agribusiness (Park et al., 2012).

\subsubsection{Limits and Transformational Adaptation}

Adaptation has traditionally been viewed as a process of incremental adjustments to climate variability and change to maintain existing objectives and values despite changes in climate conditions (Smit et al., 2001). As evidenced by the examples in Section 16.4.1, however, future changes in climate could exceed the capacity of human actors and/or natural systems to successfully adapt using incremental adjustments (medium evidence, high agreement). Since the AR4, the adaptation and resilience literature has suggested that climate change or other factors may drive actors toward the deliberate pursuit of transformational adaptation as a mechanism for managing the discontinuities associated with experiencing an adaptation limit (Pelling, 2010; Kates et al., 2012; O'Brien, 2012; O'Brien et al., 2012; O'Neill and Handmer, 2012; Dow et al., 2013a,b; see also Section 20.3). In addition, some studies have discussed the interactions between incremental and transformational adaptation and the pathways by which actors can transition from one to the other (Pelling, 2010; Park et al., 2012).

As a relatively new concept in the adaptation literature, clear operational definitions of what constitutes transformational adaptation remain elusive. Several authors have offered criteria that include a significant increase in the magnitude of a management effort; introduction of new technologies or practices; formation of new structures or systems of governance; or geographic shifts in the location of activities (Pelling, 
2010; Stafford Smith et al., 2011; Kates et al., 2012; 0'Neill and Handmer, 2012; Park et al., 2012; see also Sections 20.1, 20.5). However, the concept has also been identified as having normative elements involving changes in desired values, objectives, and perceptions of problems (Pelling, 2010; O'Neill and Handmer, 2012; O'Brien et al., 2012; Park et al., 2012). The current complexity and ambiguity in the definition of transformational adaptation may constrain its effective operationalization in policy environments (very low confidence). However, this matter has not been investigated.

In the context of limits to adaptation, transformational adaptation represents options and strategies that human actors can exploit to reorganize systems when incremental adaptation has reached its limits. As with incremental adaptation, these changes can be reactions to what has been experienced in the past or decisions made in anticipation of the future (Kates et al., 2012). As a fundamental change in a system, transformation may involve changes in actors' objectives and associated values. Therefore, transformational adaptation is not without risks or costs (Orlove, 2009; Kates et al., 2012; 0'Brien, 2012). For example, the level of investment needed to relocate a community or economic enterprise to reduce the risk of system failure (Kates et al., 2012; O'Neill et al., 2012) and/or to take advantage of changing climatic conditions (Park et al., 2012) may be quite substantial. Furthermore, transformational adaptation may be associated with various externalities. Strategies such as migration, for example, may involve the loss of sense of place and cultural identity, particularly if migration is involuntary (Adger et al., 2009). The feasibility of transformational adaptation may therefore be dependent in part on whether it results in outcomes that are perceived to be positive versus negative (Preston and Stafford Smith, 2009). This suggests that the factors that constrain incremental adaptation (e.g., Section 16.3.2) also can constrain transformation, but the greater level of investment and/or shift in fundamental values and expectations required for transformational change may create greater resistance (limited evidence, medium agreement; Pelling, 2010; O'Brien, 2012; O'Neill and Handmer, 2012; Park et al., 2012).

\subsection{Sectoral and Regional Synthesis}

The adaptation literature since the AR4 indicates that despite a range of opportunities to enable adaptation, multiple factors will constrain adaptation planning and implementation (very high confidence; see Section 16.3), and, in some cases, such constraints may limit adaptation (medium evidence, high agreement; see Section 16.4). However, adaptation opportunities, constraints, and limits for adaptation vary significantly among different sectors and regional contexts (very high confidence; Adger et al., 2007; see also Sections 16.3-4; Table 16-3). This heterogeneity arises from a range of sources including regional differences with respect to the rate and magnitude of climate change that is experienced, differential exposure and sensitivity of sectors or ecological systems, and differential capacity to adapt. Given this diversity, it is important that opportunities, constraints, and limits are evaluated in the specific context in which they arise. Therefore, this section draws on the various assessments of adaptation presented in the sectoral (Chapters 3 to 13) and regional (Chapters 22 to 30) chapters of the WGII AR5 to synthesize knowledge regarding opportunities, constraints, and limits across these contexts.

\subsubsection{Sectoral Synthesis}

Each of the sectoral chapters in the WGII AR5 addresses the opportunities for, and constraints associated with, the pursuit of adaptation (Table 16-3). Collectively, this represents a rich body of knowledge regarding how adaptation processes are evolving among different human and natural systems. Although each sectoral chapter assesses the relevant literature on adaptation independently, common themes emerge (Table 16-3). Opportunities most often cited include building awareness, strengthening adaptive capacity, developing tools for improving vulnerability and risk assessments, and adopting favorable policies to improve governance. Likewise, common constraints arise among different sectors, but the bulk of the evidence for adaptation constraints is focused on inadequate governance and institutional structures at the scale of the challenge, lack of access to financial resources or relevant information for adaptation, and social and cultural norms that prevent adoption of viable adaptation options.

There are a number of emerging, integrated approaches to adaptation planning, governance, and implementation identified by many sectoral and regional chapters. For example, Integrated Water Resource Management (IWRM), Integrated Coastal Zone Management (ICZM), Community-Based Adaptation, and Ecosystem-Based Adaptation (EBA) are identified as cross-sectoral adaptation options, which are viewed as more effective than standalone efforts to reduce climate-related risks (Bijlsma et al., 1996; see also Sections 5.5.4, 14.3.2; Box CC-EA). Such integration is important, as many sectors experience threats not only from climate change, but also from a range of existing or emerging threats. The sectoral chapters also reflect on the distinction between autonomous adaptation, which is particularly important for natural systems such as freshwater, coastal, terrestrial, and ocean ecosystems (e.g., WGII AR5 Chapters 3 to 6), and planned adaptation, which features strongly in the literature associated with human-managed systems (WGII AR5 Chapters 5, 7 to 13).

Though the sectoral chapters offer few explicit definitions of adaptation limits, they reflect the potential for hard limits to be reached and the potential for them to be persistent due to interactions among multiple constraints (Section 16.3.2). For example, the sustainability of individual species or ecosystems may experience hard limits in a changing climate, as may ecosystem services for humans such as food crop and fisheries production. Though significantly more attention is given to sectoral adaptation opportunities, constraints, and limits than in the AR4, the AR5 chapters suggest that literature relevant to the coastal (Chapter 5), food systems (Chapter 7), and urban sectors (Chapter 8) has expanded more rapidly, perhaps because of the experience within these sectors with risk reduction planning associated with extreme weather events.

\subsubsection{Regional Synthesis}

While the regional chapters assess the relevant literature on key sectors affected by climate change, those discussions are specific to the various regional contexts (Table 16-3). Mainstreaming adaptation to climate change into national development policies, regional and local planning, and economic development has emerged as an opportunity across all regions for addressing multiple, interacting stresses (Dovers and Hezri, 
Table 16-3 | Sectoral and regional synthesis of adaptation opportunities, constraints, and limits. Each icon represents types of opportunities, constraints, and limits (described below). The size of the icon represents when there is relatively little (small icon) or relatively ample (large icon) information in the sectoral and regional chapters to describe each type of opportunity, constraint, or limit. If no information was presented, the table cell is blank.

Opportunities are defined as factors that make it easier to plan and implement adaptation actions, that expand adaptation options, or that provide ancillary co-benefits. Types of opportunities include (1) Awareness: communication, education, and awareness raising; (2) Capacity: human and institutional capacity building including preparedness, resource provision, and development of human and social capital; (3) Tools: decision making, vulnerability and risk analysis, decision support, and early warning tools; (4) Policy: integration and mainstreaming of policy, governance, and planning processes including sustainable development, resource and infrastructure planning, and design standards; (5) Learning: mutual experiential learning and knowledge management of climate vulnerability, adaptation options, disaster risk response, monitoring, and evaluation; and (6) Innovation: development and dissemination of new information, technology development, and technology application.

Constraints are defined as factors that make it harder to plan and implement adaptation actions. Types of constraints include (1) Economic: existing livelihoods, economic structures, and economic mobility; (2) Social/cultural: social norms, identity, place attachment, beliefs, worldviews, values, awareness, education, social justice, and social support; (3) Human capacity: individual, organizational, and societal capabilities to set and achieve adaptation objectives over time including training, education, and skill development; (4) Governance, Institutions \& Policy: existing laws, regulations, procedural requirements, governance scope, effectiveness, institutional arrangements, adaptive capacity, and absorption capacity; (5) Financial: lack of financial resources; (6) Information/Awareness/Technology: lack of awareness or access to information or technology; (7) Physical: presence of physical barriers; and (8) Biological: temperature, precipitation, salinity, acidity, and intensity and frequency of extreme events including storms, drought, and wind.

A Limit is defined as the point at which an actor's objectives or system's needs cannot be secured from intolerable risks through adaptive actions. Types of limits include (1) Biophysical: temperature, precipitation, salinity, acidity, and intensity and frequency of extreme events including storms, drought, and wind; (2) Economic: existing livelihoods, economic structures and economic mobility; and (3) Social/cultural: social norms, identity, place attachment, beliefs, worldviews, values, awareness, education, social justice, and social support.

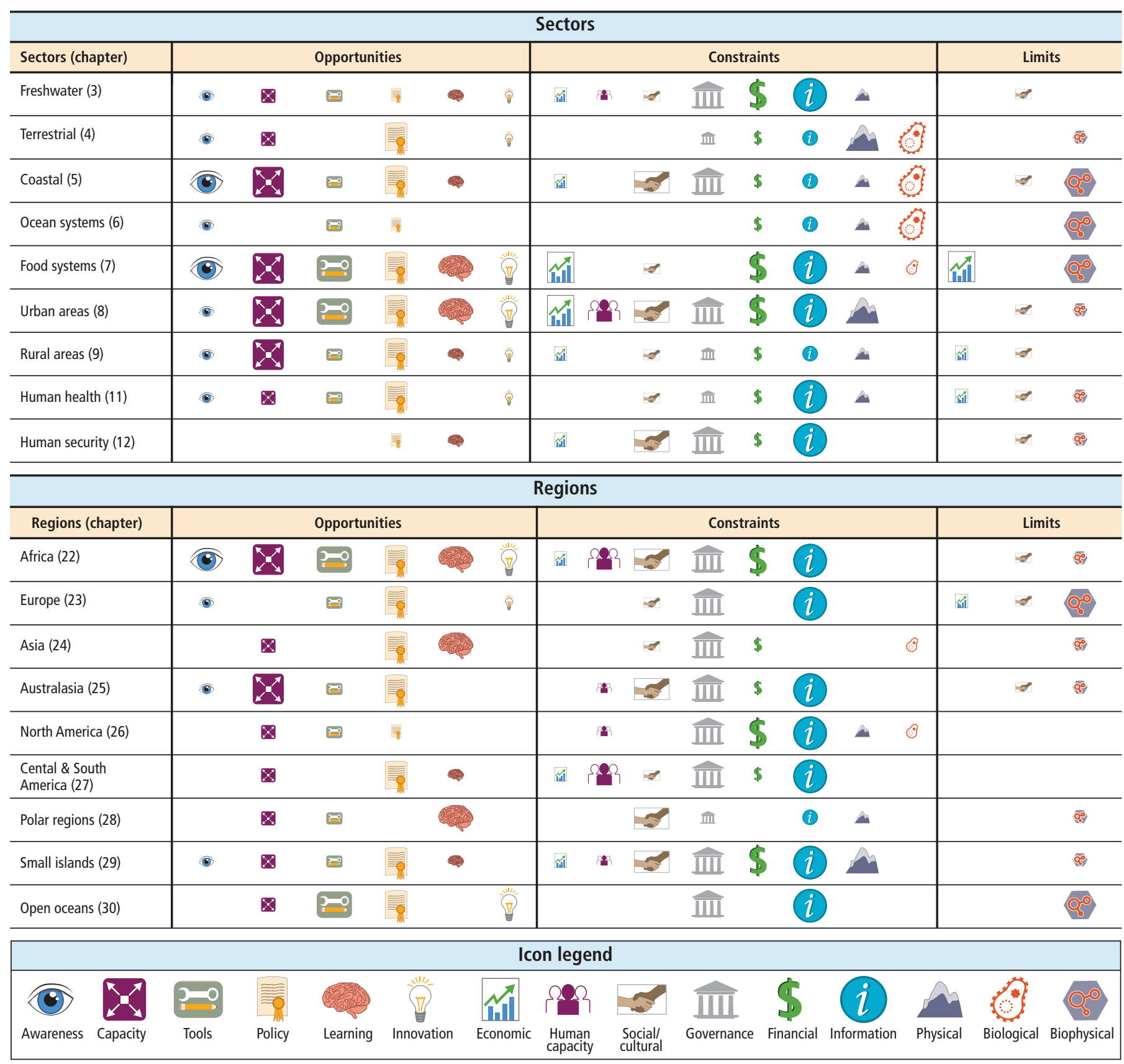


2010; Tompkins et al., 2010; Table 16-3). Most regional chapters reveal there are significant spatial and temporal mismatches between national adaptation planning on adaptation and local implementation to achieve substantive reductions in vulnerability. Adaptation interventions largely emphasize short-term risk management over long-term transformative strategic planning to reduce long-term risk, which potentially increases vulnerability and therefore the costs associated with future adaption efforts. Such short-sighted decision making can also create the potential for maladaptation (Barnett and O'Neill, 2010; Berrang-Ford et al., 2011; Preston et al., 2013b).

Effective governance and institutions for facilitating adaptation planning and implementation across multiple sectors within regions was by far the dominant opportunity and constraint. Both a shift to risk-based approaches to adaptation and to the multi-sector planning for adaptation mentioned previously (EBA, IRWM, and ICZM) offers opportunities for the development of approaches, tools, and guidelines for the construction of adaptation plans at a regional scale with a long-term focus. Developing and developed nations alike identified opportunities for building adaptive capacity and access to better information at the scale of decision making as important to making this happen. Compared with sectoral chapters, the regional chapters identified limits to adaptation less frequently (Table 16-3). This reflects the tendency for the literature to focus on limits for specific sectors, species, or ecosystems.

\subsection{Effects of Mitigation on Adaptation Opportunities, Constraints, and Limits}

The AR4 identified four ways in which adaptation and mitigation can interrelate, one of which is mitigation actions that have consequences for adaptation (Klein et al., 2007). It follows that mitigation actions could have consequences for adaptation constraints and limits. Klein et al. (2007) concluded that without mitigation, a magnitude of climate change could be reached that makes adaptation impossible for some natural systems, while for most human systems such high magnitudes of change would involve very high social and economic costs. Adaptation constraints and limits therefore have implications for the definition of dangerous anthropogenic interference under Article II of the UNFCCC (UNFCCC, 1992; see also Travis, 2010; Hoegh-Guldberg, 2011; Tao et al., 2011; Preston et al., 2013a). A number of studies published since the AR4, for example, demonstrate that constraining future greenhouse gas emissions would lower the magnitude of climate change experienced over the 20th century and constrain the magnitude of future adverse impacts or the likelihood of exceeding system thresholds (very high confidence; Stern et al., 2006; Preston and Jones, 2008; Sheehan et al., 2008; Meinshausen et al., 2009; 0'Neill et al., 2010; Garnaut, 2011; Arnell et al., 2011; Rogelj et al., 2011; Webster et al., 2011; see also discussion of mitigation in the AR5 WGII sectoral and regional chapters). Therefore, mitigation can potentially reduce the magnitude of climate change to which human and natural systems must adapt.

Understanding the relationship between damages avoided by mitigation and adaptation limits requires information regarding what magnitude of climate change and associated damages would constitute an intolerable risk. The WGI contribution to AR5 quantifies the cumulative carbon dioxide $\left(\mathrm{CO}_{2}\right)$ emissions below which-with probabilities of $>33 \%$, $>50 \%$, and $>66 \%$ - global mean warming would be limited to less than $2^{\circ} \mathrm{C}$ since the period 1861-1880 (see WGI AR5 Section12.5.4). Warming beyond $2{ }^{\circ} \mathrm{C}$ is considered to give rise to "reasons for concern" (Smith et al., 2009a; see also Section 19.6), in part because adaptation to impacts associated with such warming would be constrained or limited (Sections 16.3.2, 16.4.1; Box 16-3). Uncertainty about the location of both hard and soft limits is due to the fact that these limits are determined not only by the degree and rate of climate change (as a function of mitigation pathways), but also by the degree and rate of non-climatic stresses affecting the resilience or adaptive capacity of natural and human systems (Section 16.4). Little empirical information is available on the functional relationships between climate change, non-climatic stresses, and the emergence of limits to adaptation. The literature aiming to establish at which degree and rate of climate change, or at which levels of mitigation, such adaptation constraints and limits emerge is sparse and refers primarily to natural systems (limited evidence, medium agreement; Section 16.4).

\section{Frequently Asked Questions}

\section{FAQ 16.3 | How does greenhouse gas mitigation influence the risk of exceeding adaptation limits?}

There is very high confidence that higher rates and/or magnitudes of climate change contribute to higher adaptation costs and/or the reduced effectiveness of certain adaptation options. For example, increases in global mean temperature of $4^{\circ} \mathrm{C}$ or more would necessitate greater investment in adaptation than a temperature increase of $2^{\circ} \mathrm{C}$ or less. As future climate change is dependent on emissions of greenhouse gases, efforts to mitigate those emissions can reduce the likelihood that human or natural systems will experience a limit to adaptation. However, uncertainties regarding how future emissions translate into climate change at global and regional levels remain significant, and therefore it is difficult to draw robust conclusions regarding whether a particular greenhouse gas stabilization pathway would or would not allow residual risk to be successfully managed through adaptation. For example, evidence regarding limits to adaptation does not substantiate or refute the idea that an increase in global mean temperature beyond $2^{\circ} \mathrm{C}$ represents an adaptation limit or, subsequently, "dangerous anthropogenic interference" as defined by the UNFCCC's Article II. 
Nevertheless, studies indicating that limits to adaptation have already been reached for some systems suggest the climate change observed to date has been sufficient to threaten the sustainability of human communities, ecosystem services, or ecological systems (limited evidence, medium agreement; Section 16.4). For many valued human and natural systems, the complex spatial and temporal dynamics of impacts, adaptive capacity, and adaptation make it difficult to quantitatively project with any degree of accuracy and confidence when and where limits to adaptation will be encountered. Furthermore, although constraints and limits have been demonstrated to have cross-scale and cross-level interactions (Sections 16.3.2.10, 16.4.1), there is little evidence that indicates how limits to adaptation experienced by actors, species, or ecosystems in individual regions or sectors scale to a global aggregate limit. Therefore, there is little evidence to either substantiate or refute the idea that global mean warming beyond $2^{\circ} \mathrm{C}$ represents a global adaptation limit.

Analysis by Christensen et al. (2011) (see also WGI AR5 Section 12.4.1) shows that all emission scenarios-whether aggressive mitigation scenarios consistent with a $2^{\circ} \mathrm{C}$ stabilization pathway or medium-high emission scenarios such as Special Report on Emission Scenarios (SRES) A1B and A1Fi, or Representative Concentration Pathway 6.0 (RCP6.0) and RCP8.5-are very similar in terms of projected climate up to 2040 (i.e., the "era of climate responsibility"). The effects of mitigation on overall adaptation potential will therefore arise in the medium to long term, during the "era of climate options." Integrated Assessment Models (IAMs) can assess the relative damage-reducing effect of mitigation and adaptation, based on the assumption that the two strategies are substitutes. In reality, however, mitigation and adaptation are hardly substitutable: they create benefits on different spatial, institutional and temporal scales and involve different actors with different interests. Substitutability of mitigation and adaptation in IAMs requires the reconciliation of welfare impacts on people living in different places and at different points in time into an aggregate measure of well-being (Klein et al., 2007). Moreover, defining the costs and benefits of adaptation is particularly difficult, limited by data, and depends on value judgments (Chapter 17).

Since AR4 the literature on tipping elements (Lenton et al., 2008; Kriegler et al., 2009; Levermann et al., 2012) has provided a greater separation of mitigation and adaptation, because only mitigation can avoid these discontinuities. While there could be potential for mitigation and adaptation substitutability under scenarios where catastrophic climate change is avoided, the thresholds for the onset of any tipping elements (anticipated to drive some systems to the limits of adaptation) are not known. These concerns have been picked up in the economic literature, in relation to the plausible, if unknown, probability of catastrophic climate change as well as "fat tails," where uncertainty is so large that the tails of the probability distribution tend to dominate (Weitzman, 2009). Against this background, mitigation can prevent or delay catastrophic climate change and the reaching of adaptation limits.

Several studies using IAMs have investigated tradeoffs between mitigation and adaptation (de Bruin et al., 2009a; Bosello et al., 2010), treating the two strategies as substitutes in order to find a balance or even an optimal mix. De Bruin et al. (2009a) report that short-term optimal policies need to consist of a mixture of substantial investments in adaptation measures, coupled with investments in mitigation, even though the latter will decrease damages only in the longer term. They also find that the relative mix of the two depends critically on the assumptions, notably in relation to discount rate and the parameterization of damages. Felgenhauer and de Bruin (2009) examine the role that uncertainty over climate sensitivity has on optimal mitigation and adaptation policy levels over time. They find that optimal levels of both mitigation and adaptation are lower under uncertainty than under certainty, and that the optimal mitigation level is more dependent on adaptation costs than vice versa.

Such findings are all preliminary, because the current representation of adaptation in IAMs is generally very simple (Ackerman et al., 2009; Patt et al., 2010b). The models adopt a highly aggregated and theoretical approach without considering any real-world constraints on adaptation (Ackerman et al., 2009; Patt et al., 2010b). They also often assume perfect foresight, no uncertainty, and no maladaptation (see also Watkiss, 2011; Berkhout, 2012). More recent models have attempted to address some of these issues. De Bruin and Dellink (2011), for example, model different types of constraints of adaptation over time. Also the PAGE09 model assumes adaptation to be about half as effective as it was in PAGE02 (Hope, 2011). Along with other factors, the reduced effectiveness of adaptation in the model leads to a strong increase in the economic costs of climate change (Hope, 2011).

\subsection{Ethical Dimensions of Adaptation Opportunities, Constraints, and Limits}

Hartzell-Nichols (2011, p. 690) argues that, in general terms, "Adaptation is fundamentally an ethical issue because the aim of adaptation is to protect that which we value." More specifically, ethical issues concern the distribution of costs and benefits of prevention measures and adaptation activities, compensation for residual damages, and participation in the related decision processes (Grasso, 2009). These distributive and procedural justice-related issues can be diverse and contextually specific (Paavola, 2011). Brisley et al. (2012) argue that ensuring social justice in adaptation requires both an understanding of which groups are most vulnerable to climate change impacts, as well as social choice processes about adaptation responses that are seen to meet the needs of the vulnerable fairly. The key ethical issues raised by adaptation opportunities, constraints, and limits as they are discussed here are summarized in Table 16-4, together with the public policy questions they raise.

Defining general moral principles to clarify how to handle risks to objectives, values, and needs, including where they are unavoidable and catastrophic, is difficult. According to Gardiner (2006, p. 407), "Even our best theories face basic and often severe difficulties addressing basic issues ... such as scientific uncertainty, intergenerational equity, contingent persons, nonhuman animals, and nature. But climate change involves all of these matters and more."

Complicating this picture further is the observation that social and personal values are not universal or static (O'Brien, 2009; O'Brien and Wolf, 2010). There may be different, but equally legitimate, values that are fostered or put at risk by climate change (Adger et al., 2012). These are not limited to instrumental or economic values, but include cultural 
Table 16-4 | Ethical dimensions of adaptation opportunities, constraints, and limits and their policy implications.

\begin{tabular}{|c|c|c|c|c|}
\hline & Ethical dimensions & Commentary & Public policy issues & References \\
\hline Adaptation opportunities & Access to opportunities & $\begin{array}{l}\text { Inequitable access to the factors } \\
\text { that make it easier to adapt and } \\
\text { achieve adaptation objectives }\end{array}$ & $\begin{array}{l}\text { Whether national or international } \\
\text { policy should support more } \\
\text { equitable access to adaptation } \\
\text { opportunities }\end{array}$ & $\begin{array}{l}\text { Thomas and Twyman (2005); } \\
\text { Paavola and Adger (2006); Paavola } \\
\text { (2008); Füssel (2010); Rübbelke } \\
\text { (2011); Klinsky et al. (2012) }\end{array}$ \\
\hline Adaptation constraints & Distribution of constraints & $\begin{array}{l}\text { Inequitable distribution of factors } \\
\text { that make it harder to plan and } \\
\text { implement adaptation actions }\end{array}$ & $\begin{array}{l}\text { Whether national or international } \\
\text { policy should reduce or remove } \\
\text { constraints to adaptation }\end{array}$ & $\begin{array}{l}\text { Paavola and Adger (2006); Klein } \\
\text { and Möhner (2009); Grasso (2010) }\end{array}$ \\
\hline \multirow[t]{5}{*}{ Adaptation limits } & Differing attitudes to risk & $\begin{array}{l}\text { What is deemed an acceptable, } \\
\text { tolerable, and intolerable risk will } \\
\text { vary across cultures, social groups, } \\
\text { and individuals. }\end{array}$ & $\begin{array}{l}\text { Risk governance is concerned } \\
\text { with balancing differentiated } \\
\text { and dynamic attitudes to risk in } \\
\text { allocating resources to managing } \\
\text { risks. }\end{array}$ & $\begin{array}{l}\text { Bisaro et al. (2010); Juhola et al. } \\
\text { (2011); Lata and Nunn (2012); } \\
\text { Sovacool (2012); Fatti and Patel } \\
\text { (2013); Ward et al. (2013) }\end{array}$ \\
\hline & $\begin{array}{l}\text { Rights and potentials of people to } \\
\text { secure particular valued objectives }\end{array}$ & $\begin{array}{l}\text { Limits are related to given valued } \\
\text { objectives, but such objectives vary } \\
\text { between individuals and collectives. }\end{array}$ & $\begin{array}{l}\text { Risk governance related to } \\
\text { adaptation limits is concerned with } \\
\text { setting priorities between different } \\
\text { (and conflicting) valued objectives. }\end{array}$ & $\begin{array}{l}\text { Foale (2008); Devine-Wright (2009); } \\
\text { Gorman-Murray (2010); Jacob et al. } \\
\text { (2010); Brown et al. (2011); Adger } \\
\text { et al. (2012) }\end{array}$ \\
\hline & $\begin{array}{l}\text { Differing rates at which limits are } \\
\text { reached }\end{array}$ & $\begin{array}{l}\text { Limits will be reached earlier by } \\
\text { some groups and regions (Arctic, } \\
\text { unprotected coastal zones) than } \\
\text { others. }\end{array}$ & $\begin{array}{l}\text { Risk governance at different scales } \\
\text { will be confronted with choices } \\
\text { about adaptation limits emerging } \\
\text { through time. }\end{array}$ & $\begin{array}{l}\text { Baum and Easterling (2010); } \\
\text { Edvardsson-Bjornberg and Hansson } \\
\text { (2011); Dow et al. (2013a) }\end{array}$ \\
\hline & $\begin{array}{l}\text { Trade-offs in securing valued } \\
\text { objectives }\end{array}$ & $\begin{array}{l}\text { Adaptive responses will involve } \\
\text { choices between valued objectives } \\
\text { at adaptation limits (i.e., between } \\
\text { river water quality and water } \\
\text { demand from irrigation). }\end{array}$ & $\begin{array}{l}\text { As adaptation limits that affect } \\
\text { multiple valued objectives are } \\
\text { reached, private and public choices } \\
\text { will be made about which values } \\
\text { have priority over others. }\end{array}$ & $\begin{array}{l}\text { Steenberg et al. (2011); Towler et } \\
\text { al. (2012); Pittock (2013); Seidl and } \\
\text { Lexer (2013) }\end{array}$ \\
\hline & $\begin{array}{l}\text { Intergenerational and interspecies } \\
\text { equity and adaptation limits }\end{array}$ & $\begin{array}{l}\text { Valued objectives may be } \\
\text { irrecoverably lost at adaptation } \\
\text { limits, denying them to future } \\
\text { generations. }\end{array}$ & $\begin{array}{l}\text { Species extinctions and loss of } \\
\text { cultural heritage, place, or identity } \\
\text { may call for extraordinary public } \\
\text { policy interventions. }\end{array}$ & Albrecht et al. (2013) \\
\hline
\end{tabular}

values as well. Berkes $(2008$, p. 163), for instance, documents that in Inuit culture, the loss of sea ice in summer months leaves some people "Ionely for the ice." Whether the risk of irreversible cultural losses would be seen as intolerable remains a complicated question, but has been noted to manifest in a psychological response termed "solastalgia" (Albrecht et al., 2007). The loss of traditional ways of experiencing and seeing the world is a common occurrence throughout human history. The ethical question is whether such losses should be acknowledged in considering adaptation opportunities, constraints, and limits (as well as in human responses to climate change more generally).

One ethical principle that is widely applied in ethical discussions of climate is "equity" (Gardiner, 2010). It is now well established that nations, peoples, and ecosystems are differentially vulnerable to current and future projected climate change impacts, which themselves are unequally distributed across world regions (very high confidence; IPCC, 2007b; Füssel, 2009, 2010). This inequity is exacerbated by the fact that exposure to adverse impacts is involuntary for many societies (Paavola and Adger, 2006; Patz et al., 2007; Dellink et al., 2009; Füssel, 2010). Thus, adaptation constraints have the potential to create or exacerbate inequitable consequences due to climate change (very high confidence). Where limits to adaptation lead to catastrophic losses there is often a need for humanitarian responses, as well as more structural adaptations at the societal level (medium evidence, high agreement; Bardsley and Hugo, 2010). Linked to this is the complex question of the attribution of risks to anthropogenic forcing of climate change and whether there could be grounds for redress or compensation (Verheyen, 2005). In this regard, different ethical positions taken by countries such as through "equity weighting" would result in very different compensation outcomes (Anthoff and Tol, 2010).
Inequity resulting from adaptation constraints and limits emerge across several dimensions: inter-country equity, inter-generational equity, interspecies equity (Schneider and Lane, 2006b), and intra-country or subnational equity (Thomas and Twyman, 2005). Climate change, and the need for adaptation, unfairly shifts burdens onto future generations, contradicting the principle of intergenerational equity. This raises ethical and justice questions because benefits are extracted from the global environment by those who do not bear the burden of that extraction (UNEP, 2007). Policy debates about intergenerational equity considerations have been dominated by the need to treat the time discount rate consistently across cases (Nordhaus, 2001; Stern et al., 2006; Beckerman and Hepburn, 2007). But this debate largely ignores the challenge of irreversible damages associated with limits to adaptation, especially those that may result from nonlinear damage functions (Hanemann, 2008). Inter-species equity is the subject of an evolving ethics debate (e.g., Jolibert et al., 2011), but adaptation interventions involving ecosystems and wild species increasingly invoke human and societal benefits as a primary motivation (CBD, 2009; Box CC-EA).

Law codifies the social values and objectives influenced by opportunities, constraints, and limits to adaptation, and sets norms and procedures for dealing with problems of risk and loss, including the intolerable losses experienced at adaptation limits (Section 16.3.2.8). Changing such values and objectives, including the shifting and sharing of risks this may involve, will often involve complex and time-consuming governance effort. National and international law will play a role in managing and sharing climate-related risks. The Cancun Adaptation Framework (UNFCCC, 2011) adopted at COP16 of the UNFCCC sets out principles for international cooperation on adaptation "...to enable and support the implementation of adaptation actions" (UNFCCC, 2010, 
p. 4). Nevertheless, the complexity of international law comprises a significant constraint to making the case for addressing the breaching of adaptation limits (Koivurova, 2007). At national and subnational levels, cultural attitudes can contribute to stakeholder marginalization from adaptation processes (Section 16.3.2.7), thus preventing some constraints and limits from being identified (such as gender issues and patriarchal conventions).

\subsection{Seizing Opportunities, Overcoming Constraints, and Avoiding Limits}

As discussed in this chapter, researchers and practitioners now have a richer understanding of how constraints and limits influence adaptation (Sections 16.3-7). Based on the available literature, however, less attention has been paid to understanding the range of opportunities that exist and how they create enabling conditions for adaptation (Section 16.3.1; Table 16-1). Focused research on facilitating such enabling conditions and how these lead to the minimization or avoidance of adaptation constraints would support capacity building of individuals and institutions (very high confidence; Smith et al., 2008; Ford, 2009; Burch, 2010; Ford et al., 2010; Eisenack, 2012; Biesbroek et al., 2013a). Translating knowledge of potential opportunities into adaptation responses requires that they be recognized and then exploited by actors. Such opportunities are being created through policies, tools, and guidelines that are emerging throughout the developed and developing world (Sections 15.2, 16.3.2.1). It is not yet clear if these efforts are translating into effective adaptation actions for the benefit of human and natural systems including the avoidance of limits. As adaptation practice has focused on what adaptation efforts can achieve in terms of avoided damages rather than on the residual damages that adaptation cannot avoid (Jenkins et al., 2011; McNamara et al., 2011), this question remains largely unexplored.

Adaptation constraints have contributed to uneven adaptation planning and implementation, with some sectoral and regional actors progressing more rapidly than others (very high confidence; Urwin et al., 2008; Biesbroek et al., 2010; Tompkins et al., 2010; Bichard and Kazmierczak, 2012; Bierbaum et al., 2012; Carmin et al., 2012). Multiple studies have concluded that adaptation is largely proceeding autonomously and incrementally, often in response to perceived climate change trends and impacts that have been experienced (medium evidence, high agreement; Ford, 2009; Ford et al., 2010, 2011; Berrang-Ford et al., 2011; Preston et al., 2011a; Lesnikowski et al., 2013). In so doing, however, actors may not adequately invest in adaptation responses that will address future long-term risks associated with higher levels of climate change (limited evidence, medium agreement; Preston et al., 2013b; see also Section 16.3.2.2). The suggestion that incremental approaches to mitigation and adaptation may be inadequate to avoid intolerable risks has led to a growing discourse regarding transformational adaptation (Pelling, 2010; Kates et al., 2012; 0'Brien, 2012; O'Neill and Handmer, 2012; Park et al., 2012). While various practical examples of transformational adaptation appear in the literature (Kates et al., 2012; 0'Neill and Handmer, 2012; Park et al., 2012; see also Section 16.4.2), the extent to which transformational adaptation can be operationalized within adaptation policy remains unclear. Unresolved issues including which actors, sectors, and regions should be considering transformational adaptations, when, and what constitutes appropriate adaptation actions under such circumstances would benefit from focused investigation.

Better understanding and quantification of how future GHG emissions trajectories and climate change translates into impacts would improve understanding of limits to adaptation. Fundamental understanding of the vulnerability of different regions and sectors to climate change suggest that adaptive capacity is finite and thus, in general, limits to adaptation can be anticipated to arise as a consequence of future global change (medium evidence, high agreement; Sections 16.3.2, 16.4-6). Yet, at present, understanding of limits to adaptation is largely qualitative, and it is unclear whether current approaches to assessing climate change impacts and adaptation sufficiently explore the range of potential future climates and adaptive capacities of human and natural systems in a manner that is sufficient to identify limits. The parallel process for scenario development may provide a coherent framework for internally consistent analyses of climate change impacts that address uncertainty among climate models, emissions scenarios, and socioeconomic scenarios (Moss et al., 2010; van Vuuren et al., 2012; Ebi et al., 2013). Such knowledge could subsequently provide early warning of systems at risk of experiencing intolerable risks (Dow et al., 2013a,b) while also providing guidance regarding GHG mitigation targets.

Finally, recent literature questions whether existing institutions and systems of governance are adequate to effectively manage climate change risk. This includes not only institutions engaging in adaptation planning and implementation (Berkes and Armitage, 2010; Chapin et al., 2010; National Research Council, 2010; UKCIP, 2011; Kates et al., 2012; Biesbroek et al., 2013a), but also those associated with adaptation research (Meyer, 2011; Kates et al., 2012). New institutions and institutional arrangements have in fact emerged including adaptation research institutions with boundary spanning functions (Preston et al., 2013c; see also Section14.2.3), as well as those designed to facilitate adaptation and improve environmental and risk management (medium evidence, high agreement; National Research Council, 2009; Biesbroek et al., 2011; Jäger and Moll, 2011; Lemos et al., 2013). However, others have cautioned that the complexity of modern governance systems poses significant constraints on institutional change (Adger et al., 2009; see also Section 16.3.2.8), and new institutions do not necessarily resolve complex governance challenges (Lebel et al., 2013). Additional research is therefore needed regarding the extent to which new institutions will be required to effectively govern adaptation.

\section{References}

Aaheim, A., H. Amundsen, T. Dokken, and T. Wei, 2012: Impacts and adaptation to climate change in European economies. Global Environmental Change, 22(4), 959-968.

Abbott, P. and A.B. de Battisti, 2011: Recent global food price shocks: causes, consequences and lessons for African governments and donors. Journal of African Economies, 20(Suppl. 1), 12-62.

Abel, N., R. Gorddard, B. Harman, A. Leitch, J. Langridge, A. Ryan, and S. Heyenga, 2011: Sea level rise, coastal development and planned retreat: analytical framework, governance principles and an Australian case study. Environmental Science \& Policy, 14(3), 279-288.

Acheson, J.M., 2006: Institutional failure in resource management. Annual Review of Anthropology, 35, 117-134. 
Ackerman, F., S.J. DeCanio, R.B. Howarth, and K. Sheeran, 2009: Limitations of integrated assessment models of climate change. Climatic Change, 95(3-4), 297-315.

Adaptation Fund Board, 2013: Adaptation Fund Trust Fund: Financial Report Prepared by the Trustee. AFB/EFC.12/8, Ethics and Finance Committee, Thirteenth Meeting, Adaptation Fund Board, Bonn, Germany, 15 pp.

Adaptation Sub-Committee, 2012: Climate Change: Is the UK Preparing for Flooding and Water Scarcity? Adaptation Sub-Committee Progress Report, Committee on Climate Change, London, UK, $51 \mathrm{pp}$.

Adger, W.N., 2010: Social capital, collective action, and adaptation to climate change. In: Der Klimawandel [Voss, M. (ed.)]. VS Verlag für Sozialwissenschaften, Dordrecht, Netherlands, pp. 327-345.

Adger, W.N. and J. Barnett, 2009: Four reasons for concern about adaptation to climate change. Environment and Planning A, 41(12), 2800-2805.

Adger, W.N., S. Agrawala, M.M.Q. Mirza, C. Conde, K. O'Brien, J. Pulhin, R. Pulwart B. Smit, and K. Takahashi, 2007: Assessment of adaptation practices, options, constraints and capacity. In: Climate Change 2007: Impacts, Adaptation and Vulnerability. Contribution of Working Group II to the Fourth Assessment Report of the Intergovernmental Panel on Climate Change [Parry, M.L., O.F. Canziani, J.P. Palutikof, P.J. van der Linden, and C.E. Hanson (eds.)]. Cambridge University Press, Cambridge, UK and New York, NY, USA, pp. 717-743.

Adger, W.N., H. Eakin, and A. Winkels, 2008: Nested and teleconnected vulnerabilities to environmental change. Frontiers in Ecology and the Environment, 7(3), 150157.

Adger, W.N., S. Dessai, M. Goulden, M. Hulme, I. Lorenzoni, D.R. Nelson, L.O. Naess, J. Wolf, and A. Wreford, 2009: Are there social limits to adaptation to climate change? Climatic Change, 93(3-4), 335-354

Adger, W.N., J. Barnett, F.S. Chapin, and H. Ellemor, 2011: This must be the place: underrepresentation of identity and meaning in climate change decisionmaking. Global Environmental Politics, 11(2), 1-25.

Adger, W.N., J. Barnett, K. Brown, N.A. Marshall, and K. O'Brien, 2012: Cultura dimensions of climate change impacts and adaptation. Nature Climate Change, 3, 112-117.

Adger, W.N., T. Quinn, I. Lorenzoni, C. Murphy, and J. Sweeney, 2013: Changing social contracts in climate-change adaptation. Nature Climate Change, 3(4), 330333.

Afreen, S., N. Sharma, R.K. Chaturvedi, R. Gopalakrishnan and N.H. Ravidranath, 2011: Forest policies and programs affecting vulnerability and adaptation to climate change. Mitigation and Adaptation Strategies for Global Change, 16(2), 177-197.

Agrawala, S., 2005: Putting climate change in the development mainstream introduction and framework. In: Bridge Over Troubled Waters: Linking Climate Change and Development [Agrawala, S. (ed.)]. Organisation for Economic Cooperation and Development (OECD), Paris, France, pp. 23-43.

Ahmed, S. and E. Fajber, 2009: Engendering adaptation to climate variability in Gujarat, India. Gender \& Development, 17(1), 33-50.

Aitken, S.N., S. Yeaman, J.A. Holliday, T. Wang, and S. Curtis-McLane, 2008: Adaptation, migration or extirpation: climate change outcomes for tree populations. Evolutionary Applications, 1(1), 95-111.

Aitken, S.N., S. Yeaman, E.J. Eliason, T.D. Clark, M.J. Hague, L.M. Hanson, Z.S Gallagher, K.M. Jeffries, and A.P. Farrell, 2011: Differences in thermal tolerance among sockeye salmon populations. Science, 332(6025), 109-112.

Alberti, M., 2010: Maintaining ecological integrity and sustaining ecosystem function in urban areas. Current Opinion in Environmental Sustainability, 2, 178-184.

Albrecht, G., G.-M. Sartore, L. Conner, N. Higginbotham, S. Freeman, B. Kelly, H. Stain A. Tonna, and G. Pollard, 2007: Solastalgia: the distress caused by environmental change. Australasian Psychiatry, 15(Suppl. 1), 595-S98.

Albrecht, G.A., C. Brooke, D.H. Bennett, and S.T. Garnett, 2013: The ethics of assisted colonization in the age of anthropogenic climate change. Journal of Agricultural and Environmental Ethics, 26(4), 827-845.

Alcamo, J., J.M. Moreno, B. Nováky, M. Bindi, R. Corobov, R.J.N. Devoy, C. Giannakopoulos, E. Martin, J.E. Olesen, and A. Shvidenko, 2007: Europe. In: Climate Change 2007: Impacts, Adaptation and Vulnerability. Contribution of Working Group II to the Fourth Assessment Report of the Intergovernmental Panel on Climate Change [Parry, M.L., O.F. Canziani, J.P. Palutikof, P.J. van der Linden, and C.E. Hanson (eds.)]. Cambridge University Press, Cambridge, UK and New York, NY, USA, pp. 541-580.

Ali, A., 1999: Climate change impacts and adaptation assessment in Bangladesh. Climate Research, 12, 109-116.
Allison, E.H., A.L. Perry, M.C. Badjeck, N. Adger, K. Brown, D. Conway, and N.K. Dulvy, 2009: Vulnerability of national economies to the impacts of climate change on fisheries. Fish and Fisheries, 10(2), 173-196.

Almansi, F., 2009: Regularizing land tenure within upgrading programmes in Argentina; the cases of Promeba and Rosario Hábitat. Environment and Urbanization, 21(2), 389-413.

Alston, M. and R. Mason, 2008: Who turns the taps off? Introducing social flow to the Australian water debate. Rural Society, 18(2), 131-139.

Amaru, S. and N.B. Chhetri, 2013: Climate adaptation: Institutional response to environmental constraints, and the need for increased flexibility, participation, and integration of approaches. Applied Geography, 39, 128-139.

Anisimov, O.A., D.G. Vaughan, T.V. Callaghan, C. Furgal, H. Marchant, T.D. Prowse, H. Vilhjálmsson, and J.E. Walsh, 2007: Polar regions (Artic and Antarctica). In: Climate Change 2007: Impacts, Adaptation and Vulnerability. Contribution of Working Group II to the Fourth Assessment Report of the Intergovernmental Panel on Climate Change [Parry, M.L., O.F. Canziani, J.P. Palutikof, P.J. van der Linden, and C.E. Hanson (eds.)]. Cambridge University Press, Cambridge, UK and New York, NY, USA, pp. 653-685.

Anthoff, D. and R.S. Tol, 2010: On international equity weights and national decision making on climate change. Journal of Environmental Economics and Management, 60(1), 14-20.

Anwar, M.R., D. Li Liu, I. Macadam, and G. Kelly, 2013: Adapting agriculture to climate change: a review. Theoretical and Applied Climatology, 113(1-2), 225-245.

Aporta, C. and E. Higgs, 2005: Satellite culture: global positioning systems, Inuit wayfinding, and the need for a new account of technology. Current Anthropology, 46, 729-753.

Armour, K.C. and G.H. Roe, 2011: Climate commitment in an uncertain world. Geophysical Research Letters, 38(1), L01707, doi:10.1029/2010GL045850.

Arnell, N.W., D.P. van Vuuren, and M. Isaac, 2011: The implications of climate policy for the impacts of climate change on global water resources. Global Environmental Change, 21(2), 592-603.

Artur, L. and D. Hilhorst, 2012: Everyday realities of climate change adaptation in Mozambique. Global Environmental Change, 22(2), 529-536.

Ayers, J., 2009: International funding to support urban adaptation to climate change, Environment and Urbanization, 21(1), 225-240

Ayers, J. and S. Huq, 2009: Supporting adaptation to climate change: what role for official development assistance? Development Policy Review, 27(6), 675692.

Badjeck, M.C., E.H. Allison, A.S. Halls, and N.K. Dulvy, 2010: Impacts of climate variability and change on fishery-based livelihoods. Marine Policy, 34(3), 375383.

Baldassarre, G., A. Montanari, H. Lins, D. Koutsoyiannis, L. Brandimarte, and G. Blöschl, 2010: Flood fatalities in Africa: from diagnosis to mitigation. Geophysical Research Letters, 37(22), L22402, doi:10.1029/2010GL045467.

Bangay, C. and N. Blum, 2012: Education responses to climate change and quality: two parts of the same agenda? International Journal of Educational Development, 30(4), 359-368.

Bardsley, D.K. and G.J. Hugo, 2010: Migration and climate change: examining thresholds of change to guide effective adaptation decision-making. Population and Environment, 32, 238-262.

Bark, R.H., B.G. Colby, and F. Dominguez, 2010: Snow days? Snowmaking adaptation and the future of low latitude, high elevation skiing in Arizona, USA. Climatic Change, 102(3-4), 467-491.

Barr, R., S. Fankhauser, and K. Hamilton, 2010: Adaptation investments: a resource allocation framework. Mitigation and Adaptation Strategies for Global Change, 15(8), 843-858.

Barnett, J. and J. Campbell, 2009: Climate Change and Small Island States: Power, Knowledge and the South Pacific. Earthscan, London, UK, 232 pp.

Barnett, J. and S. O'Neill, 2010: Maladaptation. Global Environmental Change, 20, 211-213.

Barnett, J., S. Lambert, and I. Fry, 2009: The hazards of indicators: insights from the environment vulnerability index. Annals of the Association of American Geographers, 98(1), 102-119.

Bates, B.C., Z.W. Kundzewicz, S. Wu, and J.P. Palutikof (eds.), 2008: Climate Change and Water. Intergovernmental Panel on Climate Change (IPCC) Technical Paper VI, IPCC Secretariat, Geneva, Switzerland, 200 pp.

Baum, S.D. and W.E. Easterling, 2010: Space-time discounting in climate change adaptation. Mitigation and Adaptation Strategies for Global Change, 15, 591 609. 
Beard, L.M., J.B. Cardell, I. Dobson, F. Galvan, D. Hawkins, W. Jewell, M. Kezunovic T.J. Overbye, P.K. Sen, and D.J. Tylavsky, 2010: Key technical challenges for the electric power industry and climate change. IEEE Transactions on Energy Conversion, 25(2), 465-473.

Becker, A., S. Inoue, M. Fischer, and B. Schwegler, 2012: Climate change impacts on international seaports: knowledge, perceptions, and planning efforts among port administrators. Climatic Change, 110(1-2), 5-29.

Becker, N., D. Lavee, and D. Katz, 2010: Desalination and alternative water-shortage mitigation options in Israel: a comparative cost analysis. Journal of Water Resource and Protection, 2, 1042-1056.

Beckerman, W. and C. Hepburn, 2007: Ethics of the discount rate in the Stern Review on the economics of climate change. World Economics, 8(1), 187-210.

Begum, R.A. and J.J. Pereira, 2013: The awareness, perception and motivational analysis of climate change and business perspectives in Malaysia. Mitigation and Adaptation Strategies for Global Change, link.springer.com/article/10.1007 Is11027-013-9495-6.

Benito, B., J. Lorite, and J. Peñas, 2011: Simulating potential effects of climatic warming on altitudinal patterns of key species in Mediterranean-alpine ecosystems. Climatic Change, 108(3), 471-483.

Berkes, F., 2008: Sacred Ecology. Routledge, Abingdon, UK and New York, NY, USA, $363 \mathrm{pp}$.

Berkes, F. and D. Armitage, 2010: Co-management institutions, knowledge, and learning: adapting to change in the Arctic. Études/Inuit/Studies, 34(1), 109-131.

Berkhout, F., 2012: Adaptation to climate change by organizations. Wiley Interdisciplinary Reviews: Climate Change, 3(1), 91-106.

Berkhout, F., J. Hertin, and D. M. Gann, 2006: Learning to adapt: organisational adaptation to climate change impacts. Climatic Change, 78(1), 135-156.

Bern, C., J. Sniezek, G.M. Mathbor, M.S. Siddiqi, C. Ronsmans, A.M. Chowdhury, and E. Noji, 1993: Risk factors for mortality in the Bangladesh cyclone of 1991. Bulletin of the World Health Organization, 71(1), 73-78.

Bernazzani, P., B.A. Bradley, and J.J. Opperman, 2012: Integrating climate change into habitat conservation plans under the US Endangered Species Act. Environmental Management, 49(6), 1103-1114.

Berrang-Ford, L., J.D. Ford, and J. Paterson, 2011:Are we adapting to climate change? Global Environmental Change, 21, 25-33.

Berry, P., K.L. Clarke, M. Pajot, and D. Hutton, 2011: Chapter 14: Risk perception, health communication, and adaptation to the health impacts of climate change in Canada. In: Climate Change Adaptation in Developed Nations: From Theory to Practice [Ford, J.D. and L. Berrang-Ford (eds.)]. Advances in Global Change Research Series, Vol. 42, Springer, New York, NY, USA, pp. 205-219.

Bichard, E. and A. Kazmierczak, 2012: Are homeowners willing to adapt to and mitigate the effects of climate change? Climatic Change, 112(3-4), 633-654.

Bierbaum, R., J.B. Smith, A. Lee, M. Blair, L. Carter, F.S. Chapin III, P. Fleming, S. Ruffo, M. Stults, S. McNeeley, E. Wasley, and L. Verduzco, 2013: A comprehensive review of climate adaptation in the United States: more than before, but less than needed. Mitigation and Adaptation Strategies for Global Change, 18(3), 361-406.

Biesbroek, G.R., R.J. Swart, T.R. Carter, C. Cowan, T. Henrichs, H. Mela, M.D. Morecroft, and D. Rey, 2010: Europe adapts to climate change: comparing national adaptation strategies. Global Environmental Change, 20(3), 440-450.

Biesbroek, G.R., J. Klostermann, C. Termeer, and P. Kabat, 2011: Barriers to climate change adaptation in the Netherlands. Climate Law, 2(2), 181-199.

Biesbroek, G.R., J. Klostermann, C. Termeer, and P. Kabat, 2013a: On the nature of barriers to climate change adaptation. Regional Environmental Change, 13(5), 1119-1129.

Biesbroek, G.R., C.J. Termeer, J.E. Klostermann, and P. Kabat, 2013b: Analytical lenses on barriers in the governance of climate change adaptation. Mitigation and Adaptation Strategies for Global Change, doi:10.1007/s11027013-9457-z.

Bijlsma, L., C.N. Ehler, R.J.T. Klein, S.M. Kulshrestha, R.F. McLean, N. Mimura, R.J. Nicholls, L.A. Nurse, H. Pérez Nieto, E.Z. Stakhiv, R.K. Turner, and R.A. Warrick, 1996: Coastal zones and small islands. In: Climate Change 1995: Impacts, Adaptations and Mitigation of Climate Change: Scientific-Technical Analyses. Contribution of Working Group II to the Second Assessment Report of the Intergovernmental Panel on Climate Change [Watson, R.T., M.C. Zinyowera, and R.H. Moss (eds.)]. Cambridge University Press, Cambridge, UK, New York, NY, USA, and Melbourne, Australia, pp. 289-324.

Birkmann, J., M. Garschagen, F. Kraas, and Q. Nguyen, 2010: Adaptive urban governance: new challenges for the second generation of urban adaptation strategies to climate change. Sustainability Science, 5(2), 185-206.
Bisaro, A., S. Wolf, and J. Hinkel, 2010: Framing climate vulnerability and adaptation at multiple levels: addressing climate risks or institutional barriers in Lesotho? Climate and Development, 2(2), 161-175.

Blennow, K. and J. Persson, 2009: Climate change: motivation for taking measure to adapt. Global Environmental Change, 19(1), 100-104.

Bosello, F., C. Carraro, and E. De Cian, 2010: Climate policy and the optimal balance between mitigation, adaptation and unavoided damage. Climate Change Economics, 1(02), 71-92.

Botzen, W., J. Aerts, and J. van den Bergh, 2009: Willingness of homeowners to mitigate climate risk through insurance. Ecological Economics, 68(8-9), 22652277.

Botzen, W., J. van den Bergh, and L. Bouwer, 2010: Climate change and increased risk for the insurance sector: a global perspective and an assessment for the Netherlands. Natural Hazards, 52(3), 577-598.

Bourgeon, J., W. Easter, and R. Smith, 2008: Water markets and third-party effects. American Journal of Agricultural Economics, 90(4), 902-917.

Bouwer, L.M., 2011: Have disaster losses increased due to anthropogenic climate change? Bulletin of the American Meteorological Society, 92(1), 39-46.

Bouwer, L.M. and J.C. Aerts, 2006: Financing climate change adaptation. Disasters, 30(1), 49-63.

Bowen, A., S. Cochrane, and S. Fankhauser, 2012: Climate change, adaptation and economic growth. Climatic Change, 113(2), 95-106.

Boxall, A., A. Hardy, S. Beulke, T. Boucard, L. Burgin, P. Falloon, P. Haygarth, T. Hutchinson, R. Kovats, G. Leonardi, L. Levy, G. Nichols, S. Parsons, L. Potts, D. Stone, E. Topp, D. Turley, K. Walsh, E. Wellington, and R. Williams, 2009: Impacts of climate change on indirect human exposure to pathogens and chemicals from agriculture. Environmental Health Perspectives, 117(4), 508-514.

Bradshaw, W.E. and C.M. Holzapfel, 2006: Evolutionary response to rapid climate change. Science, 312, 1477-1478.

Breakwell, G.M., 2010: Models of risk construction: some applications to climate change. Wiley Interdisciplinary Reviews: Climate Change, 1(6), 857-870.

Briske, D.D., R.A. Washington-Allen, C.R. Johnson, J.A. Lockwood, D.R. Lockwood, T.K. Stringham, and H.H. Shugart, 2010: Catastrophic thresholds: a synthesis of concepts, perspectives, and applications. Ecology and Society, 15(3), 37, www.ecologyandsociety.org/vol15/iss3/art37/.

Brisley, R., J. Welstead, R. Hindle, and J. Paavola, 2012: Socially Just Adaptation to Climate Change. Joseph Roundtree Foundation, York, UK, 118 pp.

Brook, B.W., N.S. Sodhi, and J.A. Bradshaw, 2008: Synergies among extinction drivers under global change. Trends in Ecology \& Evolution, 23(8), 453-460.

Brouwer, S., T. Rayner, and D. Huitema, 2013: Mainstreaming climate policy. The case of climate adaptation and the implementation of EU water policy. Environment and Planning C, 31(1), 134-153.

Brown, D., 2011: Making the linkages between climate change adaptation and spatial planning in Malawi. Environmental Science \& Policy, 14(8), 940949.

Brown, T., L. Budd, M. Bell, and H. Rendell, 2011: The local impact of global climate change: reporting on landscape transformation and threatened identity in the English regional newspaper press. Public Understanding of Science, 20,658673.

Brunsma, D.L., D. Overfelt, and J.S. Picou, 2010: The Sociology of Katrina: Perspectives on a Modern Catastrophe. Brown and Littlefield, Lanham, MD, USA, 365 pp.

Bryan, E., T.T. Deressa, G.A. Gbetibouo, and C. Ringler, 2009: Adaptation to climate change in Ethiopia and South Africa: options and constraints. Environmental Science \& Policy, 12(4), 413-426.

Bulkeley, H. and V. Castán Broto, 2012: Government by experiment? Global cities and the governing of climate change. Transactions of the Institute of British Geographers, 38(3), 361-375.

Buob, S. and G. Stephan, 2013: On the incentive compatibility of funding adaptation. Climate Change Economics, 04(2), 1350005, doi:10.1142/\$20100078135000 $5 X$.

Bulleri, F. and M.G. Chapman, 2010: The introduction of coastal infrastructure as a driver of change in marine environments. Journal of Applied Ecology, 47, 2635.

Burch, S., 2010: Transforming barriers into enablers of action on climate change: insights from three municipal case studies in British Columbia, Canada. Global Environmental Change, 20(2), 287-297.

Burton, I. 2008: Beyond Borders: The Need for Strategic Global Adaptation. Sustainable Development Opinion Series, Policy Briefing December 2008, International Institute for Environment and Development (IIED), London, UK, 2 pp. 
Burton, I., O.P. Dube, D. Campbell-Lendrum, I. Davis, R.J.T. Klein, J. Linnerooth-Bayer, A. Sanghi, and F. Toth, 2012: Managing the risks: international level and integration across scales. In: Managing the Risks of Extreme Events and Disasters to Advance Climate Change Adaptation. A Special Report of Working Groups I and II of the Intergovernmental Panel on Climate Change [Field, C.B., V. Barros, T.F. Stocker, D. Qin, D.J. Dokken, K.L. Ebi, M.D. Mastrandrea, K.J. Mach, G.-K. Plattner, S.K. Allen, M. Tignor, and P.M. Midgley (eds.)]. Cambridge University Press, Cambridge, UK and New York, NY, USA, pp. 393-435.

Butzer, K.W., 2012: Collapse, environment, and society. Proceedings of the National Academy of Sciences of the United States of America, 109(10), 3632-3639.

Butzer, K.W. and G.H. Endfield, 2012: Critical perspectives on historical collapse. Proceedings of the National Academy of Sciences of the United States of America, 109(10), 3628-3631.

Byg, A. and J. Salick, 2009: Local perspectives on a global phenomenon: climate change in Eastern Tibetan villages. Global Environmental Change, 19, 156166.

Cabral, J.S., F. Jeltsch, W. Thuiller, S. Higgins, G.F. Midgley, A.G. Rebelo, M. Rouget, and F.M. Schurr, 2013: Impacts of past habitat loss and future climate change on the range dynamics of South African Proteaceae. Diversity and Distributions, 19(4), 363-376.

Carlsson-Kanyama, A., H. Carlsen, and K.H. Dreborg, 2013: Barriers in municipal climate change adaptation: results from case studies using backcasting. Futures, 49, 9-21.

Cardona, O.D., M.K. van Aalst, J. Birkmann, M. Fordham, G. McGregor, R. Perez, R.S. Pulwarty, E.L.F. Schipper, and B.T. Sinh, 2012: Determinants of risk: exposure and vulnerability. In: Managing the Risks of Extreme Events and Disasters to Advance Climate Change Adaptation. A Special Report of Working Groups I and II of the Intergovernmental Panel on Climate Change [Field, C.B., V. Barros, T.F. Stocker, D. Qin, D.J. Dokken, K.L. Ebi, M.D. Mastrandrea, K.J. Mach, G.-K. Plattner, S.K. Allen, M. Tignor, and P.M. Midgley (eds.)]. Cambridge University Press, Cambridge, UK and New York, NY, USA, pp. 65-108.

Carmin, J., N. Nadkarni, and C. Rhie, 2012: Progress and Challenges in Urban Climate Adaptation Planning: Results of a Global Survey. Massachusetts Institute of Technology (MIT), Department of Urban Studies and Planning, Cambridge, MA, USA, $30 \mathrm{pp}$.

Cash, D.W., W.N. Adger, F. Berkes, P. Garden, L. Lebel, P. Olsson, L. Pritchard, and 0. Young, 2006: Scale and cross-scale dynamics: governance and information in a multilevel world. Ecology and Society, 11(2), 8, www.ecologyandsociety.org/ vol11/iss2/art8/.

CBD, 2009: Connecting Biodiversity and Climate Change Mitigation and Adaptation: Report of the Second Ad Hoc Technical Expert Group on Biodiversity and Climate. CBD Technical Series No. 41, Secretariat of the Convention on Biological Diversity (CBD), Montreal, QC, Canada, $126 \mathrm{pp}$.

CCSP, 2009: Thresholds of Climate Change in Ecosystems. Synthesis and Assessment Product 4.2, Report by the U.S. Global Change Research Program and the Subcommittee on Global Change Research [Fagre, D.B., C.W. Charles, C.D. Allen, C. Birkeland, F.S. Chapin III, P.M. Groffman, G.R. Guntenspergen, A.K. Knapp A.D. McGuire, P.J. Mulholland, D.P.C. Peters, D.D. Roby, and G. Sugihara (authors)]. U.S. Geological Survey (USGS), Reston, VA, USA, 156 pp.

CDP, 2012: Insights into Climate Change Adaptation by UK Companies. Commissioned by the Department for Environment, Food and Rural Affairs (DEFRA), Carbon Disclosure Project (CDP), London, UK, 55 pp.

Charmantier, A., R.H. McCleery, L.R. Cole, C. Perrins, L.E.B. Kruuk, and B.C. Sheldon, 2008: Adaptive phenotypic plasticity to climate change in a wild bird population. Science, 320, 1024-1026.

Chapin III, F.S., S.R. Carpenter, G.P. Kofinas, C. Folke, N. Abel, W.C. Clark, P. Olsson, D.M. Stafford Smith, B. Walker, O.R. Young, F. Berkes, R. Biggs, J.M. Grove, R.L. Naylor, E. Pinkerton, W. Steffen, and F.J. Swanson, 2010: Ecosystem stewardship: sustainability strategies for a rapidly changing planet. Trends in Ecology \& Evolution, 25(4), 241-249.

Chen, A. and W.C. Chang, 2012: Human health and thermal comfort of office workers in Singapore. Building and Environment, 58, 172-178.

Chen, D., X. Ma, H. Mu, and P. Li, 2010: The inequality of natural resources consumption and its relationship with the social development level based on the ecological footprint and the HDI. Journal of Environmental Assessment Policy and Management, 12, 69-86.

Chen, I.C., J.K. Hill, R. Ohlemüller, D.B. Roy, and C.D. Thomas, 2011: Rapid range shifts of species associated with high levels of climate warming. Science, 333(6045), 1024-1026.
Chhetri, N.B., W.E. Easterling, A. Terando, and L. Mearns, 2010: Modeling path dependence in agricultural adaptation to climate variability and change. Annals of the Association of American Geographers, 100(4), 894-907.

Chhetri, N., P. Chaudhary, P.R. Tiwari, and R.B. Yadaw, 2012: Institutional and technological innovation: Understanding agricultural adaptation to climate change in Nepal. Applied Geography, 33, 142-150.

Chiew, F.H.S., W.J. Young, W. Cai, and J. Teng, 2011: Current drought and future hydroclimate projections in southeast Australia and implications for water resources management. Stochastic Environmental Research and Risk Assessment, 25(4), 601-612.

Chin, A., P.M. Kyne, T.I. Walker, and R.B. McAuley, 2010: An integrated risk assessment for climate change: analysing the vulnerability of sharks and rays on Australia's Great Barrier Reef. Global Change Biology, 16(7), 1936-1953.

Chowdhury, A.M.R., A.U. Bhuyia, A.Y. Choudhury, and R. Sen, 1993: The Bangladesh cyclone of 1991: why so many people died. Disasters, 17(4), 291-304.

Christensen, O.B., C.M. Goodess, I. Harris, and P. Watkiss, 2011: European and global climate change projections: discussion of climate change model outputs, scenarios and uncertainty in the EC RTD ClimateCost Project. In: The Climate Cost Project, Final Report. Volume 1: Europe [Watkiss, P. (ed.)]. Technical Policy Briefing Note 01, Stockholm Environment Institute (SEI), Stockholm, Sweden.

Clar, C., A. Prutsch, and R. Steurer, 2013: Barriers and guidelines for public policies on climate change adaptation: a missed opportunity of scientific knowledgebrokerage. Natural Resources Forum, 37(1), 1-18.

Clark, D, D. Lee, M. Freeman, and S. Clark, 2008: Polar bear conservation in Canada: defining the policy problems. Arctic, 61(4), 347-360.

Clark, J.S., D.M. Bell, M.H. Hersh, and L. Nichols, 2011: Climate change vulnerability of forest biodiversity: climate and resource tracking of demographic rates. Global Change Biology, 17, 1834-1849.

Colwell, R.K., G. Brehm, C.L. Cardelús, A.C. Gilman, and J.T. Longino, 2008: Global warming, elevational range shifts, and lowland biotic attrition in the wet tropics. Science, 322(5899), 258-261.

Commonwealth of Australia, 2010: Securing our Water Future. Australian Government, Department of the Environment, Water, Heritage and the Arts, Canberra, ACT, Australia, $24 \mathrm{pp}$.

Connell, D. and R.Q. Grafton, 2011:Water reform in the Murray-Darling Basin. Water Resources Research, 47, W00G03, doi:10.1029/2010WR009820.

Côté, I.M. and E.S. Darling, 2010: Rethinking ecosystem resilience in the face of climate change. PLoS Biology, 8(7), e1000438, doi:10.1371/journal.pbio.1000438.

Craig, R.K., 2010: "Stationarity is dead" - long live transformation: five principles for climate change adaptation law. Harvard Environmental Law Review, 34, 9-73.

Crespo Cuaresma, J., J. Hlouskova, and M. Obersteiner, 2008: Natural disasters as creative destruction? Evidence from developing countries. Economic Inquiry, 46, 214-226.

Crowley, P., 2011: Interpreting 'dangerous' in the United Nations framework convention on climate change and the human rights of Inuit. Regional Environmental Change, 11(1), 265-274.

Crutzen, P.J., 2002: Geology of mankind. Nature, 415(6867), 23.

Cutter, S.L. and C.T. Emrich, 2006: Moral hazard, social catastrophe: the changing face of vulnerability along the hurricane coasts. The Annals of the American Academy of Political and Social Science, 604(1), 102-112.

Cutter, S., B. Osman-Elasha, J. Campbell, S. Cheong, S. McCormick, R. Pulwarty, S. Supratid, and G. Ziervogel, 2012: Managing the risks from climate extremes at the local level. In: Managing the Risks of Extreme Events and Disasters to Advance Climate Change Adaptation. A Special Report of Working Groups I and II of the Intergovernmental Panel on Climate Change [Field, C.B., V. Barros, T.F. Stocker, D. Qin, D.J. Dokken, K.L. Ebi, M.D. Mastrandrea, K.J. Mach, G.-K. Plattner, S.K. Allen, M. Tignor, and P.M. Midgley (eds.)]. Cambridge University Press, Cambridge, UK and New York, NY, USA, pp. 291-338.

Dale, V.H., R.A. Efroymson, and K.L. Kline, 2011: The land use-climate change-energy nexus. Landscape Ecology, 26(6), 755-773.

Das, S. and J.R. Vincent, 2009: Mangroves protected villages and reduced death toll during Indian super cyclone. Proceedings of the National Academies of Sciences of the United States of America, 106(18), 7357-7360.

Dasgupta, S., M. Huq, Z. Khan, M. Ahmed, N. Mukherjee, M. Khan, and K. Pandey, 2010: Vulnerability of Bangladesh to Cyclones in a Changing Climate: Potential Damages and Adaptation Cost. Policy Research Working Paper No. 5280, Environment and Energy Team, Development Research Group, The International Bank for Reconstruction and Development / The World Bank, Washington, DC, USA, 54 pp. 
de Bruin, K. and R.B. Dellink, 2011: How harmful are restrictions on adapting to climate change? Global Environmental Change, 21(1), 34-45.

de Bruin, K., R.B. Dellink, and S. Agrawala, 2009a: Economic Aspects of Adaptation to Climate Change: Integrated Assessment Modelling of Adaptation Costs and Benefits. OECD Publishing, Paris, France, 48 pp.

de Bruin, K., R.B. Dellink, A. Ruijs, L. Bolwidt, A. van Buuren, J. Graveland, R.S. de Groot, P.J. Kuikman, S. Reinhard, R.P. Roetter, V.C. Tassone, A. Verhagen, and E.C. van lerland, 2009b: Adapting to climate change in The Netherlands: an inventory of climate adaptation options and ranking of alternatives. Climatic Change, 95(1-2), 23-45.

Delgado, J.A., P. M. Groffman, M.A. Nearing, T. Goddard, D. Reicosky, R. Lal, and P. Salon, 2011: Conservation practices to mitigate and adapt to climate change. Journal of Soil and Water Conservation, 66(4), 118A-129A.

Dellink, R., M. den Elzen, H. Aiking, E. Bergsma, F. Berkhout, T. Dekker, and J. Gupta, 2009: Sharing the burden of adaptation financing. Global Environmental Change, 19, 411-421.

deMenocal, P.B., 2001: Cultural responses to climate change during the late Holocene. Science, 292(5517), 667-673.

Denton, F., 2010: Financing adaptation in least developed countries in West Africa: is finance the 'real deal'? Climate Policy, 10(6), 655-671.

Deressa, T.T., R.M. Hassan, C. Ringler, T. Alemu, and M. Yesuf, 2009: Determinants of farmers' choice of adaptation methods to climate change in the Nile Basin of Ethiopia. Global Environmental Change, 19(2), 248-255.

Deressa, T.T., R.M. Hassan, and C. Ringler, 2011: Perception of and adaptation to climate change by farmers in the Nile basin of Ethiopia. Journal of Agricultural Science, 149, 23-31.

Dessai, S., M. Hulme, R. Lempert, and R.A. Pielke Jr., 2009: Do we need more precise and accurate predictions in order to adapt to a changing climate. Eos, 90(13), 111-112.

Devine-Wright, P., 2009: Rethinking nimbyism: the role of place attachment and place identity in explaining place-protective action. Journal of Community and Applied Social Psychology, 19, 426-441.

Diamond, J.D., 2005: Collapse: How Societies Choose to Fail or Succeed. Penguin Books, New York, NY, USA, 575 pp.

Diaz, R. and R. Rosenberg, 2008: Spreading dead zones and consequences for marine ecosystems. Science, 321(5891), 926-929.

Baldassarre, G., A. Montanari, H. Lins, D. Koutsoyiannis, L. Brandimarte, and G. Blöschl, 2010: Flood fatalities in Africa: from diagnosis to mitigation. Geophysical Research Letters, 37(22), doi:10.1029/2010GL045467.

Dirnböck, T., F. Essl, and W. Rabitsch, 2011: Disproportional risk for habitat loss of high-altitude endemic species under climate change. Global Change Biology, 17(2), 990-996.

Dobes, L., 2008: Getting real about adapting to climate change: using 'real options' to address the uncertainties. Agenda, 15, 55-72.

Dolcinar, S., A. Hurlimann, and B. Grun, 2011: What affects public acceptance of recycled and desalinated water? Water Research, 45(2), 933-943.

Donelson, J.M., P.L. Munday, M.I. McCormick, and C.R. Pitcher, 2011: Rapid transgenerational acclimation of a tropical reef fish to climate change. Nature Climate Change, 2(1), 30-32.

Doney, S.C., M. Ruckelshaus, J.E. Duffy, J.P. Barry, F. Chan, C.A. English, H.M. Galindo, J.M. Grebmeier, A.B. Hollowed, N. Knowlton, J. Polovina, N.N. Rabalais, W.J. Sydeman, and L.D. Talley, 2012: Climate change impacts on marine ecosystems. Marine Science, 4, 11-37.

Donohew, Z. 2008: Property rights and western United States water markets. The Australian Journal of Agricultural and Resource Economics, 53, 85-103.

Dovers, S., 2010: Normalizing adaptation. Global Environmental Change, 19, 4-6.

Dovers, S. and R. Hezri, 2010: Institutions and policy processes: the means to the ends of adaptation. Wiley Interdisciplinary Reviews: Climate Change, 1(2), 212231.

Dow, K., F. Berkhout, and B.L. Preston, 2013a: Limits to adaptation: a risk approach. Current Opinion in Environmental Sustainability, 5(3-4), 384-391.

Dow, K., F. Berkhout, B.L. Preston, R.J.T. Klein, G. Midgley, and R. Shaw, 2013b: Limits to adaptation. Nature Climate Change, 3, 305-307.

Dryden-Cripton, S., J. Smithers, R. de Loë, and R. Kreutzwiser, 2007: An Evaluation of Options for Responding to Agricultural Droughts and Water Shortages in Canada. Final Report, Prepared by the Guelph Water Management Group for Natural Resources Canada, Climate Change Impacts and Adaptation Program, Guelph Water Management Group, University of Guelph, Guelph, ON, Canada, $68 \mathrm{pp}$.
Drysdale, R., G. Zanchetta, J. Hellstrom, R. Maas, A. Fallick, M. Pickett, I. Cartwright, and L. Piccini, 2006: Late Holocene drought responsible for the collapse of Old World civilizations is recorded in an Italian cave flowstone. Geology, 34(2), 101-104.

Dugmore, A.J., C. Keller, T.H. McGovern, A.F. Casely, and K. Smiarowski, 2009: Norse Greenland settlement and limits to adaptation. In: Adapting to Climate Change: Thresholds, Values, Governance [Adger, W.N., I. Lorenzoni, and K.L. O'Brien (eds.)]. Cambridge University Press, Cambridge, UK, pp. 96-113.

Dukes, J.S., J. Pontius, D. Orwig, J.R. Garnas, V.L. Rodgers, N. Brazee, and M. Ayres, 2009: Responses of insect pests, pathogens, and invasive plant species to climate change in the forests of northeastern North America: what can we predict? Canadian Journal of Forest Research, 39(2), 231-248.

Dugmore, A.J., T.H. McGovern, O. Vesteinsson, J. Arneborg, R. Streeter, and C. Keller, 2012: Cultural adaptation, compounding vulnerabilities and conjunctures in Norse Greenland. Proceedings of the National Academy of Sciences of the United States of America, 109(10), 3658-3663.

Dunlop, M. and P. Brown, 2008: Implications of Climate Change for Australia's National Reserve System: A Preliminary Assessment. A Report to the Australian Government, Department of Climate Change and the Department of the Environment, Water, Heritage and the Arts, Department of Climate Change, Canberra, ACT, Australia, $188 \mathrm{pp}$.

Dunning, N.P., T.P. Beach, and S. Luzzadder-Beach, 2012: Kax and kol: collapse and resilience in lowland Maya civilization. Proceedings of the National Academy of Sciences of the United States of America, 109(10), 3652-3657.

Duru, M., B. Felten, J.P. Theau, and G. Martin, 2012: A modelling and participatory approach for enhancing learning about adaptation of grassland-based livestock systems to climate change. Regional Environmental Change, 12(4), 739-750.

Eakin, H., A. Winkels, and J. Sendzimir, 2009: Nested vulnerability: exploring crossscale linkages and vulnerability teleconnections in Mexican and Vietnamese coffee systems. Environmental Science \& Policy, 12(4), 398-412.

EBI, 2013: Emerging Business Opportunities in the Climate Change Adaptation Industry. EBI Report 4800, Climate Change Business Journal, A Climate Change Industry Business Segment Review by Environmental Business International (EBI), Inc., San Diego, CA, USA, 6 pp.

Ebi, K. and J. Semenza, 2008: Community-based adaptation to the health impacts of climate change. American Journal of Preventive Medicine, 35(5), 501-507.

Ebi, K.L., J. Balbus, P.L. Kinney, E. Lipp, D. Mills, M.S. O'Neill, and M.L. Wilson, 2009: US funding is insufficient to address the human health impacts of and public health responses to climate variability and change. Environmental Health Perspectives, 117(6), 857-862

Ebi, K.L., J. Padgham, M. Doumbia, J. Smith, T. Butt, and B. McCarl, 2011: Smallholders adaptation to climate change in Mali. Climatic Change, 108(3), 423-436.

Ebi, K.L., S. Hallegatte, T. Kram, N.W. Arnell, T.R. Carter, J. Edmonds, E. Kriegler, R. Mathur, B. O'Neill, K. Riahi, H. Winkler, D.P. Van Vuuren, and T. Zwickel, 2013: A new scenario framework for climate change research: background, process, and future directions. Climatic Change, doi:10.1007/s10584-0130912-3.

Edwards, B., M. Gray, and B. Hunter, 2009: A sunburnt country: the economic and financial impact of drought on rural and regional families in Australia in an era of climate change. Australian Journal of Labour Economics, 12(1), 109-131.

Edvardsson-Bjornberg, K. and S.O. Hansson, 2011: Five areas of value judgement in local adaptation to climate change. Local Government Studies, 37(6), 671687.

Eisenack, K. and R. Stecker; 2012: A framework for analyzing climate change adaptations as actions. Mitigation and Adaptation Strategies for Global Change, 17, 243-260.

Eisenack, K., R. Stecker, D. Reckien, and E. Hoffmann, 2012: Adaptation to climate change in the transport sector: a review of actions and actors. Mitigation and Adaptation Strategies for Global Change, 17(5), 451-469.

Endfield, G.H., 2012: The resilience and adaptive capacity of social-environmental systems in colonial Mexico. Proceedings of the National Academy of Sciences of the United States of America, 109(10), 3676-3681.

Engle, N.L. and M.C. Lemos, 2010: Unpacking governance: building adaptive capacity to climate change of river basins in Brazil. Global Environmental Change, 20(1), 4-13.

Engler, R., C.F. Randin, P. Vittoz, T. Czáka, M. Beniston, N.E. Zimmermann, and A. Guisan, 2009: Predicting future distributions of mountain plants under climate change: does dispersal capacity matter? Ecography, 32(1), 34-45. 
Eriksen, S., P. Aldunce, C.S. Bahinipati, R.D.A. Martins, J.I. Molefe, C. Nhemachena, K. O'Brien, F. Olorunfemi, J. Park, L. Sygna, and K. Ulsrud, 2011: When not every response to climate change is a good one: identifying principles for sustainable adaptation. Climate and Development, 3(1), 7-20.

EC, 2013: Guidelines on Developing Adaptation Strategies. Brussels, 16.4.2013, SWD(2013), 134 final, Commission Staff Working Document accompanying, "Communication from the Commission to the European Parliament, the Council, the European Economic and Social Committee and the Committee of the Regions," an EU Strategy on adaptation to climate change, European Commission (EC), Brussels, Belgium, $54 \mathrm{pp}$.

EPA, 2009: Synthesis of Adaptation Options for Coastal Areas. EPA 430-F-08-024, Climate Ready Estuaries Program, U.S. Environmental Protection Agency (EPA), Washington, DC, USA, $25 \mathrm{pp}$.

Fankhauser, S. and R. Soare, 2013: An economic approach to adaptation: illustrations from Europe. Climatic Change, 118, 367-379.

FAO, 2011: The Food Security in the World. How Does Food Price Volatility Affect Domestic Economies and Food Security? Food and Agriculture Organisation of the United Nations (FAO), Rome, Italy, $52 \mathrm{pp}$.

FA0, 2013: Climate-Smart Agriculture Sourcebook. Food and Agriculture Organization of the United Nations (FAO), Rome, Italy, $557 \mathrm{pp}$.

Fatti, C.E. and Z. Patel, 2013: Perceptions and responses to urban flood risk: implications for climate governance in the South. Applied Geography, 36, 13-22.

Faysse, N., J.D. Rinaudo, S. Bento, A. Richard-Ferroudji, M. Errahj, M. Varanda, A. Imache, M. Dionnet, D. Rollin, P. Garin, M. Kuper, L. Maton, and M. Montginoul, 2012: Participatory analysis for adaptation to climate change in Mediterranean agricultural systems: possible choices in process design. Regional Environmental Change, doi:10.1007/s10113-012-0362-x.

Fedoroff, N.V., D.S. Battisti, R.N. Beachy, P.J.M. Cooper, D.A. Fischhoff, C.N. Hodges, V.C. Knauf, D. Lobell, B.J. Mazur, D. Molden, M.P. Reynolds, P.C. Ronald, M.W. Rosegrant, P.A. Sanchez, A. Vonshak, and J.K. Zhu, 2010: Radically rethinking agriculture for the 21st century. Science, 327, 833-834.

Feeley, K.J. and M.R. Silman, 2010: Land-use and climate change effects on population size and extinction risk of Andean plants. Global Change Biology, 16(12), 32153222.

Feeley, K.J., E.M. Rehm, and B. Machovina, 2012: Perspective: the responses of tropical forest species to global climate change: acclimate, adapt, migrate, or go extinct? Frontiers of Biogeography, 4(2), 69-84.

Felgenhauer, T. and K.C. de Bruin, 2009: The optimal paths of climate change mitigation and adaptation under certainty and uncertainty. International Journal of Global Warming, 1(1-3), 66-88.

Feng, S., A.B. Krueger, and M. Oppenheimer, 2010: Linkages among climate change, crop yields and Mexico-US cross-border migration. Proceedings of the National Academy of Sciences of the United States of America, 107(32), 14257-14262.

Field, C.B., L.D. Mortsch, M. Brklacich, D.L. Forbes, P. Kovacs, J.A. Patz, S.W. Running, and M.J. Scott, 2007: North America. In: Climate Change 2007: Impacts, Adaptation and Vulnerability. Contribution of Working Group II to the Fourth Assessment Report of the Intergovernmental Panel on Climate Change [Parry, M.L., O.F. Canziani, J.P. Palutikof, P.J. van der Linden, and C.E. Hanson (eds.)] Cambridge University Press, Cambridge, UK and New York, NY, USA, pp. 617-652.

Fisher, B.S., N. Nakicenovic, K. Alfsen, J. Corfee Morlot, F. de la Chesnaye, J.-C. Hourcade, K. Jiang, M. Kainuma, E. La Rovere, A. Matysek, A. Rana, K. Riahi, R. Richels, S. Rose, D. van Vuuren, and R. Warren, 2007: Issues related to mitigation in the longterm context. In: Climate Change 2007: Impacts, Adaptation and Vulnerability. Contribution of Working Group II to the Fourth Assessment Report of the Intergovernmental Panel on Climate Change [Parry, M.L., O.F. Canziani, J.P. Palutikof, P.J. van der Linden, and C.E. Hanson (eds.)]. Cambridge University Press, Cambridge, UK and New York, NY, USA, pp. 169-250.

Fiksel, J., 2006: Sustainability and resilience: towards a systems approach. Sustainability Science Practice and Policy, 2(2), 14-21.

Flåm, K.H. and J.B. Skjærseth, 2009: Does adequate financing exist for adaptation in developing countries? Climate Policy, 9(1), 109-114.

Fleischer, A., R. Mendelsohn, and A. Dinar, 2011: Bundling agricultural technologies to adapt to climate change. Technological Forecasting and Social Change, 78(6), 982-990

Foale, S.J., 2008: Conserving Melanesia's coral reef heritage in the face of climate change. Historic Environment 18, 30-36.

Ford, J.D., 2009: Dangerous climate change and the importance of adaptation for the Arctic's Inuit population. Environmental Research Letters, 4(2), 024006, doi:10.1088/1748-9326/4/2/024006.
Ford, J.D., J. MacDonald, B. Smit, and J. Wandel, 2006: Vulnerability to climate change in Igloolik, Nunavut: what we can learn from the past and present. Polar Record, 42(2), 1-12.

Ford, J.D., T. Pearce, F. Duerden, C. Furgal, and B. Smit, 2010: Climate change policy responses for Canada's Inuit population: the importance of and opportunities for adaptation. Global Environmental Change, 20, 177-191.

Ford, J.D., L. Berrang-Ford, and J. Paterson, 2011: A systematic review of observed climate change adaptation in developed nations. A letter. Climatic Change, 160, 237-336.

Foresight, 2011: Migration and Global Environmental Change: Future Challenges and Opportunities. Final Project Report, The UK Government Office for Science, London, UK, $237 \mathrm{pp}$.

Fosu-Mensah, B.Y., P.L.G. Vlek, and D.S. MacCarthy, 2012: Farmers' perception and adaptation to climate change: a case study of Sekyedumase district in Ghana. Environment, Development and Sustainability, 14, 495-505.

Frank, S., C. Fürst, L. Koschke, and F. Makeschin, 2011: A contribution toward the transfer of the ecosystem service concept to landscape planning using landscape metrics. Ecological Indicators, 21, 30-38.

Fresque-Baxter, J.A. and D. Armitage, 2012: Place identity and climate change adaptation: a synthesis and framework for understanding. Wiley Interdisciplinary Reviews: Climate Change, 3, 251-266.

Fuller, S. and H. Bulkeley, 2012: Changing countries, changing climates: achieving thermal comfort through adaptation in everyday activities. Area, 45(1), 63-69.

Fünfgeld, H. and D. McEvoy, 2011: Framing Climate Change Adaptation in Policy and Practice. Working Paper 1, Victorian Center for Climate Change Adaptation Research, Melbourne, VIC, Australia, 65 pp.

Fung, F., A. Lopez, and M. New, 2011: Water availability in $+2^{\circ} \mathrm{C}$ and $+4^{\circ} \mathrm{C}$ worlds. Philosophical Transactions of the Royal Society A, 369(1934), 99-116.

Füssel, H.M., 2006: Reducing the risk of a collapse of the Atlantic thermohaline circulation: a comment. The Integrated Assessment Journal, 6(3), 51-58.

Füssel, H.M., 2008: Assessing adaptation to the health risks of climate change: what guidance can existing frameworks provide? International Journal of Environmental Health Research, 18(1), 37-63.

Füssel, H., 2009: Ranking of national-level adaptation options. An editorial comment. Climatic Change, 95(1-2), 47-51.

Füssel, H., 2010: How inequitable is the global distribution of responsibility, capability, and vulnerability to climate change: a comprehensive indicatorbased assessment. Global Environmental Change, 20(4), 597-611.

Füssel, H. and R.J.T. Klein, 2006: Climate change vulnerability assessments: an evolution of conceptual thinking. Climatic Change, 75(3), 301-329.

Gale, M.K., S.G. Hinch, E.J. Eliason, S.J. Cooke, and D.A, Patterson, 2011: Physiological impairment of adult sockeye salmon in fresh water after simulated captureand-release across a range of temperatures. Fisheries Research, 112(1), 85-95.

Gall, M., K.A. Borden, C.T. Emrich, and S.L. Cutter, 2011: The unsustainable trend of natural hazard losses in the United States. Sustainability, 3, 2157-2181.

Gardiner, S.M., 2006: A perfect moral storm: climate change, intergenerational ethics and the problem of moral corruption. Environmental Values, 15, 397-413.

Gardiner, S.M., 2010: A perfect moral storm. Climate change, intergenerational ethics, and the problem of corruption. In: Climate Ethics: Essential Readings [Gardiner, S.M., S. Caney, D. Jamieson, and H. Shue (eds.)]. Oxford University Press, Oxford, UK, pp. 87-100.

Gardner, J., R. Parsons, and G. Paxton, 2010: Adaptation Benchmarking Survey: Initial Report. CSIRO Climate Adaptation Flagship Working Paper No. 4, The Commonwealth Scientific and Industrial Research Organisation (CSIRO), Clayton, South VIC, Australia, 58 pp.

Garfi, M., L. Ferrer-Martí, A. Bonoli, and S. Tondelli, 2011: Multi-criteria analysis for improving strategic environmental assessment of water programmes. A case study in semi-arid region of Brazil. Journal of Environmental Management, 92(3), 665-675.

Garnaut, R., 2011: The Garnaut Review 2011: Australia in the Global Response to Climate Change. Cambridge University Press, New York, NY, USA, 244 pp.

Garschagen, M., 2013: Resilience and organisational institutionalism from a crosscultural perspective: an exploration based on urban climate change adaptation in Vietnam. Natural Hazards, 67(1), 25-46.

Gedan, K.B., M.L. Kirwan, E. Wolanski, E.B. Barbier, and B.R. Silliman, 2011: The present and future role of coastal wetland vegetation in protecting shorelines: answering recent challenges to the paradigm. Climatic Change, 106, 7-29.

Gemenne, F., 2011: Climate-induced population displacements in a $4^{\circ} \mathrm{C}+$ world. Philosophical Transactions of the Royal Society A, 369(1934), 182-195. 
Gienapp, P., C. Teplitsky, J. Alho, J. Mills, and J. Merilä, 2008: Climate change and evolution: disentangling environmental and genetic responses. Molecular Ecology, 1(167), 167-178.

Gilman, E.L., J. Ellison, N.C. Duke, and C. Field, 2008: Threats to mangroves from climate change and adaptation options: a review. Aquatic Botany, 89(2), 237250.

GIZ, 2011a: Making Adaptation Count: Concepts and Options for Monitoring and Evaluation of Climate Change Adaptation. Deutsche Gesellschaft für Internationale Zusammenarbeit (GIZ) GmbH on behalf of Bundesministerium für wirtschaftliche Zusammenarbeit und Entwicklung (BMZ), GIZ, Eschborn, Germany, $92 \mathrm{pp}$.

GIZ, 2011b: Adaptation to Climate Change: New Findings, Methods and Solutions. Deutsche Gesellschaft für Internationale Zusammenarbeit (GIZ) $\mathrm{GmbH}$ on behalf of Bundesministerium für wirtschaftliche Zusammenarbeit und Entwicklung (BMZ), GIZ, Eschborn, Germany, 35 pp.

Gordon, J.S., J.B. Gruver, C.G. Flint, and A.E. Luloff, 2013: Perceptions of wildfire and landscape change in the Kenai Peninsula, Alaska. Environmental Management, 52(4), 807-820.

Gorman-Murray, A., 2010: An Australian feeling for snow: towards understanding cultural and emotional dimensions of climate change. Cultural Studies Review, $16,60-81$.

Goulden, M., D. Conway, and A. Persechino, 2009: Adaptation to climate change in international river basins in Africa: a review. Hydrological Sciences Journal, 54(5), 805-828.

Grasso, M. 2010. An ethical approach to climate adaptation finance. Global Environmental Change, 20, 74-81.

Gregory P.J., J.S.I. Ingram, and M. Brklacich, 2005: Climate change and food security. Philosophical Transactions of the Royal Society B, 360, 2139-2148.

Grothmann, T., 2011: Governance recommendations for adaptation in European urban regions: results from five case studies and a European expert survey. In: Resilient Cities: Cities and Adaptation to Climate Change [Otto-Zimmermann, K. (ed.)]. Springer, Dordrecht, Netherlands, pp. 167-176.

Grothmann, T. and A. Patt, 2005: Adaptive capacity and human cognition: the process of individual adaptation to climate change. Global Environmental Change, 15, 199-213.

Gupta, J., C. Termeer, J. Klostermann, S. Meijerink, M. van den Brink, P. Jong, S. Nooteboom, and E. Bergsma, 2010: The adaptive capacity wheel: a method to assess the inherent characteristics of institutions to enable the adaptive capacity of society. Environmental Science \& Policy, 13(6), 459-471.

Haasnoot, M., J.H. Kwakkel, W.E.Walker, and J. ter Maat, 2013: Dynamic adaptive policy pathways: a method for crafting robust decisions for a deeply uncertain world. Global Environmental Change, 23(2), 485-498.

Habib, A., M. Shahidullah, and D. Ahmed, 2012: The Bangladesh cyclone preparedness program. A vital component of the nation's multi-hazard early warning system. In: Institutional Partnerships in Multi-Hazard Early Warning Systems. Springer, Berlin Heidelberg, Germany, pp. 29-62.

Haddad, B.M., 2005: Ranking the adaptive capacity of nations to climate change when socio-political goals are explicit. Global Environmental Change, 15, 165176.

Hall, J.W., S. Brown, R.J. Nicholls, N. Pidgeon, and R.T. Watson, 2012: Proportionate adaptation. Nature Climate Change, 2, 833-834.

Hallegatte, S., 2009: Strategies to adapt to an uncertain climate change. Global Environmental Change, 19(2), 240-247.

Hamilton, L.C., 2011: Education, politics and opinions about climate change evidence for interaction effects. Climatic Change, 104(2), 231-242.

Hamin, E.M. and N. Gurran, 2009: Urban form and climate change: balancing adaptation and mitigation in the US and Australia. Habitat International, 33(3), 238-245.

Hanemann, W.M., 2008: What is the Economic Cost of Climate Change? CUDARE Working Paper Series No. 1071, University of California at Berkeley, Department of Agricultural and Resource Economics and Policy, Berkeley, CA, USA, 15 pp.

Hanjra, M.A. and M.E. Qureshi, 2010: Global water crisis and future food security in an era of climate change. Food Policy, 25(5), 365-377.

Hare, W.L., W. Cramer, M. Schaeffer, A. Battaglini, and C.C. Jaeger, 2011: Climate hotspots: key vulnerable regions, climate change and limits to warming. Regional Environmental Change, 11(Suppl. 1), S1-S13.

Harley, C.D., A. Randall Hughes, K.M. Hultgren, B.G. Miner, C.J. Sorte, C.S. Thornber, and S.L. Williams, 2006: The impacts of climate change in coastal marine systems. Ecology Letters, 9(2), 228-241.
Harris, S.E., 2012: Cyprus as a degraded landscape or resilient environment in the wake of colonial intrusion. Proceedings of the National Academy of Sciences of the United States of America, 109(10), 3670-3675.

Hartley, T.W., 2006: Public perception and participation in water reuse. Desalination, 187(1-3), 115-126.

Hartzell-Nichols, L., 2011: Responsibility for meeting the costs of adaptation. Wiley Interdisciplinary Reviews: Climate Change, 2(5), 687-700.

Hassan, R. and C. Nhemachena, 2008: Determinants of African farmers' strategies for adapting to climate change: multinomial choice analysis, African Journal of Agricultural and Resource Economics, 2(1), 83-104.

Hayward, B. 2008: 'Nowhere far from sea': political challenges of coastal adaptation to climate change in New Zealand. Political Science, 1, 47-59.

Heeres, N., T. Tillema, and J. Arts, 2012: Integration in Dutch planning of motorways: from "line" towards "area-oriented" approaches. Transport Policy, 24, 148-158.

Hellmann, J.J., J.E. Byers, B.G. Bierwagen, and J.S. Dukes, 2008: Five potential consequences of climate change for invasive species. Conservation Biology, 22(3), 534-543.

Hellmann, J.J., K.M. Prior, and S.L. Pelini, 2012: The influence of species interactions on geographic range change under climate change. Annals of the New York Academy of Sciences, 1249(1), 18-28.

Heltberg, R., P.B. Siegel, and S.L. Jorgensen, 2009: Addressing human vulnerability to climate change: toward a 'no-regrets' approach. Global Environmental Change, 19(1), 89-99.

Hennessy, K., B. Fitzharris, B.C. Bates, N. Harvey, S.M. Howden, L. Hughes, J. Salinger, and R. Warrick, 2007: Australia and New Zealand. In: Climate Change 2007: Impacts, Adaptation and Vulnerability. Contribution of Working Group II to the Fourth Assessment Report of the Intergovernmental Panel on Climate Change [Parry, M.L., O.F. Canziani, J.P. Palutikof, P.J. van der Linden, and C.E. Hanson (eds.)]. Cambridge University Press, Cambridge, UK and New York, NY, USA, pp. 507-540.

Herrfahrdt-Pähle, E., 2013: Integrated and adaptive governance of water resources: the case of South Africa. Regional Environmental Change, 13(3), 551-561.

Hertel, T.W. and S. Rosch, 2010: Climate change agriculture and poverty. Applied Economic Perspectives and Policy, 32(3), 355-385.

Hertzler, G., 2007: Adapting to climate change and managing climate risks by using real options. Crop and Pasture Science, 58(10), 985-992.

Herweijer, C., N. Ranger, and R.E.T. Ward, 2009: Adaptation to climate change: threats and opportunities for the insurance industry. The Geneva Papers, 34, 360-380.

Hess, J., J.N. Malilay, and A.J. Parkinson, 2008: Climate change: the importance of place. American Journal of Preventive Medicine, 35(5), 468-478.

Heyd, T. and N. Brooks, 2009: Exploring cultural dimensions of adaptation to climate change. In: Adapting to Climate Change: Thresholds, Values, Governance [Adger, W.N., I. Lorenzoni, and K.L. O'Brien (eds.)]. Cambridge University Press, Cambridge, UK, pp. 269-82.

Hill, J.K., H.M. Griffiths, and C.D. Thomas, 2011: Climate change and evolutionary adaptations at species' range margins. Annual Review of Entomology, 56, 143 159.

Hillie, T. and M. Hlophe, 2007: Nanotechnology and the challenge of clean water. Nature Nanotechnology, 2, 663-664.

Hinkel, J., 2011: Indicators of vulnerability and adaptive capacity: towards a clarification of the science. Global Environmental Change, 21, 198-208.

Hisali, E., P. Birungi, and F. Buyinza, 2011: Adaptation to climate change in Uganda: evidence from micro level data. Global Environmental Change, 21(4), $1245-$ 1261.

Ho, M., D. Shaw, S. Lin, and Y. Chiu, 2008: How do disaster characteristics influence risk perceptions? Risk Analysis, 28(3), 635-643.

Hodgson, J.A., C.D Thomas, B.A. Wintle, and A. Moilanen, 2009: Assessing wave energy effects on biodiversity: the Wave Hub experience. Philosophical Transactions of the Royal Society A, 370(1959), 502-529.

Hoegh-Guldberg, 0., 2008: Climate change and coral reefs: Trojan horse or false prophecy? Coral Reefs, 28, 569-575.

Hoegh-Guldberg, 0., 2011: Coral reef ecosystems and anthropogenic climate change. Regional Environmental Change, 11(1), 215-227.

Hof, A.F., K.C. de Bruin, R.B. Dellink, M.G.J. den Elzen, and D.P. van Vuuren, 2009: The effect of different mitigation strategies on international financing of adaptation. Environmental Science \& Policy, 12(7), 832-843.

Hoffmann, A.A. and C.M. Sgrò, 2011: Climate change and evolutionary adaptation. Nature, 470, 479-485. 
Hope, C., 2011: The PAGE09 Integrated Assessment Model: A Technical Description. Working Paper Series 4/2011, University of Cambridge, Judge Business School, Cambridge, UK, $44 \mathrm{pp}$.

Howden, S.M., J.F. Soussana, F.N. Tubiello, N. Chhetri, M. Dunlop, and H. Meinke, 2007: Adapting agriculture to climate change. Proceedings of the National Academy of Sciences of the United States of America, 104(50), 19691-19696.

Huang, C., P. Vaneckova, X. Wang, G. FitzGerald, Y. Guo, and S. Tong, 2011: Constraints and barriers to public health adaptation to climate change: a review of the literature. American Journal of Preventive Medicine, 40(2), 183190.

Hulme, M., W.N. Adger, S. Dessai, M. Goulden, I. Lorenzoni, D. Nelson, L.O. Naess, J. Wolf, and A. Wreford, 2007: Limits and Barriers to Adaptation: Four Propositions. Tyndall Briefing Note No. 20, Tyndall Centre for Climate Change Research, University of East Anglia, Norwich, UK, 7 pp.

Hulme, M., S. Dessai, I. Lorenzoni, and D.R. Nelson, 2009: Unstable climates: exploring the statistical and social constructions of 'normal' climate. Geoforum, 40(2), 197-206.

Hunt, T.L., 2007: Rethinking Easter Island's ecological catastrophe. Journal of Archaeological Science, 34(3), 485-502.

Huntington, H.P., E. Goodstein, and E. Euskirchen, 2012: Towards a tipping point in responding to change: rising costs, fewer options for Arctic and global societies. Ambio, 41(1), 66-74.

Huntjens, P., C. Pahl-Wostl, and J. Grin, 2010: Climate change adaptation in European river basins. Regional Environmental Change, 10, 263-284.

Huntjens, P., L. Lebel, C. Pahl-Wostl, J. Camkin, R, Schulze, and N. Kranz, 2012: Institutional design propositions for the governance of adaptation to climate change in the water sector. Global Environmental Change, 22(1), 67-81.

Iglesias, A., L. Garrote, F. Flores, and M. Moneo, 2007: Challenges to manage the risk of water security and climate change in the Mediterranean. Water Resources Management, 21, 775-788.

Iglesias, A., R. Mougou, M. Moneo, and S. Quiroga, 2011: Towards adaptation of agriculture to climate change in the Mediterranean. Regional Environmental Change, 11(Suppl. 1), 159-166.

Indraganti, M., 2010: Behavioural adaptation and the use of environmental controls in summer for thermal comfort in apartments in India. Energy and Buildings, 42(7), 1019-1025.

IPCC, 2007a: Summary for policymakers. In: Climate Change 2007: Impacts, Adaptation and Vulnerability. Contribution of Working Group II to the Fourth Assessment Report of the Intergovernmental Panel on Climate Change [Parry, M.L., O.F Canziani, J.P. Palutikof, P.J. van der Linden, and C.E. Hanson (eds.)]. Cambridge University Press, Cambridge, UK and New York, NY, USA, pp. 7-22.

IPCC, 2007b: Climate Change 2007: Impacts, Adaptation and Vulnerability. Contribution of Working Group II to the Fourth Assessment Report of the Intergovernmental Panel on Climate Change [Parry, M., O. Canziani, J. Palutikof, and P. van der Linden (eds.)]. Cambridge University Press, Cambridge, UK and New York, NY, USA, 976 pp.

IPCC, 2012: Managing the Risks of Extreme Events and Disasters to Advance Climate Change Adaptation. A Special Report of Working Groups I and II of the Intergovernmental Panel on Climate Change [Field, C.B., V. Barros, T.F. Stocker, D. Qin, D.J. Dokken, K.L. Ebi, M.D. Mastrandrea, K.J. Mach, G.-K. Plattner, S.K. Allen, M. Tignor, and P.M. Midgley (eds.)]. Cambridge University Press, Cambridge, UK and New York, NY, USA, 582 pp.

Islam, M., S. Sallu, K. Hubacek, and J. Paavola, 2014: Limits and barriers to adaptation to climate variability and change in Bangladeshi coastal fishing communities. Marine Policy, 43, 208-216

Iwasaki, S., B.H.N. Razafindrabe, and R. Shaw, 2009: Fishery livelihoods and adaptation to climate change: a case study of Chilika Lagoon, India. Mitigation and Adaptation Strategies for Global Change, 14(4), 339-355.

Jäger, J. and P. Moll, 2011: Adaptation to climate change: tools and methods. Regional Environmental Change, 11(2), 213-215.

Jackson, A.C. and J. Mcllvenny, 2011: Coastal squeeze on rocky shores in northern Scotland and some possible ecological impacts. Journal of Marine Experimental Biology and Ecology, 400, 314-321.

Jacob, C., T. McDaniels, and S. Hinch, 2010: Indigenous culture and adaptation to climate change: sockeye salmon and the St'át'imc people. Mitigation and Adaptation Strategies for Global Change, 15, 859-876.

Jantarasami, L.C., J.J. Lawler, and C.W. Thomas, 2010: Institutional barriers to climate change adaptation in U.S. national parks and forests. Ecology and Society, 15(4), 33, www.ecologyandsociety.org/vol15/iss4/art33/.
Jeffers, J.M., 2013: Double exposures and decision making: adaptation policy and planning in Ireland's coastal cities during a boom-bust cycle. Environment and Planning A, 45(6), 1436-1454.

Jenkins, K.M., R.T. Kingsford, B.J. Wolfenden, S. Whitten, H. Parris, C. Sives, and R. Rolls, 2011: Limits to Climate Change Adaptation in Floodplain Wetlands: The Macquarie Marshes. Final Report to the National Climate Change Adaptation Research Facility (NCCARF), Griffith University, Gold Coast Campus, Southport, Australia, $159 \mathrm{pp}$.

Jensen, L.F., M.M. Hansen, C. Pertoldi, G. Holdensgaard, K.L.D. Mensberg, and V. Loeschcke, 2008: Local adaptation in brown trout early life-history traits: implications for climate change adaptability. Proceedings of the Royal Society $B, 275(1653)$, 2859-2868.

Jeuland, M. and D. Whittington, 2013: Water Resources Planning under Climate Change: A "Real Options" Application to Investment Planning in the Blue Nile. Environment for Development Discussion Paper Series, EfD DP 13-05, The Environment for Development (EfD) Initiative, Resources for the Future, Washington, DC, USA, $54 \mathrm{pp}$.

Johannessen, O.M. and M.W. Miles, 2011: Critical vulnerabilities of marine and sea ice-based ecosystems in the high Arctic. Regional Environmental Change, 11(Suppl. 1), S239-S248.

Jolibert, C., M. Max-Neef, F. Rauschmayer, and J. Paavola, 2011: Should we care about the needs of non-humans? Needs assessment: a tool for environmental conflict resolution and sustainable organization of living beings. Environmental Policy and Governance, 21, 259-269.

Jones, L. and E. Boyd, 2011: Exploring social barriers to adaptation: insights from Western Nepal. Global Environmental Change, 21(4), 1262-1274.

Jones, R.N., 2001: An environmental risk assessment/management framework for climate change impact assessments. Natural Hazards, 23, 197-230.

Jones, R.N., 2010: Water resources. In: Adapting Agriculture to Climate Change [Stokes, C. and M. Howden (eds.)]. CSIRO Publishing, Collingwood, Australia, pp. 187-204.

Jones, R.N. and A.B. Pittock, 2002: Climate change and water resources in an arid continent: managing uncertainty and risk in Australia. In: Climatic Change: Implications for the Hydrological Cycle and for Water Management [Beniston, M. (ed.)]. Kluwer Academic Publishers, Dordrecht, Netherlands and Boston, MA, USA, pp. 465-501.

Jones, R.N. and B.L. Preston, 2011: Adaptation and risk management. Wiley Interdisciplinary Reviews: Climate Change, 2, 296-308.

Juhola, S. and L. Westerhoff, 2011: Challenges of adaptation to climate change across multiple scales: a case study of network governance in two European countries. Environmental Science \& Policy, 14(3), 239-247.

Juhola, S., E.C.H. Keskitalo, and L. Westerhoff, 2011: Understanding the framings of climate change adaptation across multiple scales of governance in Europe. Environmental Politics, 20(4), 445-463.

Kahan, D.M., 2010: Fixing the communications failure. Nature, 463, 296-297.

Kahan, D.M., E. Peters, M. Wittlin, P. Slovic, L.L. Ouellette, D. Braman, and G. Mandel, 2012: The polarizing impact of science literacy and numeracy on perceived climate change risks. Nature Climate Change, 2(10), 732-735.

Kalirajan, K., K. Singh, S. Thangavelu, A. Venkatachalam, and K. Perera, 2011: Climate Change and Poverty Reduction: Where Does Official Development Assistance Money Go? ADBI Working Paper Series, No. 318, Asian Development Bank Institute (ADBI), Tokyo, Japan, 43 pp.

Kapos, V. and L. Miles, 2008: Reducing greenhouse gas emissions from deforestation and forest degradation: global land-use implications. Science, 320(5882), 1454-1455.

Karim, M.F. and N. Mimura, 2008: Impacts of climate change and sea-level rise on cyclonic storm surge floods in Bangladesh. Global Environmental Change, 18(3), 490-500.

Kasperson, R.E. and M. Berberian (eds.), 2011: Integrating Science and Policy: Vulnerability and Resilience in Global Environmental Change. Earthscan, London, UK, $416 \mathrm{pp}$.

Kates, R., W. Travis, and T. Wilbanks, 2012: Transformational adaptation when incremental adaptations to climate change are insufficient. Proceedings of the National Academy of Sciences of the Unites States of America, 109(19), 71567161.

Kato, E., C. Ringler, M. Yesuf, and E. Bryan, 2011: Soil and water conservation technologies: a buffer against production risk in the face of climate change? Insights from the Nile basin in Ethiopia. Agricultural Economics, 42(5), 593604. 
Kellstedt, P.M., S. Zahran, and A. Vedlitz, 2008: Personal efficacy, the information environment, and attitudes toward global warming and climate change in the United States. Risk Analysis, 28, 113-126.

Kenny, J.F., N.L. Barber, S.S. Hutson, K.S. Linsey, J.K. Lovelace, and M.A. Maupin, 2009: Estimated Use of Water in the United States in 2005. USGS Circular 1344, U.S. Department of the Interior, U.S. Geological Survey (USGS), Washington, DC, USA, $52 \mathrm{pp}$.

Keryn, B., M.L. Kirwan, E. Wolanski, E.B. Barbier, and B.R. Silliman, 2011: The present and future role of coastal wetland vegetation in protecting shorelines: answering recent challenges to the paradigm. Climatic Change, 106, 7-29.

Keskitalo, E.C.H. (ed.), 2010: The Development of Adaptation Policy and Practice in Europe: Multi-Level Governance of Climate Change. Springer, Dordrecht, Netherlands, $376 \mathrm{pp}$.

Kiem, A.S. and E.K. Austin, 2013: Drought and the future of rural communities: opportunities and challenges for climate change adaptation in regional Victoria, Australia. Global Environmental Change, 23(5), 1307-1316.

Kiem, A.S., D.C. Verdon-Kidd, S.L. Boulter, and J.P. Palutikof, 2010: Learning from Experience: Historical Case Studies and Climate Change Adaptation. Report for the National Climate Change Adaptation Research Facility (NCCARF), Griffith University, Gold Coast Campus, Southport, Australia, 33 pp.

Klein, R.J.T., 2009: Identifying countries that are particularly vulnerable to the effects of climate change: an academic or political challenge? Carbon Climate Law Review, 3, 284-291.

Klein, R.J.T., 2010: Linking adaptation and development finance: a policy dilemma not addressed in Copenhagen. Climate and Development, 2(3), 203-206.

Klein, R.J.T. and S. Juhola, 2013: A Framework for Nordic Actor-Oriented Climate Adaptation Research. NORD-STAR Working Paper 2013-01, Nordic Centre of Excellence for Strategic Adaptation Research (NORD-STAR), Aarhus University, Business and Social Sciences, Herning, Denmark, $20 \mathrm{pp}$.

Klein, R.J.T. and A. Möhner, 2009: Governance limits to effective global financial support for adaptation. In: Adapting to Climate Change: Thresholds, Values, Governance [Adger, W.N., I. Lorenzoni, and K.L. O'Brien (eds.)]. Cambridge University Press, Cambridge, UK, pp. 465-475.

Klein, R.J.T., S. Huq, F. Denton, T.E. Downing, R.G. Richels, J.B. Robinson, and F.L. Toth, 2007: Inter-relationships between adaptation and mitigation. In: Climate Change 2007: Impacts, Adaptation and Vulnerability. Contribution of Working Group II to the Fourth Assessment Report of the Intergovernmental Panel on Climate Change [Parry, M.L., O.F. Canziani, J.P. Palutikof, P.J. van der Linden, and C.E. Hanson (eds.)]. Cambridge University Press, Cambridge, UK and New York, NY, USA, pp. 745-777.

Klinke, A. and 0. Renn, 2002: A new approach to risk evaluation and management: risk-based, precaution-based, and discourse-based strategies. Risk Analysis, 22, 1071-1094.

Klinsky, S., H. Dowlatabadi, and T. McDaniels, 2012: Comparing public rationales for justice trade-offs in mitigation and adaptation climate policy dilemmas. Global Environmental Change, 22, 862-876.

Knox, J.H., 2009: Linking human rights and climate change at the United Nations. Harvard Environmental Law Review, 33, 477-498.

Koh, J., 2011: Local vulnerability assessment of climate change and its implications: the case of Gyeonggi-Do, Korea. In: Resilient Cities: Cities and Adaptation to Climate Change -Proceedings of the Global Forum 2010, Vol. 1, Local Sustainability [Otto-Zimmermann, K. (ed.)]. Springer Science, Dordrecht, Netherlands, pp. 411-427.

Koivurova, T., 2007: International legal avenues to address the plight of victims of climate change: problems and prospects. Journal of Environmental Law and Litigation, 22, 267-299.

Kremer, A., O. Ronce, J.J. Robledo-Arnuncio, F. Guillaume, G. Bohrer, R. Nathan, and S. Schueler, 2012: Long-distance gene flow and adaptation of forest trees to rapid climate change. Ecology Letters, 15(4), 378-392.

Kriegler, E., J.W. Hall, H. Held, R. Dawson, and H.J. Schellnhuber, 2009: Imprecise probability assessment of tipping points in the climate system. Proceedings of the National Academy of Sciences of the United States of America, 106(13), 5041-5046.

Kriegler, E., B.C. O'Neill, S. Hallegatte, T. Kram, R.J. Lempert, R.H. Moss, and T. Wilbanks, 2012: The need for and use of socio-economic scenarios for climate change analysis: a new approach based on shared socio-economic pathways. Global Environmental Change, 22(4), 807-822.

Krosby, M., J. Tewksbury, N.M. Haddad, and J. Hoekstra, 2010: Ecological connectivity for a changing climate. Conservation Biology, 24(6), 1686-1689.
Krysanova, V., C. Dickens, J. Timmerman, C. Varela-Ortega, M. Schlüter, K. Roest, P. Huntjens, F. Jaspers, H. Buiteveld, E. Moreno, J. de Padraza Carrera, R. Slámová, R. Martínková, I. Blanco, P. Esteve, K. Pringle, C. Pahl-Wostl, and P. Kabat, 2010: Cross-comparison of climate change adaptation strategies across large river basins in Europe, Africa and Asia. Water Resources Management, 24(14), 4121 4160.

Kuruppu, N., 2009: Adapting water resources to climate change in Kiribati: the importance of cultural values and meanings. Environmental Science \& Policy, 12(7), 799-809.

Kuruppu, N. and D. Liverman, 2011: Mental preparation for climate adaptation: the role of cognition and culture in enhancing adaptive capacity of water management in Kirabati. Global Environmental Change, 21(2), 657-669.

Kwok, A.G. and N.B. Rajkovich, 2010: Addressing climate change in comfort standards. Building and Environment, 45(1), 18-22.

Kyung-Soo, J., C. Eun-Sung, K. Young-Gyu, and K. Yeonjoo, 2013: A fuzzy multi-criteria approach to flood risk vulnerability in South Korea by considering climate change impacts. Expert Systems with Applications, 40(4), 1003-1013.

Lafleur, B., D. Pare, A.D. Munson, and Y. Bergeron, 2010: Response of northeastern North American forests to climate change: will soil conditions constrain tree species migration? Environmental Reviews, 18, 279-289.

Lal, P.N., P. Mitchell, P. Aldunce, H. Auld, R. Mechler, A. Miyan, L.E. Romano, and S. Zakaria, 2012: National systems for managing the risks from climate extremes and disasters. In: Managing the Risks of Extreme Events and Disasters to Advance Climate Change Adaptation. A Special Report of Working Groups I and II of the Intergovernmental Panel on Climate Change [Field, C.B., V. Barros, T.F. Stocker, D. Qin, D.J. Dokken, K.L. Ebi, M.D. Mastrandrea, K.J. Mach, G.-K. Plattner, S.K. Allen, M. Tignor, and P.M. Midgley (eds.)]. Cambridge University Press, Cambridge, UK and New York, NY, USA, pp. 339-392.

Lal, R., 2011: Soil degradation and food security in South Asia. Climate Change and Food Security in South Asia, 4, 137-152.

Larson, A.M., 2011: Forest tenure reform in the age of climate change: lessons for REDD+. Global Environmental Change, 21(2), 540-549.

Lata, S. and P. Nunn, 2012: Misperceptions of climate-change risk as barriers to climate-change adaptation: a case study from the Rewa Delta, Fiji. Climatic Change, 110, 169-186.

Lavell, A., M. Oppenheimer, C. Diop, J. Hess, R. Lempert, J. Li, R. Muir-Wood, and S. Myeong, 2012: Climate change: new dimensions in disaster risk, exposure, vulnerability, and resilience. In: Managing the Risks of Extreme Events and Disasters to Advance Climate Change Adaptation. A Special Report of Working Groups I and II of the Intergovernmental Panel on Climate Change [Field, C.B., V. Barros, T.F. Stocker, D. Qin, D.J. Dokken, K.L. Ebi, M.D. Mastrandrea, K.J. Mach, G.-K. Plattner, S.K. Allen, M. Tignor, and P.M. Midgley (eds.)]. Cambridge University Press, Cambridge, UK and New York, NY, USA, pp. 25-64.

Lavergne, S., N. Mouquet, W. Thuiller, and O. Ronce, 2010: Biodiversity and climate change: integrating evolutionary and ecological responses of species and communities. Annual Review of Ecology, Evolution, and Systematics, 41(1), 321-350.

Leary, N., K. Averyt, B. Hewitson, and J. Marengo, 2009: Crossing thresholds in regional climate research: synthesis of the IPCC expert meeting on regional impacts, adaptation, vulnerability, and mitigation. Climate Research, 40(2-3), 121-131.

Lebel, L., E. Nikitina, C. Pahl-Wostl, and C. Knieper, 2013: Institutional fit and river basin governance: a new approach using multiple composite measures. Ecology and Society, 18(1), 1, www.ecologyandsociety.org/vol18/iss1/art1/.

Leichenko, R., 2012: Climate change, globalization, and the double exposure challenge to sustainability: rolling the dice in coastal New Jersey. In: Sustainability Science [Weinstein, W.P. and R.E. Turner (eds.)]. Springer, New York, NY, USA, pp. 315328.

Leichenko, R.M., K.L. O'Brien, and W.D. Solecki, 2010: Climate change and the global financial crisis: a case of double exposure. Annals of the Association of American Geographers, 100(4), 963-972.

Lemieux, C.J., T.J. Beechey, and P.A. Gray, 2011: Prospects for Canada's protected areas in an era of rapid climate change. Land use Policy, 28(4), 928-941.

Lemos, M.C., C.J. Kirchhoff, and V. Ramprasad, 2012: Narrowing the climate information usability gap. Nature Climate Change, 2, 789-794.

Lemos, M.C., A. Agrawal, H. Eakin, D.R. Nelson, N.L. Engle, and O. Johns, 2013: Building adaptive capacity to climate change in less developed countries. In: Climate Science for Serving Society [Asrar, G.R. and J.W. Hurrell (eds.)]. Springer Science, Dordrecht, Netherlands, pp. 437-457. 
Lenton, T., H. Held, E. Kriegler, J. Hall, W. Lucht, S. Rahmstorf, and S. Hoachim, 2008: Tipping points in the Earth's climate system. Proceedings of the National Academy of Sciences of the United States of America, 105(6), 1786-1793.

Lenton, T.M., V.N. Livina, V. Dakos, E.H. Van Nes, and M. Scheffer, 2012: Early warning of climate tipping points from critical slowing down: comparing methods to improve robustness. Philosophical Transactions of the Royal Society A, 370(1962), 1185-1204.

Lesnikowski, A.C., J.D. Ford, L. Berrang-Ford, M. Barrera, P. Berry, J. Henderson, and S.J. Heymann, 2013: National-level factors affecting planned, public adaptation to health impacts of climate change. Global Environmental Change, 23(5), 1153-1163.

Levermann, A., J.L. Bamber, S. Drijfhout, A. Ganopolski, W. Haeberli, N.R. Harris, M. Huss, K. Krüger, T.M. Lenton, R.W. Lindsay, D. Notz, P. Wadhams, and S. Weber, 2012: Potential climatic transitions with profound impact on Europe. Climatic Change, 110(3-4), 845-878.

Levin, K. and B. Petersen, 2011: Tradeoffs in the policy process in advancing climate change adaptation: the case of Australia's Great Eastern Ranges Initiative. Journal of Natural Resources Policy Research, 3(2), 145-162.

Li, W. and L. Huntsinger, 2011: China's grassland contract policy and its impacts on herder ability to benefit in Inner Mongolia: tragic feedbacks. Ecology and Society, 16(2), 1, www.ecologyandsociety.org/vol16/iss2/art1/.

Libecap, G.D., 2010: Institutional Path Dependence in Climate Adaptation: Coman's "Some Unsettled Problems of Irrigation". NBER Working Paper No. w16324, National Bureau of Economic Research (NBER), Cambridge, MA, USA, 27 pp.

Lieske, D.J., T. Wade, and L.A. Roness, 2013: Climate change awareness and strategies for communicating the risk of coastal flooding: a Canadian Maritime case example. Estuarine, Coastal and Shelf Science, www.sciencedirect.com/science/ article/pii/S0272771413002035.

Liu, G.Y., Z.F. Yang, and B. Chen, 2012: Energy-based urban dynamic modeling of long-run resource consumption, economic growth and environmental impact: conceptual considerations and calibration. Procedia Environmental Sciences, 13, 1179-1188.

Lobell, D.B., M.B. Burke, C. Tebaldi, M.D. Mastrandrea, W.P. Falcon, and R.L. Naylor, 2008: Prioritizing climate change adaptation needs for food security in 2030. Science, 319(5863), 607-610.

Lobell, D.B., W. Schlenker, and J. Costa-Roberts, 2011: Climate trends and global crop production since 1980. Science, 333(6042), 616-620.

Lovejoy, T.E., 2005: Conservation with a changing climate. In: Climate Change and Biodiversity [Lovejoy, T. and L. Hannah (eds.)]. Yale University Press, New Haven, CT, USA, pp. 325-328.

Lovejoy, T.E., 2006: Protected areas: a prism for a changing world. Trends in Ecology \& Evolution, 21, 329-333.

Lowe, D., K.L. Ebi, and B. Forsberg, 2011: Heatwave early warning systems and adaptation advice to reduce human health consequences of heatwaves. International Journal of Environmental Research and Public Health, 8, 46234648.

Lowe, J.A., S.C.B. Raper, S.K. Liddicoat, and L.K. Gohar, 2009: How difficult is it to recover from dangerous levels of global warming? Environmental Research Letters, 4, 014012, doi:10.1088/1748-9326/4/1/014012.

Luzzadder-Beach, S., T.P. Beach, and N.P. Dunning, 2012: Wetland fields as mirrors of drought and the Maya abandonment. Proceedings of the National Academy of Sciences of the United States of America, 109(10), 3646-3651.

Lybbert, T.J., and D.A. Sumner, 2012: Agricultural technologies for climate change in developing countries: policy options for innovation and technology diffusion. Food Policy, 37(1), 114-123.

Maibach, E.W., A. Chadwick, D. McBride, M. Chuk, K.L. Ebi, and J. Balbus, 2008: Climate change and local public health in the United States: preparedness, programs and perceptions of local public health department directors. PLoS One, 3(7), e2838, doi:10.1371/journal.pone.0002838.

Mailhot, A. and S. Duchesne, 2009: Design criteria of urban drainage infrastructures under climate change. Journal of Water Resources Planning and Management, 136(2), 201-208.

Malhi, Y., L.E.O.C. Aragao, D. Galbraith, C. Huntingford, R. Fisher, P. Zelazowski, S. Sitch, C. McSweeney, and P. Meir, 2009a: Exploring the likelihood and mechanism of a climate-change-induced dieback of the Amazon rainforest. Proceedings of the National Academies of Sciences of the United States of America, doi:10.1073/pnas.0804619106.

Malhi, Y., J.T. Roberts, R.A. Betts, T.J. Killeen, W. Li, and C.W. Nobre, 2009b: Climate change, deforestation, and the fate of the Amazon. Science, 319(5860), 169-172.
Malka, A. and J.A. Krosnick, 2009: The association of knowledge with concern about global warming: trusted information sources shape public thinking. Risk Analysis, 29, 633-647.

Mallick, F.H. and M.A. Rahman, 2007: Cyclone shelters and alternatives for sustained development in Bangladesh. Journal of South Asia Disaster Studies, 1(1), 59-67.

Mallick, F.H. and A. Rahman, 2013: Cyclone and tornado risk and reduction approaches in Bangladesh. In: Disaster Risk Reduction Approaches in Bangladesh. Springer Japan, Osaka, Japan, pp. 91-102.

Mallick, F.H, K.H. Kabir, and M.H. Kabir, 2008: Improved Design and Construction of Rural Housing in Noakhali. International Union for Conservation of Nature and Natural Resources (IUCN) Bangladesh Country Office, Dhaka, Bangladesh, $43 \mathrm{pp}$.

Marshall, N.A., 2010: Understanding social resilience to climate variability in primary enterprises and industries. Global Environmental Change, 20, 36-43.

Marvin, H.J.P., G.A. Kleter, H.J. Van der Fels-Klerx, M.Y. Noordam, E. Franz, D.J.M. Willems, and A. Boxall, 2013: Proactive systems for early warning of potential impacts of natural disasters on food safety: climate-change-induced extreme events as case in point. Food Control, 34, 444-456.

Mastrandrea, M.D. and S.H. Schneider, 2004: Probabilistic integrated assessment of "dangerous" climate change. Science, 304(5670), 571-575.

Matasci, C., S. Kruse, N. Barawid, and P. Thalmann, 2013: Exploring barriers to climate change adaptation in the Swiss tourism sector. Mitigation and Adaptation Strategies for Global Change, doi:10.1007/s11027-013-9471-1.

Matesanz, S., E. Gianoli, and F. Valladares, 2010: Global change and the evolution of phenotypic plasticity in plants. Annals of the New York Academy of Sciences, 1206, 35-55.

Matthews, T., 2013: Institutional perspectives on operationalising climate adaptation through planning. Planning Theory \& Practice, 14(2), 198-210.

Maynard, J., A. Baird, and M. Pratchett, 2008: Revisiting the Cassandra syndrome: the changing climate of coral reef research. Coral Reefs, 27, 745-749.

McAnany, P.A. and N. Yoffee, 2010: Questioning how different societies respond to crises. Nature, 464(7291), 977-977.

McCright, A.M. and R.E. Dunlap, 2011: The politicization of climate change and polarization in the American public's views of global warming, 2001-2010. The Sociological Quarterly, 52(2), 155-194.

McDonald, J., 2011: The role of law in adapting to climate change. Wiley Interdisciplinary Reviews: Climate Change, 2, 283-295.

McGray, H., H. Hammill, R. Bradley, E.L. Schipper, and J.E. Parry, 2007: Weathering the Storm: Options for Framing Adaptation and Development. World Resources Institute, Washington, DC, USA, $57 \mathrm{pp}$.

McKune, S.L. and J.A. Silva, 2013: Pastoralists under pressure: double exposure to economic and environmental change in Niger. The Journal of Development Studies, 49(12), 1711-1727, doi:10.1080/00220388.2013.822067.

McLachlan, J.S., J.J. Hellmann, and M.W. Schwartz, 2007: A framework for debate of assisted migration in an era of climate change. Conservation Biology, 21(2), 297-302.

McNamara, K. and C. Gibson, 2009: 'We don't want to leave our land': Pacific ambassadors to the United Nations resist the category of 'climate refugees'. Geoforum, 40, 475-483.

McNamara, K.E. and J.P. McNamara, 2011: Using participatory action research to share knowledge of the local environment and climate change: case study of Erub Island, Torres Strait. The Australian Journal of Indigenous Education, 40, 30-39.

McNamara, K.E., S.G. Smithers, R. Westoby, and K. Parnell, 2011: Limits to Climate Change Adaptation for Low-Lying Communities in the Torres Strait. National Climate Change Adaptation Research Facility (NCCARF), Griffith University, Gold Coast Campus, Southport, Australia, 87 pp.

Measham, T.G and B.L. Preston, 2012: Vulnerability analysis, risk and deliberation: the Sydney climate change adaptation initiative. In: Risk and Social Theory in Environmental Management [Measham T. and S. Lockie (eds.)]. CSIRO Publishing, Collingwood, Australia, pp. 147-157.

Measham, T.G., B.L. Preston, C. Brooke, T.F. Smith, C. Morrison, G. Withycombe, and R. Gorddard, 2011: Adapting to climate change through local municipal planning: barriers and opportunities. Mitigation and Adaptation Strategies for Global Change, 16(8), 889-909.

Mechler, R. and K.N. Islam, 2013: Cost-benefit analysis of disaster risk management and climate adaptation. In: The Economic Impacts of Natural Disasters [GuhaSapir, D., I. Santos, and A. Borde (eds.)]. Oxford University Press, Oxford, UK, pp. 80-106. 
Meera, S.N., V. Balaji, P. Muthuraman, B. Sailaja, and S. Dixit, 2012: Changing roles of agricultural extension: harnessing information and communication technology (ICT) for adapting to stresses envisaged under climate change. In: Crop Stress and its Management: Perspectives and Strategies [Venkateswarlu, B., A.K. Shanker, C. Shanker, and M. Maheswari (eds.)]. Springer, Dordrecht, Netherlands, pp. 585-605.

Mees, H.L., P.P. Driessen, and H.A. Runhaar, 2012: Exploring the scope of public and private responsibilities for climate adaptation. Journal of Environmental Policy \& Planning, 14(3), 305-330.

Meinshausen, M., N. Meinshausen, W. Hare, S.C.B. Raper, K. Frieler, R. Knutti, D.J. Frame, and M.R. Allen, 2009: Greenhouse-gas emission targets for limiting global warming to $2^{\circ} \mathrm{C}$. Nature, 458(7242), 1158-1162.

Merz, B., J. Hall, M. Disse, and A. Schumann, 2010: Fluvial flood risk management in a changing world. Natural Hazards and Earth System Science, 10(3), 509-527.

Meze-Hausken, E., 2008: On the (im-)possibilities of defining human climate thresholds. Climatic Change, 89(3-4), 299-324.

Meyer, R., 2011: The public values failures of climate science in the US. Minerva, 49(1), 47-70.

Milfont, T.L. 2012: The interplay between knowledge, perceived efficacy, and concern about global warming and climate change: a one-year longitudinal study. Risk Analysis, 32(6), 1003-1020.

Millar, C.I., N.L. Stephenson, and S.L. Stephens, 2007: Climate change and forests of the future: managing in the face of uncertainty. Ecological Applications, 17(8), 2145-2151.

Milman, A., L. Bunclark, D. Conway, and W.N. Adger, 2013: Assessment of institutional capacity to adapt to climate change in transboundary river basins. Climatic Change, 121(4), 755-770.

Mimura, N., L. Nurse, R.F. McLean, J. Agard, L. Briguglio, P. Lefale, R. Payet, and G. Sem, 2007: Small islands. In: Climate Change 2007: Impacts, Adaptation and Vulnerability. Contribution of Working Group II to the Fourth Assessment Report of the Intergovernmental Panel on Climate Change [Parry, M.L., O.F. Canziani, J.P. Palutikof, P.J. van der Linden, and C.E. Hanson (eds.)]. Cambridge University Press, Cambridge, UK and New York, NY, USA, pp. 687-716.

Montgomery, M.R., 2008: The urban transformation of the developing world. Science, (5864), 761-764.

Mooney, C. and P. Tan, 2012: South Australia's River Murray: social and cultural values in water planning. Journal of Hydrology, 474, 29-37.

Moreno, A. and S. Becken, 2009: A climate change vulnerability assessment methodology for coastal tourism. Journal of Sustainable Tourism, 17(4), 473488.

Morgan, C.L., 2011: Limits to Adaptation: A Review of Limitation Relevant to the Project "Building Resilience to Climate Change - Coastal Southeast Asia". International Union for Conservation of Nature and Natural Resources (IUCN), Gland, Switzerland, $31 \mathrm{pp}$.

Morin, X. and W. Thuiller, 2009: Comparing niche-and process-based models to reduce prediction uncertainty in species range shifts under climate change. Ecology, 90(5), 1301-1313.

Morrison, C. and C. Pickering, 2012: Limits to Climate Change Adaptation: Case Study of the Australian Alps. National Climate Change Adaptation Research Facility (NCCARF), Griffith University, Gold Coast Campus, Southport, Australia, $78 \mathrm{pp}$.

Mortreux, C. and J. Barnett, 2009: Climate change, migration and adaptation in Funafuti, Tuvalu. Global Environmental Change, 19, 105-112.

Moser, B., J.D. Fridley, A.P. Askew, and J.P. Grime, 2011: Simulated migration in a long-term climate change experiment: invasions impeded by dispersal limitation, not biotic resistance. Journal of Ecology, 99(5), 1229-1236.

Moser, S.C., 2010a: Communicating climate change: history, challenges, process and future directions. Wiley Interdisciplinary Reviews: Climate Change, 1(1), 31-53.

Moser, S.C., 2010b: Now more than ever: the need for more societally-relevant research on vulnerability and adaptation to climate change. Applied Geography, 30(4), 464-474.

Moser, S.C. and J.A. Ekstrom, 2010: A framework to diagnose barriers to climate change adaptation. Proceedings of the National Academy of Sciences of the United States of America, 107(51), 22026-22031.

Moss, R.H., J.A. Edmonds, K.A. Hibbard, M.R. Manning, S.K. Rose, D.P. van Vuuren, T.R. Carter, S. Emori, M. Kainuma, T. Kram, G.A. Meehl, J.F.B., Mitchell, N. Nakicenovic, K. Riahi, S.J. Smith, R.J. Stougger, A.M. Thomson, J.P. Weyant, and T.J. Wilbanks, 2010: The next generation of scenarios for climate change research and assessment. Nature, 463, 747-756.
Mukheibir, P., N. Kuruppu, A. Gero, and J. Herriman, 2013: Overcoming cross-scale challenges to climate change adaptation for local government: a focus on Australia. Climatic Change, 121(2), 271-283.

Müller, N., W. Kuttler, and A.B. Barlag, 2013: Counteracting urban climate change: adaptation measures and their effect on thermal comfort. Theoretical and Applied Climatology, doi:10.1007/s00704-013-0890-4.

Munich Re, 2011: Great Natural Catastrophes Worldwide 1950 - 2010. Münchener Rückversicherungs-Gesellschaft, Geo Risks Research, NatCatSERVICE, Munich, Germany.

Murphy, C.F., D. Allen, B. Allenby, J. Crittenden, C.I. Davidson, C. Hendrickson, and H.S. Matthews, 2009: Sustainability in engineering education and research at U.S. universities. Environmental Science \& Technology, 43(15), 5558-5564.

Mustelin, J., R. Klein, B. Assaid, T. Sitari, M. Khamis, A. Mzee, and T. Haji, 2010: Understanding current and future vulnerability in coastal settings: community perceptions and preferences for adaptation in Zanzibar, Tanzania. Population \& Environment, 31(5), 371-398.

Næss, L.O., G. Bang, S. Eriksen, and J. Vevatne, 2005: Institutional adaptation to climate change: flood responses at the municipal level in Norway. Global Environmental Change, 15(2), 125-138.

Nassopoulos, H., P. Dumas, and S. Hallegatte, 2012: Adaptation to an uncertain climate change: cost benefit analysis and robust decision making for dam dimensioning. Climatic Change, 114(3-4), 497-508.

National Research Council, 2009: Informing Decisions in a Changing Climate. Panel on Strategies and Methods for Climate-Related Decision Support, Committee on the Human Dimensions of Global Change, Division of Behavioral and Social Sciences and Education, National Research Council, The National Academies Press, Washington, DC, USA, 188 pp.

National Research Council, 2010: Adapting to the Impacts of Climate Change. America's Climate Choices: Panel on Adapting to Impacts of Climate Change, Division on Earth and Life Studies, National Research Council, The National Academies Press, Washington, DC, USA, $272 \mathrm{pp}$.

Nelson, R., M. Howden, and M. Stafford Smith, 2008: Using adaptive governance to rethink the way science supports Australian drought policy. Environmental Science \& Policy, 11(7), 588-601.

Nelson, R., P. Kokic, S. Crimp, P. Martin, H. Meinke, and S.M. Howden, 2010a: The vulnerability of Australian rural communities to climate variability and change: part I - conceptualizing and measuring vulnerability. Environmental Science \& Policy, 13(1), 8-17.

Nelson, R., P. Kokic, S. Crimp, P. Martin, H. Meinke, and S.M. Howden, 2010b: The vulnerability of Australian rural communities to climate variability and change: part II - integrating impacts with adaptive capacity. Environmental Science \& Policy, 13(1), 18-27.

New, M., D. Liverman, H. Schroder, and K. Anderson, 2011: Four degrees and beyond: the potential for a global temperature increase of four degrees and its implications. Philosophical Transactions of the Royal Society A, 369, 6-19.

Newton, P.W., 2013: Regenerating cities: technological and design innovation for Australian suburbs. Building Research and Information, 41(5), 575-588.

Nhemachena, C. and R. Hassan, 2007: Micro-Level Analysis of Farmers'Adaptation to Climate Change in Southern Africa. IFPRI Discussion Paper No. 00714 International Food Policy Research Institute (IFPRI), Washington, DC, USA, 30 pp.

Nicholls, R.J., N. Marinova, J.A. Lowe, S. Brown, P. Vellinga, D. De Gusmao, and R.S. Tol, 2011: Sea-level rise and its possible impacts given a 'beyond $4^{\circ} \mathrm{C}$ world' in the twenty-first century. Philosophical Transactions of the Royal Society A, 369(1934), 161-181.

Nicholls, R., 2007: Adaptation Options for Coastal Zones and Infrastructure: An Analysis for 2030. Report to the Financial and Technical Support Division, United Nations Framework Convention on Climate Change (UNFCCC), Bonn, Germany, $35 \mathrm{pp}$.

Nielsen, J.0. and A. Reenberg, 2010: Cultural barriers to climate change adaptation: a case study from Northern Burkina Faso. Global Environmental Change, 20(1), 142-152.

Nisbet, M. and D. Scheufele, 2009: What's next for science communication? Promising directions and lingering distractions. American Journal of Botany, 96(10), 1767-1778

Nkem, J., F.B. Kalame, M. Idinoba, O.A. Somorin, O. Ndoye, and A. Awono, 2010: Shaping forest safety nets with markets: adaptation to climate change under changing roles of tropical forests in Congo Basin. Environmental Science \& Policy, 13, 498-508.

Nordhaus, W.D., 2001: Global warming economics. Science, 294(5545), 1283-1284. 
Norman, L., N. Tallent-Halsell, W. Labiosa, M. Weber, A. McCoy, K. Hirschboeck, J. Callegary, C. Van Riper III, and F. Gray, 2010: Developing an ecosystem services online decision support tool to assess the impacts of climate change and urban growth in the Santa Cruz watershed; where we live, work, and play. Sustainability, 2(7), 2044-2069.

Nunavut Social Development Council, 1999: On our own terms: the state of Inuit culture and society. In: Taking Stock: A Review of the First Five Years of Implementing the Nunavut Land Claims Agreement [Nunavut Social Development Council (ed.)]. Nunavut Tunngavik, Inc., Iqaluit, NU, Canada, pp. 70-97.

O'Brien, K., 2009: Do values subjectively define the limits to climate change adaptation? In: Adapting to Climate Change: Thresholds, Values, Governance [Adger, N.W., I. Lorenzoni, and K. O'Brien (eds.)]. Cambridge University Press, Cambridge, UK, pp. 164-180.

O'Brien, K., 2012: Global environmental change II: from adaptation to deliberate transformation. Progress in Human Geography, 36(5), 667-676.

O'Brien, K.L. and J. Wolf, 2010: A values-based approach to vulnerability and adaptation to climate change. Wiley Interdisciplinary Reviews: Climate Change, 1(2), 232-242.

O'Brien, K., M. Pelling, A. Patwardhan, S. Hallegatte, A. Maskrey, T. Oki, U. OswaldSpring, T. Wilbanks, and P.Z. Yanda, 2012: Toward a sustainable and resilient future. In: Managing the Risks of Extreme Events and Disasters to Advance Climate Change Adaptation. A Special Report of Working Groups I and II of the Intergovernmental Panel on Climate Change [Field, C.B., V. Barros, T.F. Stocker, D. Qin, D.J. Dokken, K.L. Ebi, M.D. Mastrandrea, K.J. Mach, G.-K. Plattner, S.K Allen, M. Tignor, and P.M. Midgley (eds.)]. Cambridge University Press, Cambridge, UK and New York, NY, USA, pp. 437-486.

OHCHR, 2009: Report of the Office of the United Nations High Commissioner for Human Rights on the Relationship Between Climate Change and Human Rights. United Nations Document: A/HRC/10/61, Human Rights Council, Tenth Session, the United Nations High Commissioner for Human Rights (OHCHR), United Nations, New York, NY, USA, 32 pp.

O'Hara, J.K., 2012: Ensuring the Harvest: Crop Insurance and Credit for a Healthy Farm and Food Future. Union of Concerned Scientists (UCS), Cambridge, MA, USA, $30 \mathrm{pp}$.

O'Neill, B.C., M. Dalton, R. Fuchs, L. Jiang, S. Pachauri, and K. Zigova, 2010: Global demographic trends and future carbon emissions. Proceedings of the National Academy of Sciences of the United States of America, (41), 17521-17523.

O'Neill, S. and J. Handmer, 2012: Responding to bushfire risk: the need for transformative adaptation. Environmental Research Letters, 7, 014018 doi:10.1088/1748-9326/7/1/014018.

O'Neill, S.J. and S. Nicholson-Cole, 2009: "Fear won't do it": promoting positive engagement with climate change through visual and iconic representations. Science Communication, 30, 355-379.

Olesen, J.E., M. Trnka, K.C. Kersebaum, A.O. Skjelvåg, B. Seguin, P. Peltonen-Sainio, F. Rossi, J. Kozyra, and F. Micale, 2011: Impacts and adaptation of European crop production systems to climate change. European Journal of Agronomy, 34(2), 96-112.

Orlove, B., 2009: Glacier retreat: reviewing the limits of human adaptation to climate change. Environment, 51(3), 22-34.

Osbahr, H., C. Twyman, W.N. Adger, and D.S.G Thomas, 2010: Evaluating successful livelihood adaptation to climate variability and change in southern Africa. Ecology and Society, 15(2), 27, www.ecologyandsociety.org/vol15/iss2/art27/.

Ospina, A.V. and R. Heeks, 2010a: Linking ICTs and Climate Change Adaptation. Institute for Development Policy and Management, University of Manchester, Manchester, UK, $39 \mathrm{pp}$.

Ospina, A.V. and R. Heeks, 2010b: Unveiling the Links between ICTs and Climate Change in Developing Countries: A Scoping Study. Institute for Development Policy and Management, University of Manchester, Manchester, UK, 59 pp.

Paavola, J. 2008. Livelihoods, vulnerability and adaptation to climate change in Morogoro, Tanzania. Environmental Science \& Policy, 11(7), 642-654.

Paavola, J. and W.N. Adger, 2006: Fair adaptation to climate change. Ecological Economics, 56(4), 594-609.

Papademetriou, M.K., F.J. Dent, and F.M. Herath (eds.), 2000: Bridging the Rice Yield Gap in the Asia-Pacific Region. RAP PUBLICATION: 2000/16, Food and Agricultural Organisation of the United Nations (FAO), Regional Office for Asia and the Pacific, Bangkok, Thailand, $222 \mathrm{pp}$.

Park, S.E., N.A. Marshall, E. Jakku, A.M. Dowd, S.M. Howden, and A. Fleming, 2012: Informing adaptation responses to climate change through theories of transformation. Global Environmental Change, 22(1), 115-126.
Parry, M., N. Arnell, P. Berry, D. Dodman, S. Fankhauser, C. Hope, S. Kovats, R. Nicholls, D. Satterthwaite, R. Tiffin, and T. Wheeler, 2009: Assessing the Costs of Adaptation to Climate Change: A Review of the UNFCCC and Other Recent Estimates. International Institute for Environment and Development (IIED) and the Grantham Institute for Climate Change, Imperial College, London, UK, $111 \mathrm{pp}$.

Pasquini, L., R.M. Cowling, and G. Ziervogel, 2013: Facing the heat: barriers to mainstreaming climate change adaptation in local government in the Western Cape Province, South Africa. Habitat International, 40, 225-232.

Patt, A.G. and D. Schröter, 2008: Perceptions of climate risk in Mozambique: implications for the success of adaptation strategies. Global Environmental Change, 18(3), 458-467.

Patt, A.G., L. Ogallo, and M. Hellmuth, 2007: Learning from 10 years of climate outlook forums in Africa. Science, 318(5847), 49-50.

Patt, A.G., M. Tadross, P. Nussbaumer, A. Kwabena, M. Metzger, J. Rafael, A. Goujon, and G. Brundri, 2010a: Estimating least-developed countries' vulnerability to climate-related extreme events over the next 50 years. Proceedings of the National Academy of Sciences of the United States of America, 107(4), 1333-1337.

Patt, A.G., D.P. van Vuuren, F. Berkhout, A. Aaheim, A.F. Hof, M. Isaac, and R. Mechler, 2010b: Adaptation in integrated assessment modeling: where do we stand? Climatic Change, 99, 383-402.

Patz, J.A., H.K. Gibbs, J.A. Foley, J.V. Rogers, and K.R. Smith, 2007: Climate change and global health: quantifying a growing ethical crisis. EcoHealth, 4(4), 397-405.

Pautasso, M., T.F. Döring, M. Garbelotto, L. Pellis, and M.J. Jeger, 2012: Impacts of climate change on plant diseases - opinions and trends. European Journal of Plant Pathology, 133(1), 295-313.

Paavola, J., 2011: Climate Change: The Ultimate 'Tragedy of the Commons'? Centre for Climate Change Economics and Policy Working Paper No. 53, Sustainability Research Institute Paper No. 24, Center for Climate Change Economics and Policy and Sustainability Research Institute (SRI), SRI, School of Earth and Environment, The University of Leeds, Leeds, UK, $32 \mathrm{pp}$.

PCAST, 2011: Sustaining Environmental Capital: Protecting Society and the Economy. Report to the President, President's Council of Advisors on Science and Technology (PCAST), Executive Office of the President, Washington, DC, USA, $126 \mathrm{pp}$.

Pearce, T.D., J.D. Ford, G.J. Laidler, B. Smit, F. Duerden, M. Allarut, M. Andrachuk, S. Baryluk, A. Dialla, P. Elee, A. Goose, T. Ikummaq, E. Joamie, F. Kataoyak, E. Loring, S. Meakin, S. Nickels, K. Shappa, J. Shirley, and J. Wandel, 2009: Community collaboration and climate change research in the Canadian Arctic. Polar Research, 28(1), 10-27.

Pearce, T., H. Wright, R. Notaina, A. Kudlak, B. Smit, J. Ford, and C. Furgal, 2011: Transmission of environmental knowledge and land skills among Inuit men in Ulukhaktok, Northwest Territories, Canada. Human Ecology, 39(3), 271-288.

Peck, L.S., M.S. Clark, S.A. Morley, A. Massey, and H. Rossetti, 2009: Animal temperature limits and ecological relevance: effects of size, activity and rates of change. Functional Ecology, 23(2), 248-256.

Pederson, N., A.R. Bell, T.A. Knight, C. Leland, N. Malcomb, K.J. Anchkaitis, K. Tackett, J. Scheff, A. Brice, B. Catron, W. Blozan, and J. Riddle, 2012: A long-term perspective on a modern drought in the American Southwest. Environmental Research Letters, 7, 014034, doi:10.1088/1748-9326/7/1/014034.

Pelling, M. 2010: Adaptation to Climate Change: From Resilience to Transformation. Routledge, Abingdon, UK and New York, NY, USA, 224 pp.

Peters, G.P., R.M. Andrew, T. Boden, J.G. Canadell, P. Ciais, C. Le Quere, G. Marland, M.R. Raupach, and C. Wilson, 2013: The challenge to keep global warming below $2{ }^{\circ} \mathrm{C}$. Nature Climate Change, 3, 4-6.

Pfister, S., A. Koehler, and S. Hellweg, 2009: Assessing the environmental impacts of freshwater consumption in LCA. Environmental Science \& Technology, 43(11), 4098-4104.

Pfister, S., P. Bayer, A. Koehler, and S. Hellweg, 2011a: Environmental impacts of water use in global crop production: hotspots and trade-offs with land use. Environmental Science \& Technology, 45(13), 5761-5768.

Pfister, S., P. Bayer, A. Koehler, and S. Hellweg, 2011 b: Projected water consumption in future global agriculture: scenarios and related impacts. Science of the Total Environment, 409(20), 4206-4216.

Piao, S., P. Ciais, Y. Huang, Z. Shen, S. Peng, J. Li, L. Zhou, H. Liu, Y. Ma, Y. Ding, P. Friedlingstein, C. Liu, K. Tan, Y. Yu, T. Zhang, and J. Fang, 2010: The impacts of climate change on water resources and agriculture in china. Nature, 467, 43-51.

Pidgeon, N., 2012: Climate change risk perception and communication: addressing a critical moment? Risk Analysis, 32(6), 951-956. 
Pidgeon, N. and C. Butler, 2009: Risk analysis and climate change. Environmental Politics, 18(5), 670-688.

Pidgeon, N. and B. Fischhoff, 2011: The role of social and decision sciences in communicating uncertain climate risks. Nature Climate Change, 1(1), 3541.

Pielke Jr., R.A., 2007: Future economic damage from tropical cyclones: sensitivities to societal and climate changes. Philosophical Transactions of the Royal Society A, 365, 2717-2729.

Pielke Jr., R.A., J. Gratz, C.W. Landsea, D. Collins, M.A. Saunders, and R. Musulin, 2008: Normalized hurricane damages for the United States: 1900-2005. Natural Hazards Review, 9(1), $29-42$.

Pini, B., S. Wild River, and F.M.H. McKenzie, 2007: Factors inhibiting local government engagement in environmental sustainability: case studies from rural Australia. Australian Geographer, 38(2), 161-175.

Pinto, R. and F.C. Martins, 2013: The Portuguese national strategy for integrated coastal zone management as a spatial planning instrument to climate change adaptation in the Minho River Estuary (Portugal NW-Coastal Zone). Environmental Science and Policy, 33, 76-96.

Pittock, J., 2011: National climate change policies and sustainable water management: conflicts and synergies. Ecology and Society, 16(2), 25, www.ecologyand society.org/vol16/iss2/art25/.

Pittock, J., 2013: Lessons from adaptation to sustain freshwater environments in the Murray-Darling Basin, Australia. Wiley Interdisciplinary Reviews: Climate Change, 4, 429-438.

Pray, C., L. Nagarajan, L. Li, J. Huang, R. Hu, K.N. Selvaraj, O. Napasintuwong, and R. Chandra, 2011: Potential impact of biotechnology on adaptation of agriculture to climate change: the case of drought tolerant rice breeding in Asia. Sustainability, 3, 1723-1741.

Preston, B.L. 2009: Equitable climate policy in a dangerous world. In: Climate Change and Social Justice [Moss, J. (ed.)]. Melbourne University Press, Melbourne, Australia, pp. 224-245.

Preston, B.L, 2013: Local path dependence of U.S. socioeconomic exposure to climate extremes and the vulnerability commitment. Global Environmental Change, 23(4), 719-732.

Preston, B.L. and Jones, R.N., 2008: Evaluating sources of uncertainty in Australian runoff projections. Advances in Water Resources, 31(5), 758-775.

Preston, B.L. and M. Stafford Smith, 2009: Framing Vulnerability and Adaptive Capacity Assessment. CSIRO Climate Adaptation Flagship Working Paper No. 2, Clayton, VIC, Australia, $52 \mathrm{pp}$.

Preston, B.L., R.M. Westaway, and E.J. Yuen, 2011 a: Climate adaptation planning in practice: an evaluation of adaptation plans from three developed nations. Mitigation and Adaptation Strategies for Global Change, 16(4), 407-438.

Preston, B.L., E.J. Yuen, and R.M. Westaway, 2011 b: Putting climate vulnerability on the map: a critical look at approaches, benefits, and risks. Sustainability Science, 6(2), 177-202.

Preston, B.L., K. Dow, and F. Berkhout, 2013a: The climate adaptation frontier. Sustainability, 5, 1011-1035.

Preston, B.L., J. Mustelin, and M.C. Maloney, 2013b: Climate adaptation heuristics and the science/policy divide. Mitigation and Adaptation Strategies for Global Change, doi:10.1007/s11027-013-9503-x.

Preston, B.L., L. Rickards, S. Dessai, and R. Meyer, 2013c: Water, seas, and wine: science for successful adaptation. In: Successful Adaptation to Climate Change [Moser, S. and M. Boykoff (eds.)]. Routledge, Abingdon, UK and New York, NY, USA, pp. 151-169.

Productivity Commission, 2009: Government Drought Support. Report, No. 46, Australian Government, Productivity Commission Final Inquiry Report, Melbourne, VIC, Australia, 486 pp.

Ragen, T.J., H.P. Huntington, G. Hovelsrud, and K. Grete, 2008: Conservation of Arctic marine mammals faced with climate change. Ecological Applications, $18(2$ Suppl.), S166-S174.

Rayner, T. and A. Jordan, 2010: Adapting to climate change: an emerging European policy? In: Climate Change Policy in the European Union: Confronting the Dilemmas of Mitigation and Adaptation [Jordan, A., D. Huitema, H. van Asselt, T. Rayner, and F. Berhout (eds.)]. Cambridge University Press, Cambridge, UK, pp. 145-166.

Raudsepp-Hearne, C., G.D. Peterson, M. Tengo, E.M. Bennett, T. Holland, K. Benessaiah, G.K. MacDonald, and L. Pfeifer, 2010: Untangling the environmentalist's paradox: why is human well-being increasing as ecosystem services degrade? BioScience, 60(8), 576-589.
Ren, Z., Z. Chen, and X. Wang, 2011: Climate change adaptation pathways for Australian residential buildings. Building and Environment, 46(11), 23982412.

Renn, 0., 2008: Risk Governance: Coping with Uncertainty in a Complex World. Earthscan, London, UK, $368 \mathrm{pp}$.

Renn, 0., 2011: The social amplification/attenuation of risk framework: application to climate change. Wiley Interdisciplinary Reviews: Climate Change, 2(2), 154 169.

Renn, 0. and A. Klinke, 2013: A framework of adaptive risk governance for urban planning. Sustainability, 5, 2036-2059.

Roberts, D., R. Boon, N. Diederichs, E. Douwes, N. Govender, A. Mcinnes, and M. Spires, 2012: Exploring ecosystem-based adaptation in Durban, South Africa: "learning-by-doing" at the local government coal face. Environment and Urbanization, 24(1), 167-195.

Rockström, J., W. Steffen, K. Noone, A. Persson, F.S. Chapin, E.F. Lambin, T.M. Lenton, M. Scheffer, C. Folke, H.J. Schellnhuber, B. Nykvist, C.A. de Wit, T. Hughes, S. van der Leeuw, H. Rodhe, S. Sorlin, P.K. Snyder, R. Costanza, U. Svedin, M. Falkenmark, L. Karlberg, R.W. Corell, V.J. Fabry, J. Hansen, B. Walker, D. Liverman, K. Richardson, P. Crutzen, and J.A. Foley, 2009: A safe operating space for humanity. Nature, 461(7263), 472-475.

Rodima-Taylor, D., M.F. Olwig, and N. Chhetri, 2012: Adaptation as innovation, innovation as adaptation: an institutional approach to climate change. Applied Geography, 33, 107-111.

Rogelj, J., W. Hare, J. Lowe, D.P. van Vuuren, K. Riahi, B. Matthews, T. Hanaoka, K. Jian, and M. Meinshausen, 2011: Emission pathways consistent with a $2^{\circ} \mathrm{C}$ global temperature limit. Nature Climate Change, 1(8), 413-418.

Romieu, E., T. Welle, S. Schneiderbauer, M. Pelling, and C. Vinchon, 2010:Vulnerability assessment within climate change and natural hazard contexts: revealing gaps and synergies through coastal applications. Sustainability Science, 5(2), 159170.

Rosenau, J.N., 2005: Strong demand, huge supply: governance in an emerging epoch. In: Multi-level Governance [Bache, I. and M. Flinders (eds.)]. Oxford University Press, Oxford, UK, pp. 31-48.

Rosen, A.M. and I. Rivera-Collazo, 2012: Climate change, adaptive cycles, and the persistence of foraging economies during the late Pleistocene/Holocene transition in the Levant. Proceedings of the National Academy of Sciences of the United States of America, 109(10), 3640-3645.

Rosenberg, E.A., P.W. Keys, D.B. Booth, D. Hartley, J. Burkey, A.C. Steinemann, and D.P. Lettenmaier, 2010: Precipitation extremes and the impacts of climate change on stormwater infrastructure in Washington State. Climatic Change, 102(1-2), 319-349.

Rübbelke, D.T.G., 2011: International support of climate change policies in developing countries: strategic, moral and fairness aspects. Ecological Economics, 70, 1470-1480.

Rupp-Armstrong, S. and R. Nicholls 2007: Coastal and estuarine retreat: a comparison of the application of managed realignment in England and Germany. Journal of Coastal Research, 236, 1418-1430.

Rygaard, M., P.J. Binning, and H.-J. Albrechtsen, 2011: Increasing urban water selfsufficiency: new era, new challenges. Journal of Environmental Management, 92, 185-194.

Sathaye, J., A. Najam, C. Cocklin, T. Heller, F. Lecocq, J. Llanes-Regueiro, J. Pan, G. Petschel-Held, S. Rayner, J. Robinson, R. Schaeffer, Y. Sokona, R. Swart, and H. Winkler, 2007: Sustainable development and mitigation. In: Climate Change 2007: Impacts, Adaptation and Vulnerability. Contribution of Working Group II to the Fourth Assessment Report of the Intergovernmental Panel on Climate Change [Parry, M.L., O.F. Canziani, J.P. Palutikof, P.J. van der Linden, and C.E. Hanson (eds.)]. Cambridge University Press, Cambridge, UK and New York, NY, USA, pp. 691-743.

Schipper, E.L.F., 2008: Religion and risk: the challenge of harnessing faith and reducing exposure. In: Proceedings of Living with Climate Change: Are There Limits to Adaptation? 7- 8 February 2008, the Royal Geographical Society in London. The Tyndall Centre for Climate Change Research and the University of Oslo, with the support of the Global Environmental Change and Human Security (GECHS) project, The Tyndall Centre for Climate Change Research, University of East Anglia, Norwich, UK, www.tyndall.ac.uk/events/2008/are-there-limitsadaptation.

Schilling, J., K.P. Freier, E. Hertig, and J. Scheffran, 2012: Climate change, vulnerability and adaptation in North Africa with focus on Morocco. Agriculture, Ecosystems and Environment, 156, 12-26. 
Schneider, S.H. and J. Lane, 2006a: An overview of 'dangerous' climate change. In: Avoiding Dangerous Climate Change [Schellnhuber, H.J., W. Cramer, N. Nakicenovic, T. Wigley, and G. Yohe (eds.)]. Cambridge University Press, Cambridge, UK, pp. 159-176.

Schneider, S.H. and J. Lane, 2006b: Dangers and thresholds in climate change and the implications for justice. In: Fairness in Adaptation to Climate Change [Adger, W.N., J. Paavola, S. Huq, and M.J. Mace (eds.)]. Cambridge University Press, Cambridge, UK, pp. 23-52.

Schneider, S.H., S. Semenov, A. Patwardhan, I. Burton, C.H.D. Magadza, M. Oppenheimer, A.B. Pittock, A. Rahman, J.B. Smith, A. Suarez, and F. Yamin, 2007: Assessing key vulnerabilities and the risk from climate change. In: Climate Change 2007: Impacts, Adaptation and Vulnerability. Contribution of Working Group II to the Fourth Assessment Report of the Intergovernmental Panel on Climate Change [Parry, M.L., O.F. Canziani, J.P. Palutikof, P.J. van der Linden, and C.E. Hanson (eds.)]. Cambridge University Press, Cambridge, UK and New York, NY, USA, pp. 779-810.

Schweizer, V.J. and B.C. O'Neill, 2013: Systematic construction of global socioeconomic pathways using internally consistent element combinations. Climatic Change, doi:10.1007/s10584-013-0908-z.

Scott, D., G. McBoyle, A. Minogue, and B. Mills, 2006: Climate change and the sustainability of ski-based tourism in eastern North America: a reassessment. Journal of Sustainable Tourism, 14(4), 376-398.

Seidl, R. and M.J Lexer, 2013: Forest management under climatic and social uncertainty: trade-offs between reducing climate change impacts and fostering adaptive capacity. Journal of Environmental Management, 114, 461-469.

Seneviratne, S.I., N. Nicholls, D. Easterling, C.M. Goodess, S. Kanae, J. Kossin, Y. Luo, J. Marengo, K. McInnes, M. Rahimi, M. Reichstein, A. Sorteberg, C. Vera, and X. Zhang, 2012: Changes in climate extremes and their impacts on the natural physical environment. In: Managing the Risks of Extreme Events and Disasters to Advance Climate Change Adaptation. A Special Report of Working Groups I and II of the Intergovernmental Panel on Climate Change [Field, C.B., V. Barros, T.F. Stocker, D. Qin, D.J. Dokken, K.L. Ebi, M.D. Mastrandrea, K.J. Mach, G.-K. Plattner, S.K. Allen, M. Tignor, and P.M. Midgley (eds.)]. Cambridge University Press, Cambridge, UK and New York, NY, USA, pp. 109-230.

Sehring, J., 2007: Irrigation reform in Kyrgyzstan and Tajikistan. Irrigation and Drainage Systems, 21, 277-290.

Shah, T., 2009: Climate change and groundwater: India's opportunities for mitigation and adaptation. Environmental Research Letters, 4, 035005, doi:10.1088/17489326/4/3/035005.

Shaw, R. and J. Etterson, 2012: Rapid climate change and the rate of adaptation: insight from experimental quantitative genetics. The New Phytologist, 195(4), 752-765.

Sheehan, P., R.N. Jones, A. Jolley, B.L. Preston, M. Clarke, P.J. Durack, S.M.N. Islam, and P.H. Whetton, 2008: Climate change and the new world economy: implications for the nature and timing of policy responses. Global Environmental Change, 18(3), 380-396.

Shen, L.Y., J.J. Ochoa, M.N. Shah, and X. Zhang, 2011: The application of urban sustainability indicators - a comparison between various practices. Habitat International, 35, 17-29.

Shen, Y., T. Oki, N. Utsumi, S. Kanae, and N. Hansaki, 2008: Projection of future world water resources under SRES scenarios: water withdrawal. Hydrological Sciences Journal, 53(1), 11-33.

Sheppard, S.R., A. Shaw, D. Flanders, S. Burch, A. Wiek, J. Carmichael, and S. Cohen, 2011: Future visioning of local climate change: a framework for community engagement and planning with scenarios and visualisation. Futures, 43(4), 400-412.

Sheridan, S.C., 2007: A survey of public perception and response to heat warnings across four North American cities: an evaluation of municipal effectiveness. Journal of Biometeorology, 52, 3-15.

Silva, J.A., S. Eriksen, and Z.A. Ombe, 2010: Double exposure in Mozambique's Limpopo River basin. The Geographical Journal, 176(1), 6-24.

Smit, B., I. Burton, R.J.T. Klein, and J. Wandel, 1999: The science of adaptation: a framework for assessment. Mitigation and Adaptation Strategies for Global Change, 4, 199-213.

Smit, B., O. Pilifisofa, I. Burton, B. Challenger, S. Huq, R.J.T. Klein, and G. Yohe, 2001: Adaptation to climate change in the context of sustainable development and equity. In: Climate Change 2001: Impacts, Adaptation, and Vulnerability. Contribution of Working Group II to the Third Assessment Report of the Intergovernmental Panel on Climate Change [Smit, B., O. Pilifosova, I. Burton, B. Challenger, S. Huq, R.J.T. Klein, and G. Yohe (eds.)]. Cambridge University Press, Cambridge, UK and New York, NY, USA, pp. 877-912.
Smith, J.B., S.H. Schneider, M. Oppenhimer, G.W. Yohe, W. Haref, M.D. Mastrandrea, A. Patwardhang, I. Burton, J. Corfee-Morloti, C.H.D. Magadzaj, H. Füssel, A.B. Pittock, A. Rahman, A. Suarez, and J.-P. van Yperselen, 2009a: Assessing dangerous climate change through an update of the Intergovernmental Panel on Climate Change (IPCC) "reasons for concern". Proceedings of the National Academy of Sciences of the United States of America, 106(11), 4133-4137.

Smith, J.B., J.M. Vogel, and J.E. Cromwell, 2009b: An architecture for government action on adaptation to climate change. An editorial comment. Climatic Change, 95(1-2), 53-61.

Smith, T.F., C. Brooke, T.G. Measham, B.L. Preston, R. Gorddard, G. Withycombe, B. Beveridge, and C. Morrison, 2008: Case Studies of Adaptive Capacity: Systems Approach to Regional Climate Change Adaptation Strategies. Sydney Coastal Councils Group, Inc., Sydney, New South Wales, Australia, 108 pp.

Smith, T.F., R.W. Carter, P. Daffara, and N. Keys, 2010: The Nature and Utility of Adaptive Capacity Research. National Climate Change Adaptation Research Facility (NCCARF), Griffith University, Gold Coast Campus, Southport, Australia, 68 pp.

Somero, G.N., 2010: The physiology of climate change: how potentials for acclimatization and genetic adaptation will determine 'winners' and 'losers'. The Journal of Experimental Biology, 213(6), 912-920.

Sorte, C.J., S.J. Jones, and L.P. Miller, 2011: Geographic variation in temperature tolerance as an indicator of potential population responses to climate change. Journal of Experimental Marine Biology and Ecology, 400(1), 209-217.

Sosa-Rodriguez, F.S., 2010: Impacts of water management decisions on the survival of a city: from ancient Tenochtitlan to modern Mexico City. Journal of Water Resources Development, 27(4), 667-689.

Sosa-Rodriguez, F.S., 2013: From federal to city mitigation and adaptation: climate change policy in Mexico City. Mitigation and Adaptation Strategies for Global Change, doi:10.1007/s11027-013-9455-1.

Sowers, J., A. Vengosh, and E. Weinthal, 2011: Climate change, water resources, and the politics of adaptation in the Middle East and North Africa. Climatic Change, 104(3-4), 599-627.

Sovacool, B.K., 2012: Perceptions of climate change risks and resilient island planning in the Maldives. Mitigation and Adaptation Strategies for Global Change, 17, 731-752.

Spies, T.A., T.W. Giesen, F.J. Swanson, J.F. Franklin, D. Lach, and K.N. Johnson, 2010: Climate change adaptation strategies for federal forests of the Pacific Northwest, USA: ecological, policy, and socio-economic perspectives. Landscape Ecology, 25(8), 1185-1199.

Stafford Smith, M., L. Horrocks, A. Harvey, and C. Hamilton, 2011: Rethinking adaptation for a $4^{\circ} \mathrm{C}$ world. Philosophical Transactions of the Royal Society $A$, 369, 196-216.

Steenberg, J.W.N., P.N. Duinker, and P.G. Bush, 2011: Exploring adaptation to climate change in the forests of central Nova Scotia, Canada. Forest Ecology and Management, 262, 2316-2327.

Steffen, W., A. Burbidge, L. Hughes, R. Kitching, D. Lindenmayer, W. Musgrave, M. Stafford Smith, and P. Werner, 2009: Australian Biodiversity and Climate Change. CSIRO Publishing, Collingwood, Australia, 248 pp.

Stern, N., S. Peters, V. Bakhshi, A. Bowen, C.S. Cameron, C.D. Catovsky, S. Cruickshank, S. Dietz, N. Edmondson, S. Garbett, L. Hamid, G. Hoffman, D. Ingram, B. Jones, N. Patmore, H. Radcliffe, R. Sathiyarajah, M.C. Stock, V.T. Taylor, H. Wanjie, and D. Zenghelis, 2006: Stern Review on the Economics of Climate Change. Cambridge University Press, Cambridge, UK, 579 pp.

Stillwell, A.S., M.E. Clayton, and M.E. Webber, 2011: Technical analysis of a river basin-based model of advanced power plant cooling technologies for mitigating water management challenges. Environmental Research Letters, 6, 034015, doi:10.1088/1748-9326/6/3/034015.

Stoutenborough, J.W. and A. Vedlitz, 2013: The effect of perceived and assessed knowledge of climate change on public policy concerns: an empirical comparison. Environmental Science \& Policy, doi:10.1016/j.envsci.2013.08.002.

Streeter, R., A.J. Dugmore, and 0. Vesteinsson, 2012: Plague and landscape resilience in premodern Iceland. Proceedings of the National Academy of Sciences of the United States of America, 109(10), 3664-3669.

Stuart-Hill, S. and R.E. Schulze, 2010: Does South Africa's water law and policy allow for climate change adaptation? Climate and Development, 2(2), 128-144.

Sundblad, E.L., A. Biel, and T. Gärling, 2009: Knowledge and confidence in knowledge about climate change among experts, journalists, politicians, and laypersons. Environment and Behavior, 41(2), 281-302.

Svenning, J.C. and B. Sandel, 2013: Disequilibrium vegetation dynamics under future climate change. American Journal of Botany, doi:10.3732/ajb.1200469. 
Svobodová, E., M. Trnka, M. Dubrovský, D. Semerádová, J. Eitzinger, P. Štěpánek, and Z. Žalud, 2013: Determination of areas with the most significant shift in pests' persistence in Europe under climate change. Pest Management Science, doi:10.1002/ps.3622.

Sydneysmith, R., M. Andrachuk, B. Smit, and G.K. Hovelsrud, 2010: Vulnerability and adaptive capacity in Arctic communities. In: Adaptive Capacity and Environmental Governance [Armitage, D. and R. Plummer (eds.)]. Springer, Berlin Heidelberg, Germany, pp. 133-156.

Svenning, J.C. and B. Sandel, 2013: Disequilibrium vegetation dynamics under future climate change. American Journal of Botany, 100(7), doi:10.3732/ajb.1200469.

Tal, A., 2011: The desalination debate - lessons learned thus far. Environment: Science and Policy for Sustainable Development, 53(5), 34-48.

Tan, P.L., K.H. Bowmer, and J. Mackenzie, 2012: Deliberative tools for meeting the challenges of water planning in Australia. Journal of Hydrology, 474, 2-10.

Tao, F., Z. Zhang, and M. Yokozawa, 2011: Dangerous levels of climate change for agricultural production in China. Regional Environmental Change, 11(1), 4148.

Taylor, B.M., B.P. Harman, S. Heyenga, and R.R.J. McAllister, 2012: Property developers and urban adaptation: conceptual and empirical perspectives on governance. Urban Policy and Research, 30(1), 5-24.

Termeer, C., R. Biesbroek, and M. van den Brink, 2012: Institutions for adaptation to climate change: comparing national adaptation strategies in Europe. European Political Science, 11, 41-53.

Thackeray, S.J., T.H. Sparks, M. Frederiksen, S. Burthe, P.J. Bacon, J.R. Bell, M.S. Botham, T.M. Brereton, P.W. Bright, L. Carvalho, T. Clutton-Brock, A. Dawson, M. Edwards, J.M. Elliott, R. Harrington, D. Johns, I.D. Jones, J.T. Jones, D.I. Leech, D.B. Roy, W.A. Scott, M. Smith, R.J. Smithers, I.J. Winfield, and S. Wanless, 2010: Trophic level asynchrony in rates of phenological change for marine, freshwater and terrestrial environments. Global Change Biology, 116(2), 3304-3313.

Thomas, C.D., 2010: Climate, climate change and range boundaries. Diversity and Distributions, 16(3), 488-495.

Thomas, D.S.G. and C. Twyman, 2005: Equity and justice in climate change adaptation amongst natural-resource-dependent societies. Global Environmental Change, 15(2), 115-124

Thompson, L.G., E. Mosley-Thompson, M.E. Davis, K.A. Henderson, H.H. Brecher, V.S. Zagorodnov, T.A. Mashiotta, P.N. Lin, V.N. Mikhalenko, D.R. Hardy, and J. Beer, 2002: Kilimanjaro ice core records: evidence of Holocene climate change in tropical Africa. Science, 298(5593), 589-593.

Thornton, P.K., P.G. Jones, T. Owiyo, R.L. Kruska, M. Herrero, V. Orindi, S. Bhadwal, P Kristjanson, A. Notenbaert, N. Bekele, and A. Omolo, 2008. Climate change and poverty in Africa: mapping hotspots of vulnerability. African Journal of Agricultural and Resource Economics, 2(1), 24-44.

Thornton, P.K., P. Jones, P. Ericksen, and A. Challinor, 2011: Agriculture and food systems in sub-Saharan Africa in a $4^{\circ} \mathrm{C}+$ world. Philosophical Transactions of the Royal Society A, 369(1934), 117-136.

Tilman, D., C. Balzer, J. Hill, and B.L. Befort, 2011: Global food demand and the sustainable intensification of agriculture. Proceedings of the National Academy of Sciences of the United States of America, 108(50), 20260-20264.

Timmer, C.P., 2010: The Changing Role of Rice in Asia's Food Security. ADB Sustainable Development Working Paper Series No. 15, Asian Development Bank (ADB), Manila, Phillipines, $26 \mathrm{pp}$.

Timmerman, J.G., S. Koeppel, F. Bernardini, and J.J. Buntsma, 2011: Adaptation to climate change: challenges for transboundary water management. In: The Economic, Social, and Political Elements of Climate Change [Filho, W.L. (ed.)]. Springer-Verlag, Berlin Heidelberg, Germany, pp. 523-541.

Titus, J.G., 2011: Rolling Easements. EPA 430R11001, U.S. Environmental Protection Agency (EPA), Washington, DC, USA, $169 \mathrm{pp}$.

Titus, J.G., D.E. Hudgens, D.L. Trescott, M. Craghan, W.H. Nuckols, C.H. Hershner, J.M. Kassakian, C.J. Linn, P.G. Merritt, T.M. McCue, J.F. O'Connell, J. Tanski, and J. Wang, 2009: State and local governments plan for development of most land vulnerable to rising sea level along the US Atlantic coast. Environmental Research Letters, 4, 044008, doi:10.1088/1748-9326/4/4/044008.

Tobey, J., P. Rubinoff, D. Robadue Jr., G. Ricci, R. Volk, J. Furlow, and G. Anderson, 2010: Practicing coastal adaptation to climate change: lessons from integrated coastal management. Coastal Management, 38(3), 317-335.

Tol, R.S.J. and G.W. Yohe, 2007: The weakest link hypothesis for adaptive capacity: an empirical test. Global Environmental Change, 17(2), 218-227.

Tol, R.S.J., R.J.T. Klein, and R.J. Nicholls, 2008: Toward successful adaptation to sealevel rise along Europe's coast. Journal of Coastal Research, 242, 432-442.
Tomanek, L., 2010: Variation in the heat shock response and its implication for predicting the effect of global climate change on species' biogeographical distribution ranges and metabolic costs. The Journal of Experimental Biology, 213(6), 971-979.

Tompkins, E.L. and H. Eakin, 2012: Managing private and public adaptation to climate change. Global Environmental Change, 22, 3-11.

Tompkins, E.L., W.N. Adger, E. Boyd, S. Nicholson-Cole, K. Weatherhead, and N. Arnell, 2010: Observed adaptation to climate change: UK evidence of transition to a well-adapting society. Global Environmental Change, 20(4), 627-635.

Towler, E., V.A. Saab, R.S. Sojda, K. Dickinson, C.L. Bruyere, and K.R. Newlon, 2012: A risk-based approach to evaluating wildlife demographics for management in a changing climate: a case study of the Lewis's woodpecker. Environmental Management, 50, 1152-1163.

Trærup, S.L, 2012: Informal networks and resilience to climate change impacts: a collective approach to index insurance. Global Environmental Change, 22(1), 255-267.

Travis, W.R., 2010: Going to extremes: propositions on the social response to severe climate change. Climatic Change, 98, 1-19.

Travis, W.R. and M.T. Huisenga, 2013: The effect of rate of change, variability, and extreme events on the pace of adaptation to a changing climate. Climatic Change, 121, 209-222, doi:10.1007/s10584-013-0876-3.

Tribbia, J. and S.C. Moser, 2008: More than information: what coastal managers need to plan for climate change. Environmental Science \& Policy, 11(4), 315-328.

UKCIP, 2011: Making Progress: UKCIP \& Adaptation in the UK. UK Climate Impacts Programme (UKCIP), Oxford, UK, $99 \mathrm{pp}$.

UN DESA Population Division, 2011: World Population Prospects: The 2010 Revision. CD-ROM Edition - Extended Dataset in Excel and ASCII Formats. United Nations Department of Economic and Social Affairs (UN DESA) Population Division, New York, NY, USA.

UNEP, 2007: Global Environment Outlook GEO4: Environment for Development. United Nations Environment Programme (UNEP), Nairobi, Kenya, 540 pp.

UNEP, 2011: A Practical Framework for Planning Pro-Development Climate Policy. United Nations Environment Programme (UNEP), Nairobi, Nigeria, 143 pp.

UNFCCC, 1992: United Nations Framework Convention on Climate Change. FCCC/ INFORMAL/84, UNFCCC Secretariat, Bonn, Germany, 24 pp.

UNFCCC, 2006: Application of Environmentally-Sound Technologies for Climate Change Adaptation. Climate Change Secretariat, United Nations Framework Convention on Climate Change (UNFCCC), Bonn, Germany, 107 pp.

UNFCCC, 2007a: Investment and Financial Flows to Address Climate Change. Climate Change Secretariat, United Nations Framework Convention on Climate Change (UNFCCC), Bonn, Germany, 272 pp.

UNFCCC, 2007b: Report of the Conference of the Parties on Its Sixteenth Session, Held in Bali from 3 to 15 December 2007. Part Two: Action Taken by the Conference of the Parties at Its Thirteenth Session. Decisions Adopted by the Conference of the Parties. FCCC/CP/2007/6/Add.1, United Nations Framework Convention on Climate Change (UNFCCC) Secretariat, Bonn, Germany, 60 pp.

UNFCCC, 2010: Adaptation Assessment, Planning and Practice. An Overview from the Nairobi Work Programme on Impacts, Vulnerability and Adaptation to Climate Change. United Nations Framework Convention on Climate Change (UNFCCC) Secretariat, Bonn, Germany, $77 \mathrm{pp}$.

UNFCCC, 2011: Report of the Conference of the Parties on Its Sixteenth Session, Held in Cancun from 29 November to 10 December 2010. Part Two: Action Taken by the Conference of the Parties at Its Sixteenth Session. Decisions Adopted by the Conference of the Parties. FCCC/CP/2010/7/Add.1, United Nations Framework Convention on Climate Change (UNFCCC) Secretariat, Bonn, Germany, $31 \mathrm{pp}$.

UNISDR, 2009: 2009 Global Assessment Report on Disaster Risk Reduction: Risk and Poverty in a Changing Climate - Invest Today for a Safer Tomorrow. United Nations International Strategy for Disaster Reduction (UNISDR), Geneva, Switzerland, $207 \mathrm{pp}$.

UNISDR, 2011:2011 Global Assessment Report on Disaster Risk Reduction: Revealing Risk, Redefining Development. United Nations International Strategy for Disaster Reduction (UNISDR), Geneva, Switzerland, 178 pp.

Urwin, K. and A. Jordan, 2008: Does public policy support or undermine climate change adaptation? Exploring policy interplay across different scales of governance. Global Environmental Change, 18, 180-191.

US GAO, 2009: Alaska Native Villages. Limited Progress Has Been Made on Relocating Villages Threatened by Flooding and Erosion. U.S. Government Accountability Office (US GAO), Washington, DC, USA, 53 pp. 
USCTI, 2013: Climate Change Adaptation for Coral Triangle Communities: Guide for Vulnerability Assessment and Local Early Action Planning (LEAP Guide). U.S. Coral Triangle Initiative Support Program (USCTI), Bangkok, Thailand, $144 \mathrm{pp}$.

van Aalst, M.K., T. Cannon, and I. Burton, 2008: Community level adaptation to climate change: the potential role of participatory community risk assessment. Global Environmental Change, 18, 165-179.

van den Berg, M.M., W.M. Lafferty, and F.J. Coenen, 2010: Adaptation to climate change induced flooding in Dutch municipalities. In: The Social and Behavioural Aspects of Climate Change: Linking Vulnerability, Adaptation and Mitigation [Chang, C.T. (ed.)]. Greenleaf Publishing Limited, Sheffield, UK, 130-156.

van Koningsveld, M., J.P.M. Mulder, M.J.F. Stive, L. Vandervalk, and A.W. Vanderweck, 2008: Living with sea-level rise and climate change: a case study of the Netherlands. Journal of Coastal Research, 24, 367-379.

van Nieuwaal, K., P. Driessen, T. Spit, and C. Termeer, 2009: A State of the Art Governance Literature on Adaptation to Climate Change: Towards a Research Agenda. KfC Report No. KfC 003/2009, National Research Programme Knowledge for Climate (KfC), Utrecht, Netherlands, 43 pp.

van Ruijven, B.J., M.A. Levy, A. Agrawal, F. Biermann, J. Birkmann, T.R. Carter, and V.J. Schweizer, 2013: Enhancing the relevance of Shared Socioeconomic Pathways for climate change impacts, adaptation and vulnerability research. Climatic Change, doi:10.1007/s10584-013-0931-0.

van Vuuren, D.P., K. Riahi, R. Moss, J. Edmonds, A. Thomson, N. Nakicenovic, T. Kram, F. Berkhout, R. Swart, A. Janetos, S.K. Rose, and N. Arnell, 2012: A proposal for a new scenario framework to support research and assessment in different climate research communities. Global Environmental Change, 22(1), 21-35.

Verdon-Kidd, D.C., A.S. Kiem, and E.K. Austin, 2012: Decision Making under Uncertainty - Bridging the Gap between End User Needs and Climate Science Capability. National Climate Change Adaptation Research Facility (NCCARF), Griffith University, Gold Coast Campus, Southport, Australia, 126 pp.

Verheyen, R., 2005: Climate Change Damage and International Law: Prevention Duties and State Responsibility. Brill Academic Publishers, Leiden, Netherlands, $418 \mathrm{pp}$.

Vermeulen S.J., P.K. Aggarawal, A. Ainslie, C. Angelone, B.M. Campbell, A.J. Challinor, J.W. Hansen, J.S.I. Ingraham, A. Jarvis, P. Kristjanson, C. Lau, G.C. Nelson, P.K. Thornton, P. Kristjanson, C. Lau, G.C. Nelson, P.K. Thornton, and E. Wollenberg, 2012: Options for support to agriculture and food security under climate change. Environmental Science \& Policy, 15, 136-144.

Visser, M.E., 2008: Keeping up with a warming world: assessing the rate of adaptation to climate change. Proceedings of the Royal Society B, 275(1635), 649-659.

Voinov, A. and H. Cardwell, 2009: The energy-water nexus: why should we care? Journal of Contemporary Water Research \& Education, 143, 17-29.

Wade, S.D., J. Rance, and N. Reynard, 2013: The UK climate change risk assessment 2012: assessing the impacts on water resources to inform policy makers. Water Resources Management, 27(4), 1085-1109.

Wang, C., T. He, and F. Chen, 2013: Evolutionary thinking in restoration under global environmental changes. Journal of Plant Ecology, doi:10.1093/jpe/rtt005.

Ward, P.J., W.P. Pauw, M.W. Van Buuren, and M.A. Marfai, 2013: Governance of flood risk management in a time of climate change: the cases of Jakarta and Rotterdam. Environmental Politics, 22(3), 518-536.

Warner, K., M. Hamza, A. Oliver-Smith, F. Renaud, and A. Julca, 2010: Climate change, environmental degradation and migration. Natural Hazards, 55(3), 689-715.

Washington-Allen, R.A., D.D. Briske, H.H. Shugart, and L.F. Salo, 2010: Introduction to special feature on catastrophic thresholds, perspectives, definitions, and applications. Ecology and Society, 15(3), 38, www.ecologyandsociety.org/ vol15/iss3/art38/.

Watkiss, P., 2011: Aggregate economic measures of climate change damages: explaining the differences and implications. Wiley Interdisciplinary Reviews: Climate Change, 2(3), 356-372.

Webb, R. and J. Beh, 2013: Leading Adaptation Practices and Support Strategies for Australia: An International and Australian Review of Products and Tools. National Climate Change Adaptation Research Facility (NCCARF), Griffith University, Gold Coast Campus, Southport, Australia, 106 pp.

Weber, E.U., 2006: Experience-based and description-based long term learning: why global warming doesn't scare us (yet). Climatic Change, 77, 103-120.

Webster, M., A.P. Sokolov, J.M. Reilly, C.E. Forest, S. Paltsev, A. Schlosser, C. Wang, D. Kicklighter, M. Sarofim, and H.D. Jacoby, 2012: Analysis of climate policy targets under uncertainty. Climatic Change, 112(3-4), 569-583.
Weichselgartner, J. and E. Breviere, 2011: The 2002 flood disaster in the Elbe region, Germany: a lack of context-sensitive knowledge. In: Dynamics of Disaster: Lessons on Risk, Response, and Recovery [Dowty, R.A. and B.L. Allen (eds.)]. Earthscan, London, UK, pp. 141-158.

Weitzman, M.L., 2009: On modeling and interpreting the economics of catastrophic climate change. The Review of Economics and Statistics, 91(1), 1-19.

Wenkel, K.-O., M. Berg, W. Mirschel, R. Wieland, C. Nendel, and B. Köstner, 2013: LandCaRe DSS - an interactive decision support system for climate change impact assessment and the analysis of potential agricultural land use adaptation strategies. Journal of Environmental Management, 27(Suppl.), S168-S183.

Wenzel, G., 2004: From TEK to IQ: Inuit Qaujimajatuqangit and Inuit cultural ecology. Arctic Anthropology, 41(2), 238-250.

West, J.M., S.H. Julius, P. Kareiva, C. Enquist, J.J. Lawler, B. Petersen, A.E. Johnson, and M.R. Shaw, 2009: U.S. natural resources and climate change: concepts and approaches for management adaptation. Environmental Management, 44, 1001-1021.

Westerhoff, L., E.C.H. Keskitalo, H. McKay, J. Wolf, D. Ellison, I. Botetzagias, and B. Reysset, 2010: Planned adaptation measures in industrialised countries: a comparison of select countries within and outside the EU. In: Developing Adaptation Policy and Practice in Europe: Multi-level Governance of Climate Change [Keskitalo, E.C.H. (ed.)]. Springer, Dordrecht, Netherlands, pp. 271-338.

Westerhoff, L., E.C.H. Keskitalo, and S. Juhola, 2011: Capacities across scales: local to national adaptation policy in four European countries. Climate Policy, 11(4), 1071-1085.

Wheeler, S.M., 2012: Spatial planning and climate change. Housing Studies, 27(1), 157-158.

Whitmarsh, L., 2011: Scepticism and uncertainty about climate change: dimensions, determinants and change over time. Global Environmental Change, 21(2), 690700.

Wilbanks, T.J. and R.W. Kates, 2010: Beyond adapting to climate change: embedding adaptation in responses to multiple threats and stresses. Annals of the Association of American Geographers, 100(4), 719-728.

Wilby, R.L. and S. Dessai, 2010: Robust adaptation to climate change. Weather, 65(7), 180-185.

Wilby, R.L. and R. Keenan, 2012: Adapting to flood risk under climate change. Progress in Physical Geography, 36(3), 348-378.

WMO, 2011: Climate Knowledge for Action: A Global Framework for Climate Services - Empowering the Most Vulnerable. The Report of the High Level Taskforce for the Global Framework for Climate Services, World Meteorological Organization (WMO), Geneva, Switzerland, $240 \mathrm{pp}$.

Wodon, Q. and H. Zaman, 2010: Higher food prices in Sub-Saharan Africa: poverty impact and policy responses. The World Bank Research Observer, 25(1), 157176.

Wolf, J. and S.C. Moser, 2011: Individual understandings, perceptions, and engagement with climate change: insights from in-depth studies across the world. Wiley Interdisciplinary Reviews: Climate Change, 2(4), 547-569.

Wolf, J., I. Lorenzoni, R. Few, V. Abrahamson, and R. Raine, 2009: Conceptual and practical barriers to adaptation: vulnerability and responses to heat waves in the UK. In: Adapting to Climate Change: Thresholds, Values, Governance [Adger, N.W., I. Lorenzoni, and K. O'Brien (eds.)]. Cambridge University Press, Cambridge, UK, pp. 181-196.

Wolf, J., W.N. Adger, I. Lorenzoni, V. Abrahamson, and R. Raine, 2010: Social capital, individual responses to heat waves and climate change adaptation: an empirical study of two UK cities. Global Environmental Change, 20(1), 44-52.

Wolf, J., I. Allice, and T. Bell, 2013: Values, climate change, and implications for adaptation: evidence from two communities in Labrador, Canada. Global Environmental Change, 23(2), 548-562.

Wookey, P.A., R. Aerts, R.D. Bardgett, F. Baptist, K.A. Bråthen, J.H.C. Cornelissen, L. Gough, I.P. Hartley, D.W. Hopkins, S. Lavorel, and G.R. Shaver, 2009: Ecosystem feedbacks and cascade processes: understanding their role in the responses of Arctic and alpine ecosystems to environmental change. Global Change Biology, 15(5), 1153-1172.

Yang, W., N.H. Wong, and G. Zhang, 2012: A comparative analysis of human thermal conditions in outdoor urban spaces in the summer season in Singapore and Changsha, China. International Journal of Biometeorology, 57, 895-907.

Yates, C.J., A. McNeill, J. Elith, and G.F. Midgley, 2010: Assessing the impacts of climate change and land transformation on Banksia in the South West Australian Floristic Region. Diversity and Distributions, 16(1), 187-201. 
Young, 0., 2006: Vertical interplay among scale-dependent environmental and resource regimes. Ecology and Society, 11(1), 27, www.ecologyandsociety.org/ vol11/iss1/art27/.

Zelazowski, P., Y. Malhi, C. Huntingford, S. Sitch, and J.B. Fisher, 2011: Changes in the potential distribution of humid tropical forests on a warmer planet. Philosophical Transactions of the Royal Society A, 369(1934), 137-160.

Zhang, D.D., H.F. Lee, C. Wang, B.S. Li, Q. Pei, J. Zhang, and Y.L. An, 2011: The causality analysis of climate change and large-scale human crisis. Proceedings of the National Academy of Sciences of the United States of America, 108(42), 1729617301.

Zhou, Q., P.S. Mikkelsen, K. Halsnæs, and K. Arnbjerg-Nielsen, 2012: Framework for economic pluvial flood risk assessment considering climate change effects and adaptation benefits. Journal of Hydrology, 414, 539-549.

Zhu, X., M.M. Linham, and R.J. Nicholls, 2010: Technologies for Climate Change Adaptation-Coastal Erosion and Flooding. UNEP Risø Centre on Energy, Climate and Sustainable Development, Roskilde, Denmark, $150 \mathrm{pp}$.
Ziervogel, G., P. Johnston, M. Matthew, and P. Mukheibir, 2010a: Using climate information for supporting climate change adaptation in water resource management in South Africa. Climatic Change, 103(3-4), 537-554.

Ziervogel, G., M. Shale, and M. Du, 2010b: Climate change adaptation in a developing country context: the case of urban water supply in Cape Town. Climate and Development, 2, 94-110.

Zinn, M.D., 2007: Adapting to climate change: environmental law in a warmer world. Ecology Law Quarterly, 34(1), 61-105.

Ziska, L.H., D.M. Blumenthal, G.B. Runion, E.R. Hunt Jr., and H. Diaz-Soltero, 2011: Invasive species and climate change: an agronomic perspective. Climatic Change, 105(1-2), 13-42. 